NBER WORKING PAPER SERIES

\title{
GLOBALIZATION AND THE ENVIRONMENT
}

Brian R. Copeland

Joseph S. Shapiro

M. Scott Taylor

Working Paper 28797

http://www.nber.org/papers/w28797

\author{
NATIONAL BUREAU OF ECONOMIC RESEARCH \\ 1050 Massachusetts Avenue \\ Cambridge, MA 02138 \\ May 2021
}

This paper has been prepared for the Handbook of International Economics, Volume V, edited by Gita Gopinath, Elhanan Helpman and Kenneth Rogoff. We thank our discussants, Clare Balboni and David Hemous, and participants in a Handbook conference for excellent comments, Kenneth Lai for excellent research assistance, and NSF SES-1850790. The views expressed herein are those of the authors and do not necessarily reflect the views of the National Bureau of Economic Research.

NBER working papers are circulated for discussion and comment purposes. They have not been peer-reviewed or been subject to the review by the NBER Board of Directors that accompanies official NBER publications.

(C) 2021 by Brian R. Copeland, Joseph S. Shapiro, and M. Scott Taylor. All rights reserved. Short sections of text, not to exceed two paragraphs, may be quoted without explicit permission provided that full credit, including $\odot$ notice, is given to the source. 
Globalization and the Environment

Brian R. Copeland, Joseph S. Shapiro, and M. Scott Taylor

NBER Working Paper No. 28797

May 2021

JEL No. F18,H23,Q27

\begin{abstract}
$\underline{\text { ABSTRACT }}$
How should international economic policy address climate change? Does trade cause deforestation and endangered species depletion? How does globalization affect air and water pollution? Do trade and investment create a race to the bottom in environmental policy? How important are environmental impacts of transporting goods? We review theory and empirical work linking international trade and the environment with a focus on recent work and methods. We discuss the literature linking trade to local and global pollutants, the impact of emissions from transportation, the effect of trade on the sustainability of renewable resources, and the interaction between trade and climate policy. To shape our review, we present nine new stylized facts that, together with our review of past work, highlight questions for future research.
\end{abstract}

Brian R. Copeland

Vancouver School of Economics

The University of British Columbia

6000 Iona Drive

Vancouver, BC V6T 1L4

Canada

brian.copeland@ubc.ca

Joseph S. Shapiro

University of California at Berkeley

714 University Hall \#3310

Berkeley, CA 94720

and NBER

joseph.shapiro@berkeley.edu

\author{
M. Scott Taylor \\ Professor of Economics \\ Department of Economics \\ The University of Calgary \\ 2500 University Drive, N.W. \\ Calgary, AB T2N 1N4 \\ CANADA \\ and NBER \\ m.scott.taylor1@gmail.com
}

A data appendix is available at http://www.nber.org/data-appendix/w28797 


\section{Introduction}

The relationship between international trade and environmental outcomes has been, and remains, contentious. Over the past quarter century, the issues of the day have changed, the scope of the research has broadened, and the methods of investigation improved, but there remains much that we do not know. The purpose of this review is three fold: 1) to critically review past work in order to bring researchers to the current frontier; 2) to present nine new stylized facts linking trade and environment outcomes that can serve as guideposts for future research; and 3) by bringing our discussion of both methods and data together, to stimulate future work.

Although research in the field started in the $1970 \mathrm{~s},{ }^{1}$ it was not until the debate over NAFTA's environmental consequences in the early 1990s that these issues garnered much attention. That changed dramatically with the Grossman and Krueger (1993) environmental assessment of NAFTA, which launched not only a large literature on the environmental consequences of growth, but also stimulated a still growing empirical and computational literature moving forward from their methods. Theoretical work inspired by their findings widened interest further by developing methods to incorporate environmental concerns into then-standard trade models (Copeland and Taylor 1994, 1995b). Today's contributions may look very different, but current research examines many of the same issues and struggles with the same barriers to progress. Fortunately, substantial progress has been made - on several fronts and by many new researchers - and it is on these contributions that the review is focused.

Every review has to limit its scope by defining its terms of reference. We are helped in this regard by the existence of several previous reviews. ${ }^{2}$ In comparison to these earlier reviews, ours is wider in scope by including a discussion of both transportation emissions and the impact of trade on resource use; it is novel in presenting a set of stylized facts drawn from a large cross-country data set on emissions, outputs, and trade to guide and discipline our discussion; and it is selective by not discussing in any depth early work already examined in older reviews. Our goal is to provide a forward-looking review presenting challenges for future research.

The review starts with a discussion of nine stylized facts linking trade and the environment. Many of these numbers are novel, though some cases they echo and amplify partial results found earlier. These facts provide the springboard for our discussion of how globalization affects the environment in Section 4. Here we first review recent work on globalization's

\footnotetext{
${ }^{1}$ See, for example, Baumol (1971), Walter (1973) and Markusen (1975).

${ }^{2}$ Previous reviews include Copeland and Taylor (2004); Levinson (2010); Copeland (2011); Cherniwchan et al. (2017); and Karp (2011).
} 
effect on both production and consumption emissions. Since emissions from transportation services contribute to both local and global emissions, and require quite different methods to analyze, we consider them separately. A similar argument applies to the literature examining globalization's effects on renewable resources such as forests, fish, wildlife and water. These issues have led to some of the most heated and colorful policy debates. To the extent possible, in this section we focus on positive questions and outcomes, leaving a detailed discussion of policy to Sections 5 and 6 .

Since policy debates were of course the genesis of the literature, we dedicate Section 5 to a discussion of the most important of these issues. Two key issues dominate the discussion: how and when can trade and environmental policy substitute for each other in achieving either environmental or trade policy goals? And, how do the constraints imposed in either environmental or trade agreements create unintended consequences? Answers to both questions are critical to the design of trade or environmental agreements. Climate change is the key global environmental issue of our time, and in Section 6 we discuss the interaction between trade and carbon emissions and a range of policy issues, such as carbon leakage, that link trade and environmental policy.

In our conclusion we make several suggestions for future research. Some of these arise from new data sources, others from under-explored but important issues for future research. As will become clear with our review, the methods of investigation vary widely across the field. To some extent, this is to be expected given the many quite different environmental issues we discuss and policy questions we address. Unfortunately, it is also true that real progress in a field typically comes about when agreed-upon analytical methods use relatively easy-to-obtain data to answer important policy questions. This confluence of factors creates the critical mass of researchers needed to ensure replicability, external validity, and followon innovation. This is not the case, as of yet, for the trade and environment field. There are many small truths in many nooks, but no grand unifying theory. Whether this goal is possible or even desirable to attain is open to debate.

\section{Data}

This section describes data used to create the stylized facts. Appendix A describes more general choices relevant to the analysis of international environmental issues, including the choice of environmental goods to analyze, the relative merits of studying data on ambient pollution versus pollution emissions; and different advantages of national versus global analyses.

We analyze the 2013 Release of the World Input Output Dataset (WIOD), which covers 
years 1995-2009. ${ }^{3}$ WIOD is an example of a global multi-region input-output table which combines national input-output tables, international trade data, and pollution emissions data to provide measures of economic and environmental activity comparable across all countries and industries. We focus on two pollutants. $\mathrm{CO}_{2}$ is the most important greenhouse gas. $\mathrm{NO}_{x}$ is a "local" pollutant important to health and well-being, is emitted by a wide set of tradable and non-tradable industries, and often uses fairly accurate measurement methods in at least one national dataset (Shapiro and Walker 2018). Most of our analysis describes all industries, not only manufacturing. We deflate WIOD to 2016 dollars using the U.S. GDP deflator.

Appendix tables and figures also show results for six other pollutants. Two of these are greenhouse gases - methane $\left(\mathrm{CH}_{4}\right)$ is primarily released from agriculture and natural gas processing. Nitrous oxide $\left(\mathrm{N}_{2} \mathrm{O}\right)$ comes from agriculture and to a lesser extent industrial activity. We also study four other "local" pollutants that primarily affect health and well-being in the region where they are emitted. Carbon monoxide $(\mathrm{CO})$ damages local health and primarily comes from transportation. Ammonia $\left(\mathrm{NH}_{3}\right)$ creates local health damages primarily by contributing to particulate matter, and largely comes from agriculture. Non-methane volatile organic compounds (NMVOCs), which include many cancer-causing compounds, come from many industries. Sulfur oxides $\left(\mathrm{SO}_{x}\right)$ come especially from combustion of coal and to a lesser extent oil and gas, and increase local mortality by contributing to particulate matter formation.

To measure greenhouse gas emissions, WIOD uses data from the International Energy Agency for each country and year. For air pollution like $\mathrm{NO}_{x}$, WIOD gets data primarily from the Emission Database for Global Atmospheric Research (EDGAR) (Genty et al. 2012). Crippa et al. (2016) describe how EDGAR calculates air pollution. EDGAR essentially uses information on economic activity, production technologies, uncontrolled emission rates, prevalence and effectiveness of end-of-pipe abatement technologies, and controlled emission rates for each country, industry, and year. The EDGAR values are strongly correlated with microdata from national emissions inventories (Janssens-Maenhout et al. 2015).

We look at several measures of pollution emissions. Some statistics describe "direct" emissions, which include only those emitted in the country $\times$ industry of interest (e.g., the pollution coming out of the smokestack of a Chinese vehicle manufacturing plant). Other statistics discuss "total" emissions, which include those embodied in the entire global value chain of a country $\times$ industry (e.g., the pollution from a Chinese vehicle manufacturing plant,

\footnotetext{
${ }^{3}$ The 2016 Release of WIOD covers years 2000 through 2014, and the EU recently released environmental accounts for it. These data are not completely comparable with the 1995-2009 data. We use the 1995-2009 sample in part because it covers both China's WTO accession and the 2008 recession.
} 
plus the plants supplying tires, engines, etc. to that plant, and from the plants and mines supplying rubber, steel, etc. to the input plants, and so on to reflect the entire lifecycle or environmental footprint of vehicle production). In some cases we compare these against the entire emissions from a country or the global economy. National or global emissions equal emissions from production plus emissions from final demand, where final demand emissions include categories like passenger transportation and home heating and cooling.

We use these data partly to illustrate their potential for analyzing environmental issues. Multi-region input output tables having growing influence in trade research, as illustrated by their use in several of the other chapters in this Handbook and many recent influential papers. Although most of these datasets include extremely detailed data on pollution and natural resources, they are rarely used in environmental research.

At the same time, these data have limitations. They typically focus on high- and middleincome countries. While this captures most emissions and trade measured in levels or growth, it misses patterns in most low-income countries. Additionally, they generally have a limited number of sectors, which is an important caveat to our analysis of composition changes across industries.

\section{Stylized Facts}

This section describes nine stylized facts about interactions of trade and the environment. For each fact, we discuss the associated tables or figures, broader prior evidence from existing research, and the fact's relevance for research and policy. Showing them in one place, through simple empirical patterns, helps motivate research questions discussed later in this chapter, guides the types of models and empirical studies that are important and relevant, and highlights open questions. We first look at patterns across industries and firms, then turn to facts looking over countries and over time.

\subsection{Empirical Patterns Across Industries and Firms}

\section{Stylized Fact \#1: Dirty industries are more exposed to trade.}

Table 1 describes the cleanest and dirtiest industries in the global economy. Panel A shows the cleanest five industries, while Panel B shows the dirtiest five industries. The table ranks industries from clean to dirty based on mean emission rates (tons per dollar output) across all eight pollutants in WIOD. The table only shows two pollutants (the Appendix shows the others). Columns (1) and (2) show direct emissions rates, which include emissions from the industry itself. Columns (3) and (4) show the total emissions rates, which include emissions 
embodied in the entire value chain. Column (5) shows total global output of each industry. Column (6) shows the percent of each industry's goods that are traded internationally.

Table 1: Cleanest and Dirtiest Industries in Global Data

\begin{tabular}{|c|c|c|c|c|c|c|c|}
\hline & \multicolumn{2}{|c|}{$\begin{array}{c}\text { Direct Emission } \\
\text { Rate }\end{array}$} & \multicolumn{2}{|c|}{$\begin{array}{c}\text { Total Emission } \\
\text { Rate }\end{array}$} & \multirow{2}{*}{$\begin{array}{c}\text { Total } \\
\text { Output } \\
\text { (\$trillion) } \\
(5) \\
\end{array}$} & \multirow{2}{*}{$\begin{array}{c}\text { Output } \\
\text { Traded } \\
(\%) \\
(6)\end{array}$} & \multirow{2}{*}{$\begin{array}{l}\text { Upstream- } \\
\text { ness } \\
\text { (7) }\end{array}$} \\
\hline & $\begin{array}{c}\mathrm{CO}_{2} \\
(1) \\
\end{array}$ & $\begin{array}{c}\mathrm{NO}_{\mathrm{x}} \\
(2) \\
\end{array}$ & $\begin{array}{c}\mathrm{CO}_{2} \\
(3) \\
\end{array}$ & $\begin{array}{c}\mathrm{NO}_{\mathrm{x}} \\
(4) \\
\end{array}$ & & & \\
\hline \multicolumn{8}{|l|}{ Panel A. Cleanest industries } \\
\hline Real estate activities & 8 & 0.0 & 84 & 0.3 & $\$ 7.9$ & $0.6 \%$ & 1.5 \\
\hline Financial intermediation & 11 & 0.0 & 101 & 0.3 & $\$ 7.2$ & $7.0 \%$ & 2.3 \\
\hline Equipment \& machine rentals & 28 & 0.1 & 166 & 0.6 & $\$ 10.0$ & $8.6 \%$ & 2.7 \\
\hline Wholesale trade & 25 & 0.1 & 201 & 0.8 & $\$ 5.9$ & $7.9 \%$ & 2.2 \\
\hline Retail fuel; vehicle repair, sales & 34 & 0.1 & 186 & 0.6 & $\$ 1.2$ & $1.2 \%$ & 1.9 \\
\hline Mean of cleanest 5 industries & 21 & 0.1 & 148 & 0.5 & $\$ 6.4$ & $5.1 \%$ & 2.1 \\
\hline \multicolumn{8}{|l|}{ Panel B. Dirtiest industries } \\
\hline Coke, oil refining, nuclear fuel & 359 & 0.5 & 984 & 2.4 & $\$ 2.5$ & $22.9 \%$ & 2.7 \\
\hline Air transport & 1,227 & 4.8 & 1,613 & 6.0 & $\$ 0.6$ & $31.0 \%$ & 2.1 \\
\hline Water transport & 1,147 & 12.7 & 1,681 & 16.0 & $\$ 0.6$ & $40.6 \%$ & 2.9 \\
\hline Other non-metallic mineral & 1,332 & 4.0 & 2,291 & 6.4 & $\$ 1.3$ & $11.2 \%$ & 2.6 \\
\hline Electricity, gas, water supply & 3,295 & 5.6 & 4,324 & 7.8 & $\$ 3.4$ & $2.1 \%$ & 2.8 \\
\hline Mean of dirtiest 5 industries & 1,472 & 5.5 & 2,179 & 7.7 & $\$ 1.7$ & $21.5 \%$ & 2.6 \\
\hline
\end{tabular}

Table 1 shows that outputs from dirtier industries are more often traded than outputs from clean industries are. Column (6) shows that on average, about 5 percent of output from the cleanest industries is traded, while about 22 percent of output from the dirtiest industries is. In regression results including all WIOD industries (not shown for space), the elasticity of an industry's mean emissions rate averaged across all pollutants to the industry's trade share is 0.36 (robust standard error 0.10).

In part this pattern occurs because manufacturing industries are relatively dirty while services are cleaner, and manufacturing goods are more often traded. Transportation is sometimes classified as a service, though is among the most pollution intensive industries in the global economy. Emissions from transportation are relevant because international transportation typically requires long-distance shipping. Air transportation actually emits 
more pollution per physical unit of goods transported (e.g., per ton-mile), but because it is so expensive, its total emission rate in tons of pollution per dollar of output is slightly lower than that of water transportation.

Why are dirty industries more trade exposed? Services use relatively more labor as a factor of production, which is relatively clean, while dirty industries use more energy and capital, which are dirtier factors. In addition, dirty industries tend to have lower tariffs and non-tariff barriers, which encourages trade (Shapiro 2021). The greater openness of dirty industries gives one justification for the common concern that dirty industries will relocate production away from strict environmental policies.

This stylized fact suggests that trade may have large environmental impacts, which motivates the study of trade and the environment broadly. It also leads to concerns about leakage, discussed in Section 5, and guides some environmental policies that adjust environmental regulation for trade-exposed polluting industries (Martin et al. 2014).

\section{Stylized Fact \#2: Different types of pollution are correlated.}

Table 1 also shows that $\mathrm{CO}_{2}$ emissions are correlated with $\mathrm{NO}_{x}$ emissions, though not perfectly so. Similarities across pollutants occur for many of the outcomes this chapter discusses. Between the eight pollutants in the WIOD data, the mean pairwise correlation is 0.35 , none of the 28 pairwise correlations are significantly below zero, and 13 are statistically greater than zero at 95 percent confidence.

Perhaps these correlations are unsurprising. A limit set of inputs, particularly fossil fuels, account for most greenhouse gases and a large share of air pollution emissions. Although many end-of-pipe abatement technologies target one pollutant at a time, industries highly regulated for one pollutant tend to be highly regulated for others.

This stylized fact gives some support to the common practice in research of focusing on one or a few pollutants. At the same time, this pattern suggests that policies and models studying greenhouse gases and air pollution may be related but not identical.

\section{Stylized Fact \#3: Dirty industries are more upstream.}

Column (7) of Table 1 shows how upstream the industry is from final consumption. Antràs et al. (2012) define a continuous index of upstreamness which ranges from one (least upstream) to five (most upstream); we use the application of this measure to WIOD from Miller and Temurshoev (2015). Downstream industries primarily serve final demand. The

most upstream industries primarily sell to other industries that then in turn tend to serve other industries. One can think of upstreamness as a measure of an industry's economic 
distance from final demand. In the year 2009 WIOD data, the upstreamness index values of the 35 industries range from 1.5 to 3.3 .

Table 1 shows that for the cleaner industries, most emissions are from an industry's value chain rather than from the industry itself. For example, producing a million dollars of output in the wholesale trade industry generates 25 tons of $\mathrm{CO}_{2}$ emissions from the wholesale trade industry but 201 tons of $\mathrm{CO}_{2}$ including its entire value chain. On average, for the cleanest industries, total $\mathrm{CO}_{2}$ emissions are about seven times direct emissions $(=148 / 21)$. For the dirtiest industries, total emissions are only 1.5 times direct emissions $(=2179 / 1472)$. This is partly because many of the emissions from services industries are embodied in the electricity they use, which is an intermediate good, while more of the emissions from manufacturing and transportation are from fossil fuels burned directly to generate the industry's output.

A broader explanation for this pattern has to do with the close relationship of pollution emissions and the positioning of industries in global value chains. Dirty industries tend to be relatively upstream, since they sell more of their output to other industries rather than to final consumption, and they sell to relatively upstream industries. Column (7) of Table 1 shows that the dirtiest industries on average have an upstreamness measure of 2.6 (more upstream), while the cleanest industries have a mean upstreamness measure of 2.1 (less upstream).

Other research also finds that pollution intensive industries are more upstream. Shapiro (2021) finds a monotone and in some cases fairly linear relationship between upstreamness and $\mathrm{CO}_{2}$ intensity across industries within most countries, and across countries and industries overall in the global economy. Using the more detailed set of over 275 manufacturing industries in the US economy, Antràs et al. (2012) show that the most upstream US manufacturing industries are alumina refining, other basic organic chemicals, secondary aluminum smelting, primary copper smelting, and petrochemicals. These are also some of the most pollution-intensive industries.

The importance of value chains in measuring pollution, and the differences across clean and dirty industries, suggest that it can be important to account for pollution embodied in value chains. This can take various forms - the simplest might be accounting for electricity or the presence of intermediate goods, while a more detailed approach might use national or global multi-region input-output tables. Some research is beginning to use data on the pollution embodied in firm- rather than industry-level intermediate good inputs (Lyubich et al. 2018). Nonetheless, these links between supply chains and the environment contrast with the dearth of research on interactions of the environment and global value chains or offshoring, and underscore the importance of learning more about these consequences of globalization. 


\section{Stylized Fact \#4: More Productive Plants are Cleaner}

Figure 1 shows a cross-sectional correlation between the log of a plant's total factor productivity (horizontal axis) and the log of the plant's $\mathrm{NO}_{x}$ pollution emissions per dollar of output (vertical axis). The graph includes U.S. manufacturing plants in the year 1990, and is from Shapiro and Walker (2018). The blue circles show the mean values within each decile of the productivity distribution, while the red line shows a linear regression fit.

Figure 1: Emission Rates and Firm Productivity

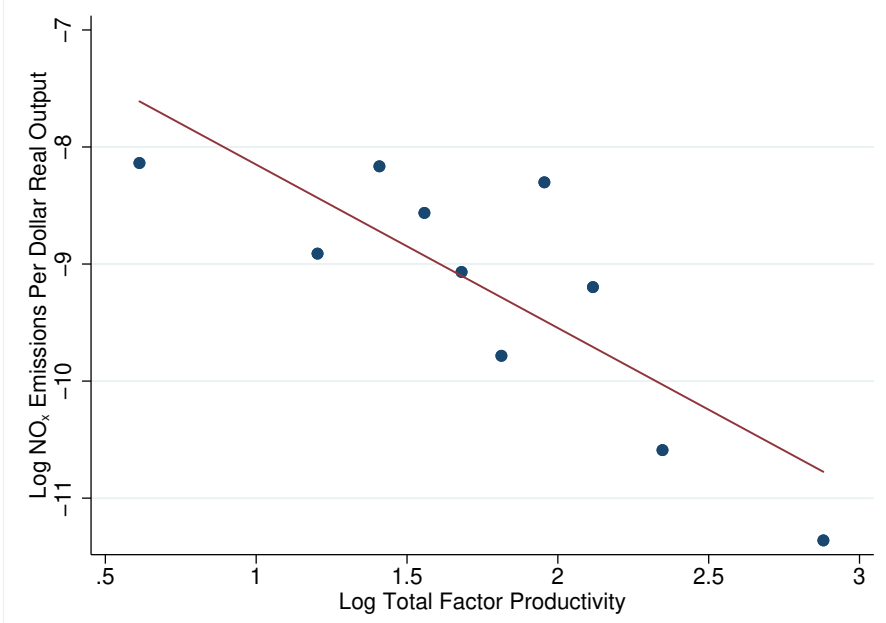

Notes: Figure from Shapiro and Walker (2018). This figure plots the relationship between plant-level total factor productivity and $\mathrm{NO}_{x}$ pollution per unit of output for U.S. manufacturing in 1990. The plant-level productivity measure is constructed from the U.S. Annual Survey of Manufacturers, using a total factor productivity index measure. The sample is divided into 10 deciles based on this plant-level productivity measure. The circles represent the mean values of log productivity and log pollution per unit of real output within each decile, weighting the decile mean by plant-level inventory-adjusted, real output. The plot is accompanied by a linear fit, relating plant-specific emissions intensities to total factor productivity at the same plant. The line is fit to the entire sample, not simply the decile means.

Figure 1 shows that more productive plants have lower pollution intensity. The slope, which is also an elasticity, is close to minus one. This suggests that output from plants that are ten percent more productive emits about ten percent less pollution per dollar of output. Appendix Figure B1 shows similar patterns for the five other pollutants where plant-level data is available from the U.S. National Emissions Inventory. Unfortunately, these data do not have measures of $\mathrm{CO}_{2}$.

Perhaps this finding is unsurprising. If productive firms require fewer inputs to produce a given output, and if pollution is closely related to the amount of fossil fuels or other inputs, then more productive plants may have less pollution per unit output.

Other studies find related patterns in different settings. Bloom et al. (2010) find that 
firms with higher scores in a standardized survey of modern management practices have lower energy intensity, which they measure in different estimates as energy expenditure per dollar of gross output, kWh of electricity per dollar of gross output, or $\mathrm{CO}_{2}$ emissions per dollar of gross output. Martin (2011) finds that in India within a given industry and year, plants with higher total factor productivity have lower fuel expenditure per dollar of output. Qi et al. (2021) show that the elasticity of a Chinese firm's water pollution emissions to its size is substantially less than one. Size is strongly correlated with productivity in most data, and the paper measures water pollution by the firm's total chemical oxygen demand emissions. They also show that larger plants install more effective pollution abatement technology.

Finding that more productive firms and plants are cleaner suggests that reallocation across firms could be an important mechanism for trade to affect the environment. An influential literature argues that the allocation of inputs across firms is an important mechanism for economic growth and for trade and other policies to affect income (Melitz 2003; Hsieh and Klenow 2009). Motivated by this broader literature and by these empirical relationships between firm-level productivity and pollution, a growing literature explores how accounting for reallocation across firms changes the analysis of trade and the environment (Cherniwchan et al. 2017; Barrows and Ollivier 2018; Shapiro and Walker 2018).

It is also worth clarifying what this pattern does not show. These patterns do not show the causal effect of changing productivity, since they provide a cross-sectional description, typically with few or no controls for other plant characteristics. More broadly, they do not distinguish why more productive plants are cleaner. Is this due to a difference in factor intensities? Is it because larger plants face stricter environmental regulation? Or because pollution abatement technologies involve large fixed costs? Additionally, finding these broad patterns across several countries, pollutants, and measures does not necessarily imply they

occur in every setting. For example, it is possible that more productive farms generate more water pollution by applying more fertilizer or using larger quantities or higher toxicity of pesticides. While we are not aware of direct evidence on the relationship between productivity and pollution for agriculture, any such relationship would be especially important in low-income countries where agriculture provides a larger share of employment and income.

\subsection{Empirical Patterns Across Countries and Over Time}

\section{Stylized Fact \#5: Pollution emission rates differ substantially across countries.}

Figure 2 shows the mean emission rate for each of the 43 countries in the WIOD data. Emission intensities are measured as metric tons of pollution emitted per million US\$ of gross output. The maps in Figure 2 are raw data, and are not adjusted for any variables. In 
part for these reasons, we describe these maps as showing emissions 'intensities,' to contrast them with the industry-specific emissions 'rates' described in other tables and graphs. These maps show the direct emission intensity. (The general pattern across countries of the total emissions rates is broadly similar, and is not shown for space, though the levels of total emissions rates are higher.) Countries without data in WIOD are colored white. Appendix Figure B2 shows similar maps for the other six pollutants in the WIOD data.

Figure 2: Direct Emission Rate, by Country and Pollutant

(a) Carbon Dioxide $\left(\mathrm{CO}_{2}\right)$

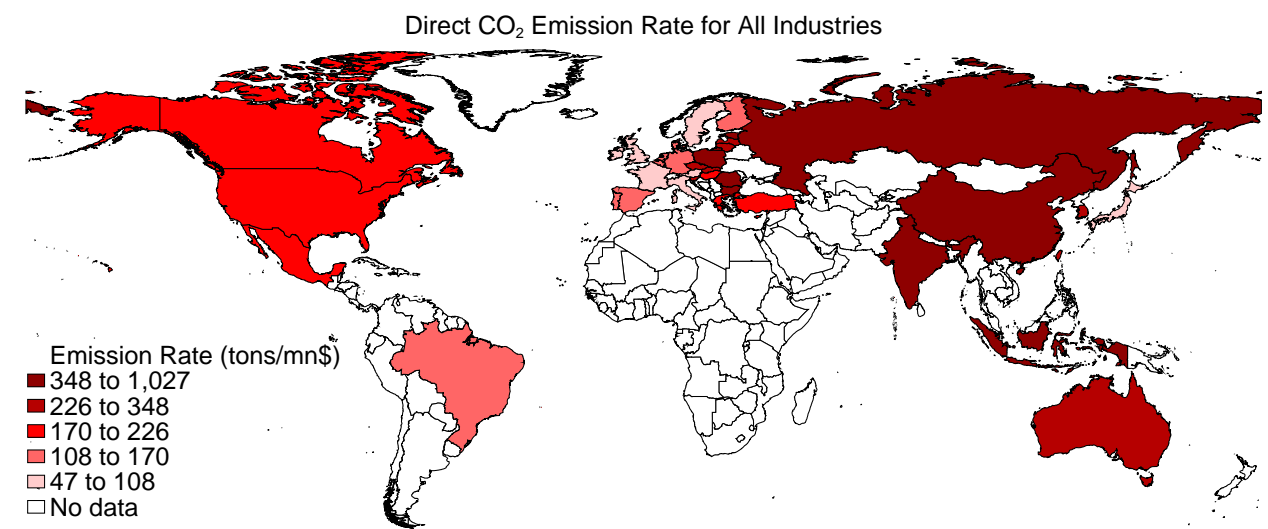

(b) Nitrogen Oxides $\left(\mathrm{NO}_{x}\right)$

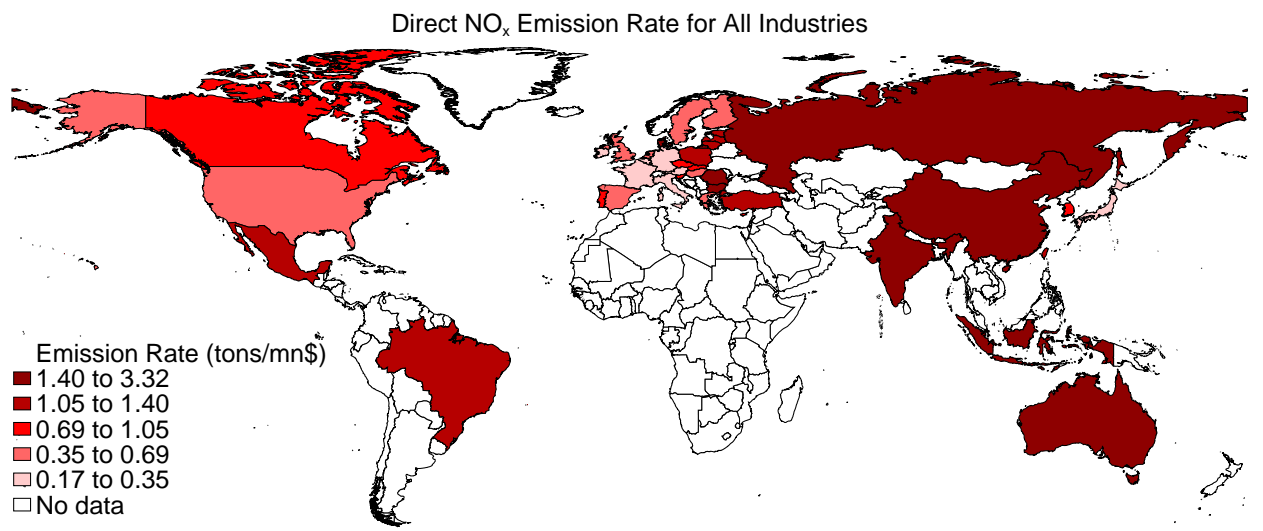

Notes: Data for the year 2009 from WIOD. See text for details.

For most pollutants, the lowest emission intensities are in Europe. The US and Canada have moderate emission intensities, with the two Latin American countries (Mexico and Brazil) slightly higher. Countries in Asia and Oceania have the highest emission intensities. The higher rates in Asia and Oceania encompass countries with a wide range of income per capita levels, from India to Australia. Emissions intensities are skewed, and the dirtiest countries have 20 or more times the emission intensity of the cleanest countries.

A few comparisons within regions provide interesting contrasts. Japan and Australia have broadly similar income per capita, and are both geographically near countries with 
high emission intensities. Japan, however, has systematically lower emission intensity than Australia. Western European countries like France and Germany have among the lowest emissions intensities of all countries. Eastern European countries like Romania and Bulgaria have among the highest emissions intensities of all countries.

An interesting and important question for future research is to explain these differences between countries. To what extent are these patterns due to variables like fuel choice, industrial composition, environmental regulation, Hicks-neutral productivity, or factor-biased productivity?

A broader implication of these maps is that geography and pollution have complex relationships that do not easily accommodate one-dimensional simplification. Models with symmetric countries miss these details. Frameworks distinguishing high- versus low-income countries capture an important share though by no means all of the variation here. The maps show potential benefit to research that can accommodate and explain the very different emission intensities around the world. Additionally, these large differences in emission rates across countries suggest that outsourcing production of dirty industries could have important environmental consequences.

\section{Stylized Fact \#6: Most global emissions growth comes from developing coun- tries.}

Figure 3 shows time-series patterns of emissions from four regions that collectively include all countries: China, the US, other high-income countries, and other low/medium-income countries. The Kyoto Protocol on climate change distinguished two groups of countries - highincome "Annex I" countries, which faced stringent emissions targets; and all other countries, typically referred to as Non-Annex I or as Annex II countries. Figure 3 uses these same groupings, but separates the US and China from the broader country groups. Appendix Figure B3 shows these patterns for other pollutants.

Pollution emissions in the EU and US are fairly flat or declining. US $\mathrm{CO}_{2}$ emissions did gradually rise between 1995 and 2008, but then declined in 2009 due to the Great Recession and advent of fracking, and by 2009 were at a lower level than in the year 1995. A similar pattern occurs in other high-income countries. US emissions of $\mathrm{NO}_{x}$ steadily declined throughout this period, and by 2009 were a fourth to a third lower than in 1995. While this pattern for $\mathrm{NO}_{x}$ in the U.S. reflects several large and stringent cap-and-trade markets (Deschenes et al. 2017), it does occur to some extent for most other air pollutants also.

By contrast, Figure 3 shows that pollution from China and other developing and middleincome countries grew rapidly. China's $\mathrm{CO}_{2}$ emissions growth was fairly flat until China 
Figure 3: Direct Emissions, by Group of Countries and Year

(a) Carbon Dioxide $\left(\mathrm{CO}_{2}\right)$ Emissions

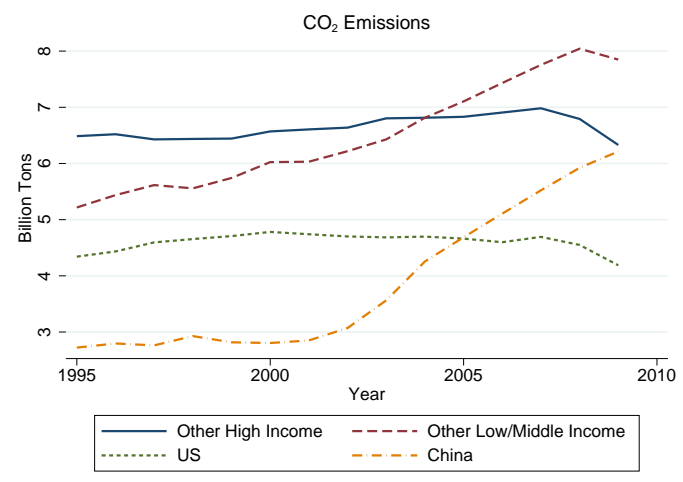

(b) Nitrogen Oxides $\left(\mathrm{NO}_{x}\right)$ Emissions

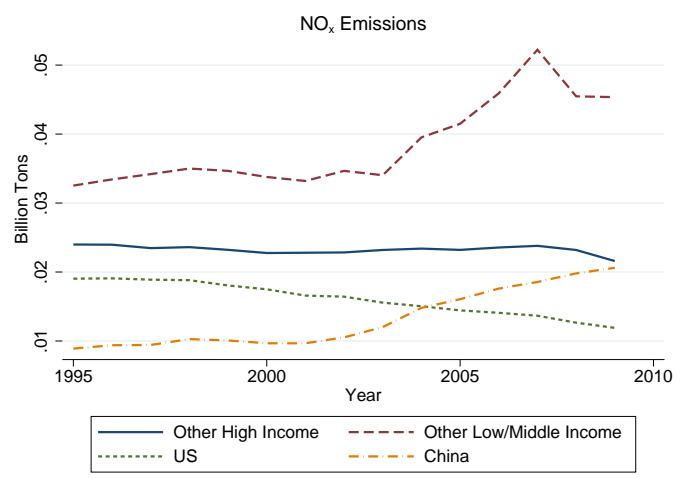

joined the WTO in the year 2001. China's $\mathrm{CO}_{2}$ emissions then doubled between 2001 and 2009. A similar pattern occurred for China's $\mathrm{NO}_{x}$ emissions. In other developing and middleincome countries, emissions of $\mathrm{CO}_{2}$ and $\mathrm{NO}_{x}$ grew fairly steadily throughout this time period, and were about 50 percent higher in 2009 than in 1995.

We have also constructed versions of Figure 3 which measure emissions based on the location where goods are consumed, rather than produced (not shown for space). Measuring emissions based on consumption rather than production does lead to higher measured emissions for the US and Other High Income countries. The trends in the graphs, however, and thus our conclusions about the main sources of global emissions growth, are similar whether emissions are measured by consumption or production.

Many studies of trade and the environment focus on one high-income country, where detailed and accurate data is widely available, and environmental and trade policies are well enforced. Other research asks how changes in developing countries affect the environment in high-income countries. More broadly, this fact and chapter highlights the potential value and scarcity of research on international environmental issues in low- and middle-income countries. While this chapter discusses a range of methods available to assess the extent to which trade is causing this emissions growth, the available literature on this question for developing countries is limited and we believe inconclusive.

Figure 3 suggests that the most rapid environmental change is occurring in low and middle-income countries. Because developing countries are where large unilateral tariff reductions have occurred, or where countries have joined the WTO, they may also represent areas where trade exposure has changed the most. These patterns collectively suggest great importance for understanding how trade is affecting the environment in low- and middleincome countries. WIOD distinguishes between several large, low and middle income coun- 
tries (Brazil, China, India, Indonesia, etc.), though it does not separate data for many other low-income countries. Additional data would be needed to determine how these patterns differ in low-income countries.

\section{Stylized Fact \#7: International trade accounts for a fourth to a third of global pollution emissions.}

Figure 4 describes the share of pollution emissions embodied in international trade. Each dot describes data for one year, covering the period 1995-2009. For each dot, we calculate the tons of emissions that traded goods create and divide it by the total tons of emissions in the global economy. The numerator for calculating each dot includes total emissions, i.e., from the traded industry and its entire global value chain. Panel A describes $\mathrm{CO}_{2}$ while Panel B describes $\mathrm{NO}_{x}$. Appendix Figure B4 shows patterns for the other pollutants.

Figure 4: Share of Global Pollution Embodied in International Trade, by Year

(a) Carbon Dioxide $\left(\mathrm{CO}_{2}\right)$

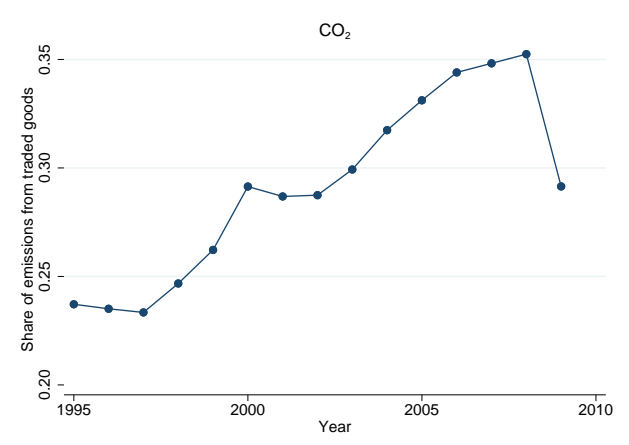

(b) Nitrogen Oxides $\left(\mathrm{NO}_{x}\right)$

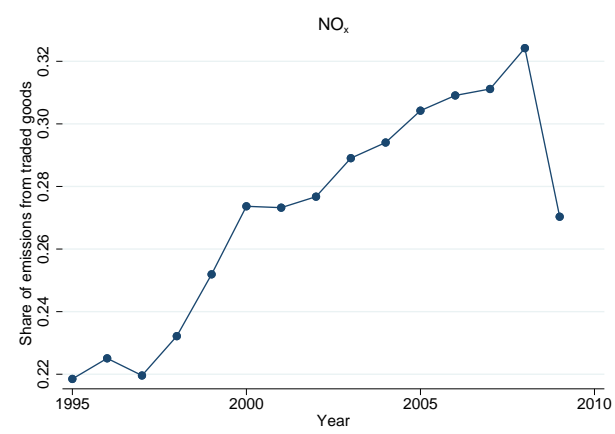

Notes: the numerator includes total emissions from own-industry plus emissions embodied in the global value chain. The denominator includes all global emissions.

The graphs in Figure 4 show that 22 to 35 percent of global pollution emissions are embodied in international trade. In the final year with data year (2009), 29 percent of $\mathrm{CO}_{2}$ emissions and 27 percent percent of global $\mathrm{NO}_{x}$ emissions are embodied in international trade. This includes emissions from the entire value chain of traded goods, including electricity and other intermediate goods, in addition to inputs used in those intermediate goods, and inputs to inputs, etc.

The time-series patterns in the two graphs are similar. The share of emissions embodied in international trade rose over time, reaching a peak in 2008. The share of emissions embodied in trade then fell abruptly in the year 2009, corresponding with a decline in global GDP and a further decline in the ratio of international trade to GDP (Eaton et al. 2016).

Existing research has found broadly similar proportions for $\mathrm{CO}_{2}$ in specific years, though has not typically reported these ratios for this wider range of pollutants and years. Some 
studies use the Global Trade and Analysis Project data, which finds slightly less emissions embodied in trade (Peters and Hertwich 2008; Davis and Caldeira 2010). Research using WIOD obtains measures of $\mathrm{CO}_{2}$ embodied in trade that resemble ours (Boitier 2012). Some research provides detailed comparisons between emissions measures in these different data (Arto et al. 2014).

These statistics do not seek to quantify effects of a counterfactual world in which international trade ceased, i.e., how emissions would change if all countries went to autarky. While studying autarky is (hopefully) not a realistic policy counterfactual, it does seek to answer the question of how international trade affects the environment. When certain goods stop being traded internationally, those goods may be produced and sold domestically, so emissions from intra-national trade simply replace at least some of the emissions from inter-national trade. In addition, policies that decrease emissions from trade may change prices, quantities, and even technologies of goods traded in all countries. The magnitudes in Figure 4 suggest that international trade and trade policy have potentially large effects on the environment, but these accounting measures do not pin down the magnitudes of counterfactuals.

\section{Stylized Fact \#8: Rich countries are increasingly outsourcing pollution.}

Figure 5 describes net imports of pollution each year by rich countries. Panel A of Figure 5 plots the total emissions embodied in imports and exports of Annex I countries, including all emissions in the value chain of goods. Panel $\mathrm{C}$ plots the same information for $\mathrm{NO}_{x}$. Panels $\mathrm{B}$ and $\mathrm{D}$ thus represent the share of global emissions embodied in net imports of high income countries, equal to imports minus exports, divided by global emissions.

Figure 5, Panel A, shows steady growth in imports and exports of emissions by highincome countries. The widening gap between the two lines also represents growing net imports of pollution by high-income countries. In the year 1995, net imports of high-income countries accounted for about half a billion tons of $\mathrm{CO}_{2}$ emissions. Panel $\mathrm{B}$ shows that this represented about two and a half percent of all global $\mathrm{CO}_{2}$ emissions. By 2008, about 1.5 billion tons of global $\mathrm{CO}_{2}$ emissions were embodied in the net imports of high-income countries, representing just over 5.5 percent of all global $\mathrm{CO}_{2}$ emissions.

Similar patterns occur for other pollutants. Figure 5, Panels C and D, show patterns for $\mathrm{NO}_{x}$. Rich countries' net imports of $\mathrm{NO}_{x}$ as a percent of global emissions in the year 2008, at about 4.5 percent, were slightly below the corresponding share for $\mathrm{CO}_{2}$, at about 5.5 percent. Appendix Figure B5 shows the share graphs for the six other pollutants. In each case, the share of global emissions embodied in rich countries' net imports grew through 2008, reaching a peak of four to ten percent of global emissions for most pollutants.

These patterns echo findings in existing research. Peters et al. (2011) use GTAP data 
Figure 5: Emissions Embodied in Net Imports of High-Income Countries

(a) $\mathrm{CO}_{2}$ : Emissions in Imports Versus Exports of High-Income Countries

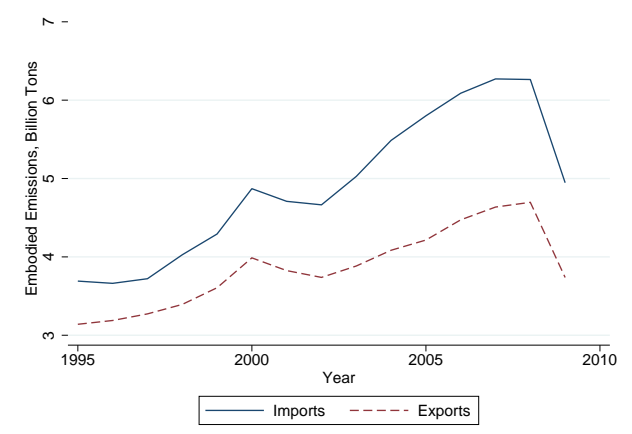

(c) $\mathrm{NO}_{x}$ : Emissions in Imports Versus Exports of High-Income Countries

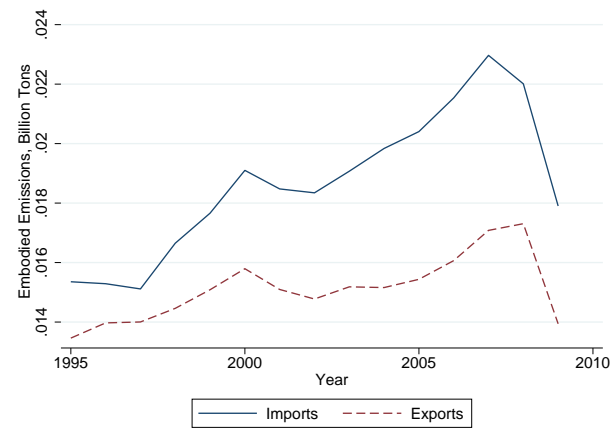

(b) $\mathrm{CO}_{2}$ : Share of Global Emissions Embodied in Net Imports of High-Income Countries

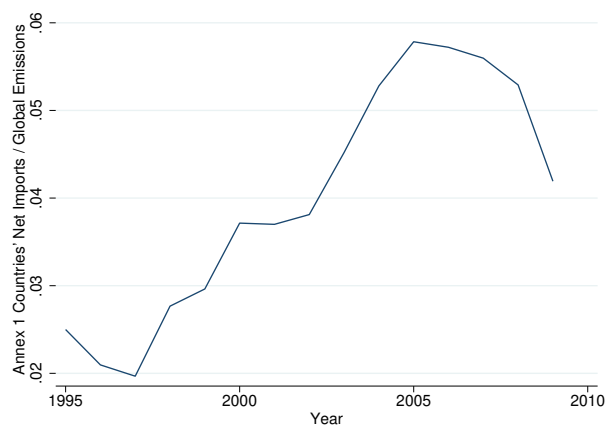

(d) $\mathrm{NO}_{x}$ : Share of Global Emissions Embodied in Net Imports of High-Income Countries

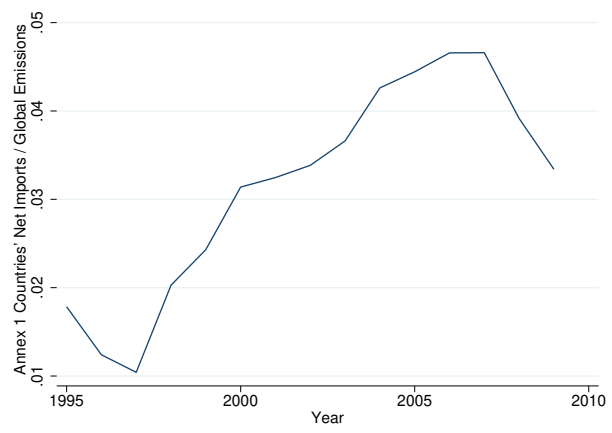

Notes: high-income countries include all "Annex I" countries from the Kyoto Protocol.

to find that net imports of $\mathrm{CO}_{2}$ by high-income (Annex I) countries grew by 1.2 gigatons between 1990 and 2008, which exceeds the reductions that the Kyoto Protocol targeted. Other work documents large quantities of emissions and natural resources embodied in trade, though often for a single year (Peters and Hertwich 2008; Hertwich and Peters 2009).

In these settings, the change in emissions embodied in net trade may reflect changes in the scale of net trade flows, the composition of net trade flows across industries, and in the techniques used to produce goods in different countries. Below we describe a decomposition into scale, composition, and technique for total production in each country, but here note that these features are also relevant to determining net emissions embodied in trade.

These patterns may contribute to the emissions growth of developing countries shown in Stylized Fact \#3. As an accounting measure, however, the magnitude here is too small to explain the majority of developing countries' emissions growth. For example, these graphs show that the net $\mathrm{CO}_{2}$ imports of high-income countries grew by about 1 billion tons between 1995 and 2009, while Figure 3 shows that $\mathrm{CO}_{2}$ emissions from China and other low and middle income countries grew by about 6 billion tons over that period. 
The large and growing quantities of emissions embodied in trade makes it potentially important for research to consider settings where countries are able to outsource pollution emissions to their trading partners and have economic reason to do so. This includes allowing for features like pollution havens, trade imbalances, leakage, and global input-output links. For research and policy, it also underscores the relevance of measuring emissions based on what a country consumes, and not merely on what it produces. For example, if the Annex I countries that had binding targets under the Kyoto Protocol achieved those goals by simply importing energy-intensive goods from countries without binding targets under Kyoto, this would obviously not reduce global emissions.

\section{Stylized Fact \#9: Technique accounts for a larger share of changes in emissions than composition.}

Since at least Grossman and Krueger (1993) and Copeland and Taylor (1994), economists have described three channels through which trade and macroeconomic changes may affect the environment. One channel is scale -increasing a country's level of production, measured as value added or gross output, can increase its pollution emissions. A second channel is composition - changing the share of national output or value added from cleaner versus dirtier industries can affect the environment. A third channel is technique - an economy can change the pollution emitted per unit of output or value added within an industry.

We calculate what share of the change in each country's emissions is due to scale, composition, and technique, using a standard method (Levinson 2009). This decomposition is calculated separately for each country. Define $e_{i t}$ as the emission rate of industry $i$ in year $t$, equal to the tons of pollution emitted per dollar of value added. Define $Y_{i t}$ as the value added of industry $i$ in year $t$. For each year $t$, we plot the following three values:

$$
\begin{aligned}
\text { Scale } & =100 * \frac{\sum_{i} Y_{i t}}{\sum_{i} Y_{i 1995}} \\
\text { Scale, composition, \& technique } & =100 * \frac{\sum_{i} Y_{i t} e_{i t}}{\sum_{i} Y_{i 1995} e_{i 1995}} \\
\text { Scale \& composition } & =100 * \frac{\sum_{i} Y_{i t} e_{i 1995}}{\sum_{i} Y_{i 1995} e_{i 1995}}
\end{aligned}
$$

Figure 6 plots these values for the year 2009. Each graph orders countries by their change in real GDP growth (i.e., scale), plotted as a blue circle for each country, calculated from equation (1). If the composition of value added across industries and the techniques used in each industry were fixed, these circles show how emissions changed. China experienced the fastest real GDP growth, about five-fold. 
Figure 6: Decomposition of Scale, Composition, and Technique

(a) Carbon Dioxide $\left(\mathrm{CO}_{2}\right)$ Decomposition

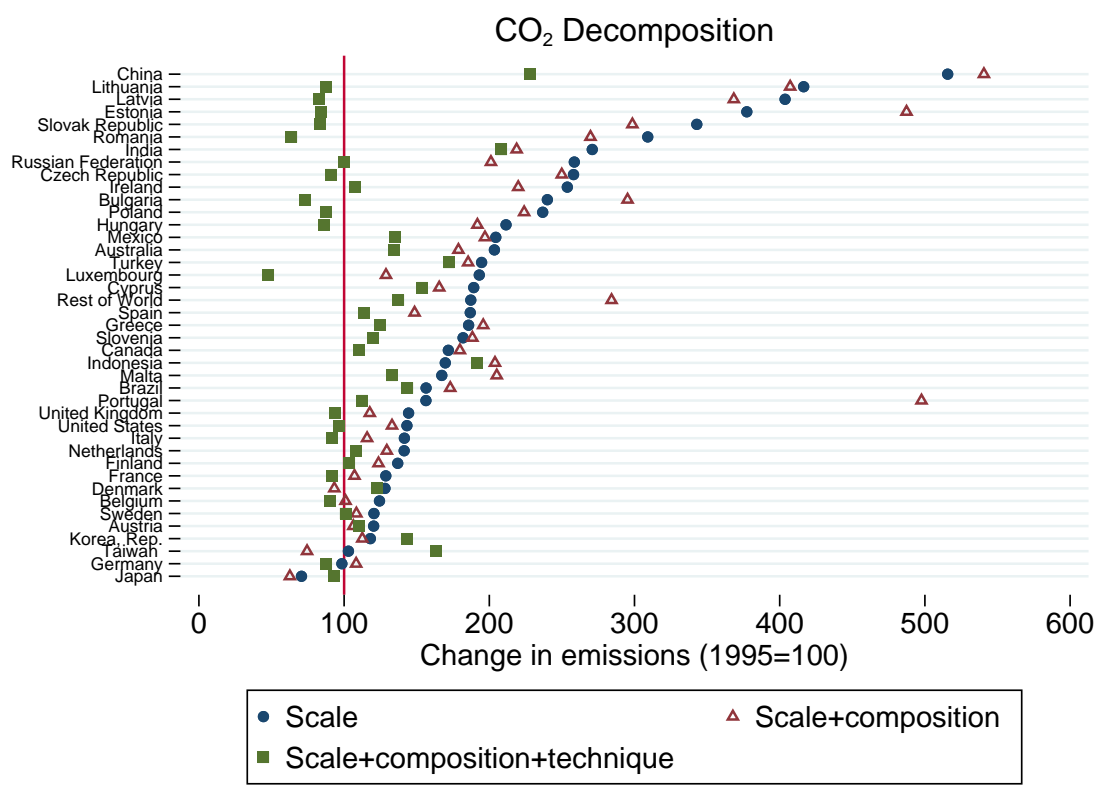

(b) Nitrogen Oxides $\left(\mathrm{NO}_{x}\right)$ Decomposition

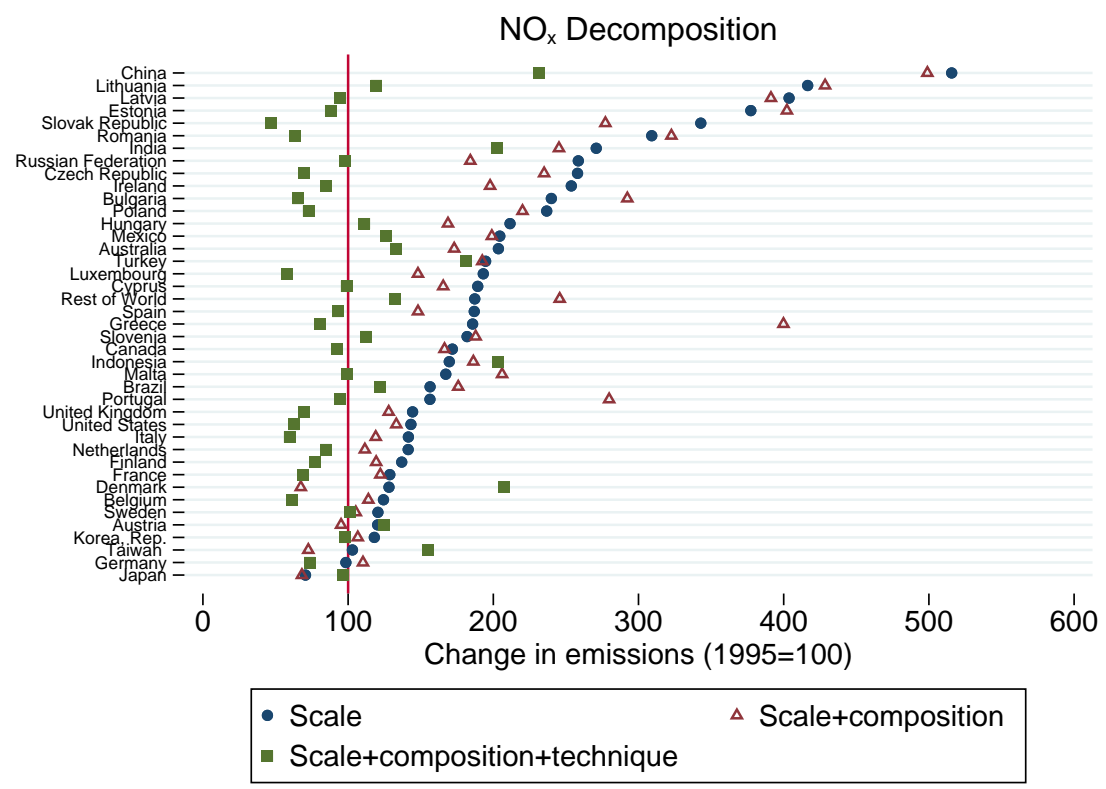

Notes: scale represents 100 times national value added (GDP) in 2009, divided by national value added in 1995. Scale+composition modifies the scale value to keep emission rates (technique) the same for each country*sector in 2009 as it was in 1995. Emission rates are measured as tons directly emitted per dollar of value added. Scale+composition+technique represents 100 times emissions in 2009, divided by emissions in 1995. Vertical red line at "Change in emissions " $=100$ represents the value for no change in emissions between 1995 and 2009. 
The hollow red triangles in Figure 6 show the combined effects of scale and composition, calculated from equation (2). These show how emissions would have evolved if composition and scale both changed but techniques were fixed. The horizontal distance between scale (blue solid circles) and scale+composition (red hollow triangles) shows how composition alone affected emissions, i.e., how reallocation of value added across industries changed emissions.

Figure 6 shows some role for composition, though the signs vary by country, and the magnitudes are smaller than scale effects. In China, for example, the composition of value added across industries increased $\mathrm{CO}_{2}$ emissions and decreased $\mathrm{NO}_{x}$ emissions.

The solid green squares in Figure 6 show the actual change in emissions, calculated from equation (3). In China and India, $\mathrm{CO}_{2}$ and $\mathrm{NO}_{x}$ emissions more than doubled between 1995 and 2009. In most high-income countries, $\mathrm{CO}_{2}$ changed relatively little but $\mathrm{NO}_{x}$ decreased by 20 to 50 percent.

The technique effect equals the horizontal distance between the hollow red triangles (scale+composition) and the solid green square (scale+composition+technique). In almost every country, the technique effect is also much larger than the composition effect. In many countries, the technique effect is larger than the scale effect.

As discussed earlier, firms do not have economically viable abatement technology to decrease $\mathrm{CO}_{2}$ emissions once a physical unit of fossil fuels is burned. Thus, the large technique effects for $\mathrm{CO}_{2}$ do not represent installation of end-of-pipe pollution control technologies like scrubbers or carbon capture and sequestration. Instead, they represent some combination of switching from dirtier to cleaner energy sources (e.g., coal to natural gas); Hicks-neutral productivity growth, which requires fewer physical inputs to produce a dollar of value added; or factor-biased productivity growth, which requires fewer fossil fuels relative to capital and labor. Although environmental policy can affect fuel choice and factor-biased productivity growth, it uncertain and even perhaps unlikely that the large technique effects for $\mathrm{CO}_{2}$ in many countries represent direct effects of environmental policies.

Using gross output rather than value added gives similar patterns. Value added has been gradually declining as a share of gross output, due to outsourcing and longer global value chains increasing the importance of intermediate goods. Between 1995 and 2009, for example, the global ratio of value added to gross output in WIOD declined gradually from 0.52 to 0.49 . Thus, undertaking this decomposition with gross output slightly increases the technique effect.

Appendix Figure B6 shows similar patterns for the other pollutants, with important exceptions for the two coming primarily from agriculture-ammonia $\left(\mathrm{NH}_{3}\right)$ and nitrous oxide $\left(\mathrm{N}_{2} \mathrm{O}\right)$, where composition effects are more systematic and important.

Overall, this comparison across countries largely echoes the findings of previous country- 
specific studies - technique, rather than composition or scale effects, accounts for the largest share of the change in emissions. Most studies, including for the US, Canada, the EU, and many other countries, generally find that the large majority of the change in pollution occurs due to technique, rather than scale or composition (Antweiler et al. 2001; Grether et al. 2009; Levinson 2009, 2015; Brunel 2016; Shapiro and Walker 2018). This is not a universal

finding - for example, Barrows and Ollivier (2018) find that technique and composition effects have similar magnitude in India. Using WIOD limits the number of sectors, which dampens the scope for composition effects, though the aforementioned detailed analyses of a few individual countries tend to find similar patterns even with data on hundreds of industries or over a thousand individual products.

Technique effects could represent a variety of forces, including environmental regulation, within-industry reallocation to cleaner plants (induced by import competition, policy, or other forces), productivity growth, or other channels.

A broad interpretation of these patterns is that under standard versions of traditional comparative advantage theories of international trade, these results may suggest that changes in the composition of production across industries due to trade are not the primary driver of environmental change. Standard Heckscher-Ohlin theories, for example, would suggest that the main effect of trade on the environment would be to reallocate production across industries. To the extent that the main change in pollution is due to decreased emission rates within industries, rather than across industries, it suggests that reallocation across industries due to comparative advantage in such models is not capturing the main drivers of environmental change. These patterns also motivate the analysis of how globalization affects the environment in Section 4.

One should be careful not to over-stretch this conclusion, for a few reasons. For example, in any trade theory, opening to trade could increase incomes, and rising incomes could increase demand for environmental quality, resulting in stricter environmental policies which may create a large negative technique effect, and positive scale effects. Alternatively factor endowment driven motivations for trade may be offset by tighter policy in richer, but also capital abundant, countries leading to small composition effects (Antweiler et al. 2001).

\section{How does globalization affect the environment?}

Globalization affects the environment through a variety of channels. Trade and foreign direct investment affect the location, scale, composition, and environmental impact of both production and consumption activities throughout the world. Environmental policy-setting may be different in a global economy, especially because of concerns about international 
competitiveness. There are direct effects of trade and travel on the environment through the emissions generated by international transport. Globalization also affects technology diffusion, lifestyle, and the spread of invasive species and disease; all of which have environmental impacts.

We will begin by discussing the effects of globalization on production-generated (primarily local) pollution; and organize it by highlighting three key hypotheses driving most of the work. We then expand our discussion to include, pollution from consumption and transportation, and globalization's impact on resource use. We leave most of the discussion of global pollution to Section 6 .

\subsection{Production-generated pollution}

Stylized fact 7 tells us that between a quarter and a third of global pollution emissions are used to produce traded goods. Moreover, the most emission-intensive industries tend to be most exposed to trade (stylized fact 1). This tells us that a substantial amount of pollution throughout the world is generated by the production of goods that are traded. But this does not necessarily imply that trade has caused an increase in pollution. In the absence of trade, the resources that go into the production of traded goods would find other uses, and these may cause more or less environmental damage than what we see now.

A simple way to think about the effects of trade on the environment is to adapt a textbook diagram from environmental economics. See Figure 7. The vertical axis is an emission price (or shadow price). The demand curve " $\mathrm{D}$ " is the demand for the right to release emissions. In environmental economics, this is referred to as the marginal benefit of polluting. If we model emissions as access to environmental services (such as using the atmosphere as a sink for waste), then this would be the value of the marginal product of emissions (summed over all sources of emissions).

The dashed curve labelled MD is the marginal damage from emissions. This comes from the Samuelson rule for public goods or bads - it is the sum of the marginal damage across all of those affected by pollution. The intersection is the socially efficient level of emissions. In practice, regulation is unlikely to be efficient, so we have sketched a curve " $R$ " which represents the willingness of regulators to allow emissions. If there is no regulation, then "R" would just be the horizontal axis. If there is a binding emission quota, then $\mathrm{R}$ is vertical. If regulation is socially efficient, then $\mathrm{R}$ would coincide with MD. In the example here, regulation is too lax, but the regulator tightens up as emissions get higher (so $R$ is upward sloping). The initial level of emissions is $z_{0}$ and the initial emission price is $\tau_{0}$. 
Figure 7: Equilibrium determination of emissions

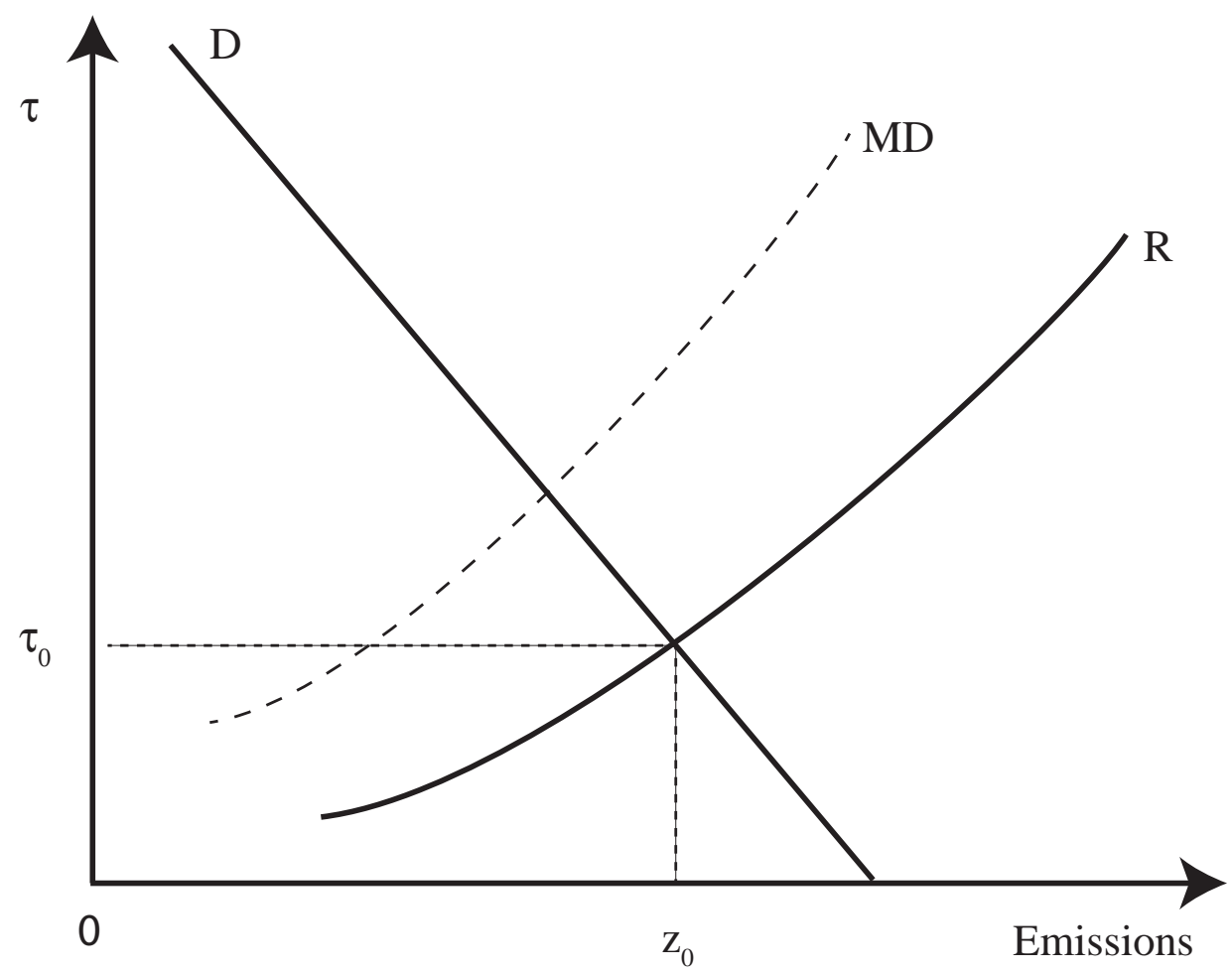

Fig. 7 allows us to illustrate some of the hypotheses about how globalization affects the environment.

\subsubsection{Trade may raise or lower pollution.}

Openness to trade tends to increase real income, and any liberalization that does so has at least two effects. An increased scale of production will shift out the demand D for the right to pollute in Fig. 7. This tends to increase pollution. If environmental quality is a normal good, the increase in per capita income will increase the demand for environmental quality so that MD shifts up. ${ }^{4}$ If regulators are responsive, the " $\mathrm{R}$ " curve will also shift up. This creates a technique effect (more stringent regulation) that tends to lower pollution. The net result on pollution is uncertain. If technique effects are very large, pollution will fall. While stylized fact 9 tells us that technique effects are, in general, a substantial determinant of emission levels it is unclear to what extent they are driven by real income gains from trade. Another obvious source of income gains is economic growth, and a large literature on the

\footnotetext{
${ }^{4}$ Trade liberalization is also accompanied by relative price changes that can, via substitution effects, affect both curves. These may dampen or reinforce the shifts creating further complications (Copeland and Taylor (2003); Ch. 4). Changes in factor prices induced by trade can also affect the distribution of income and may also effect the shift in MD.
} 
Environmental Kuznets Curve explores the relation between economic growth and environmental quality, with some evidence that the effects of increased real income on pollution are different for high income than low income countries (Grossman and Krueger 1995; Stern 2017).

Because we have to limit the scope of this chapter, we will not discuss the relation between real income and pollution in any depth. ${ }^{5}$ For our purposes, a key issue is whether trade has effects on the environment that are different from the effects of growth. There is still much variation in emissions to explore, since stylized fact 5 tells us that even after correcting for scale differences in output across countries, there remain large and interesting differences in their emission intensities. And while it is surely true that stylized fact 6 reflects, at least partially, the more rapid economic growth of developing countries, the literature has focused on a narrower question: whether there is any reason to expect the growth path of a country is cleaner or dirtier if it is more open to trade? There are in fact several hypotheses directly addressing this question. We discuss them in turn.

\subsubsection{The pollution haven hypothesis}

If a country has a comparative advantage in pollution-intensive industries, then freer trade will shift the emission demand curve D to the right due to a composition effect - on average production becomes dirtier as the mix of production shifts to more polluting industries. Conversely, the trade-induced composition effect will shift D to the left for countries with a comparative advantage in relatively clean industries. The simplest version of the pollution haven hypothesis ties the direction of these shifts to the country's level of environmental regulation; countries with relatively weak regulation will attract dirty industries driving demand rightwards; the converse holds for those with strong environmental regulation. A more sophisticated version makes the stringency of environmental regulation endogenous: trade then both reflects regulatory differences and shapes them via the real income gains from trade.

The very first and simplest versions take regulatory differences as given, and pivotal to comparative advantage. Naturally, they predict that the country with the weakest regulation will export the pollution intensive good. ${ }^{6}$ Copeland and Taylor (1994) developed a more sophisticated version with a continuum of goods that differ in their emission intensity. The government is active in setting and adjusting its efficient pollution policy; firms are active in abating pollution to escape pollution taxes. The two countries, North and South, have

\footnotetext{
${ }^{5}$ See Brock and Taylor (2005) and Xepapadeas (2005) for reviews.

${ }^{6}$ In terms of Figure 7 we can think of the pollution tax being held constant, and a rightwards shift in pollution demand then raises equilibrium pollution. For example, Pethig (1976) developed a simple two-sector to generate this result, while McGuire (1982) focused on the effects on factor mobility between countries.
} 
identical technology, but North is richer because of its higher human capital per worker. Environmental quality is a normal good and so North has more stringent pollution policy than South. Differences in policy are the only source of comparative advantage, and these differences give South a comparative advantage in polluting goods. In free trade, the most pollution intensive sectors concentrate in South. In terms of Figure 7, the demand for emissions falls in North and rises in South. With policy endogenous, and free trade bringing income gains, the equilibrium impact on pollution also depends on the regulatory response which shifts MD upwards. While the North always enjoys lower pollution, trade will increase pollution in the South unless the income elasticity of the demand for environmental quality is very high. Moreover, global pollution also rises because trade shifts the dirtiest production to the part of the world with the weakest environmental policy. This demonstrates that active and income driven pollution policy alone is unlikely to drive pollution downwards. If trade is to lower emissions, additional factors must come into play.

To see why and what role other factors must play, it is useful to break the pollution haven hypothesis into two components. The first is simply that differences across countries in environmental policy affect trade and foreign investment flows across countries. Copeland and Taylor (2004) refer to this as the pollution haven effect; the key issue is whether environmental policy has a negative effect on competitiveness in affected industries. The second component is that differences in environmental policy are not only present, they are pivotal in determining comparative advantage. Many factors contribute to comparative advantage, and even if stringent environmental policy reduces competitiveness, other factors (such as technology, relative factor abundance, distance, and agglomeration effects ${ }^{7}$ ) may be far more important determinants of trade. As an example, suppose that pollution-intensive industries are also capital intensive. Then in a simple Heckscher-Ohlin model, the capital abundant country will export pollution intensive goods. Relatively more stringent environmental policy in the capital-abundant country may reduce its net exports (a pollution haven effect), but need not reverse the pattern of trade. In this case, trade liberalization would tend to shift production of polluting goods to the high-regulation capital-abundant country (a failure of the pollution haven hypothesis). But a tightening of environmental regulation in the capital abundant country would at the margin shift some pollution-intensive production to other countries (a pollution haven effect).

The theory behind the pollution haven effect is simple - more stringent environmental policies raise production costs, and this leads to reduced net exports (or increased net im-

\footnotetext{
${ }^{7}$ Antweiler et al. (2001), Copeland and Taylor (2003), and Cole and Elliott (2003) consider the interaction between environmental policy and factor endowment differences. On the potential for agglomeration to work against the effects of stringent environmental policy, see Zeng and Zhao (2009).
} 
ports) in sectors affected by environmental regulation. ${ }^{8}$ The pollution haven effect can also work via foreign direct investment - higher production costs induced by environmental regulation can discourage incoming FDI, and conversely, weak environmental regulation may be a factor that attracts incoming FDI.

Although the rationale for the pollution haven effect is compelling, early empirical work found little or no evidence in support of it; and in some cases, found that a country's net exports were positively related to the stringency of its environmental policy (Jaffe et al. 1995). Much of this work used cross-sectional data and was hampered by issues of omitted variable bias and a failure to deal with the endogeneity of policy. ${ }^{9}$ There are several issues at play here. One is the possibility that trade and environmental policy are linked. Suppose policymakers systematically choose weaker environmental policy for industries subject to strong import competition. This could be for political economy reasons or an attempt to substitute environmental for trade policy (see section 5). Then sectors with more stringent environmental policy would have lower import penetration and the pollution haven effect may well disappear. Policy is endogenous here, and in fact exposure to trade causes environmental policy rather than the reverse (Ederington and Minier 2003). A second pitfall arises from another form of endogeneity. A vibrant growing industry may well draw regulation on itself because of its rising emissions. At the same time, this industry may feature strong net exports reflecting its success (Levinson 2009). Policy is again endogenous and its adjustment obscures the pollution haven effect. A third pitfall is that unobserved or unaccounted for industry characteristics may well be tied to the pollution intensity of production and export success. Industries in the natural resource sector are prime candidates. Not accounting for these common to industry effects will again make it difficult to estimate a pollution haven effect. A final challenge for empirical research has been finding both good measures of the stringency of environmental policy; and useful, exogenous, variation in its stringency. Many older studies used survey data on pollution abatement costs as a measure of stringency, and sought to link variation in these costs to trade flows. In addition to the problems listed earlier, this work employs industry level data aggregated over units that are heterogeneously affected by trade. This implies industry measures of pollution abatement costs are endogenous to

\footnotetext{
${ }^{8}$ See Pasurka (2008) for evidence on pollution abatement costs (and their heterogeneity across sectors and countries). There is an alternative theory - the Porter Hypothesis - whereby more stringent environmental policy can actually increase competitiveness by stimulating investment in new technologies (Porter and Van der Linde 1995). While there is evidence that regulation stimulates investment and innovation in cleaner technology, there is little empirical support for the hypothesis that the net effect on profits or other measures of competitiveness is positive. See Ambec et al. (2013) and Dechezlepetre and Sato (2017) for reviews. See also our discussion on comparative advantage in natural resource products, where a result akin to the Porter Hypothesis will hold and has empirical support.

${ }^{9}$ Grossman and Krueger (1993) contains some puzzling results in their cross-sectional empirical work, which they presciently ascribe to omitted variables.
} 
trade flows (Levinson and Taylor 2008). ${ }^{10}$

Recent work has developed strategies to deal with these issues. With industry data, researchers exploited panel data to sweep out unobservables, and instruments to identify exogenous variation in stringency measures. Moving to firm level data allowed researchers to exploit geographic variation in the implementation of major regulatory changes and eschew potentially endogenous pollution abatement cost measures. While these methods differ, the results all point in the same direction: variation in environmental policy does affect trade flows. They are less unanimous in the magnitude of the impact, and that is where the current research frontier lies. Since there are several reviews of this literature available, we will be brief and focus on later contributions. ${ }^{11}$

For example, Ederington and Minier (2003) and Broner et al. (2012) use instrumental variables to account for the endogeneity of environmental policy and find that more stringent environmental policy reduces net exports (or increase net imports). Levinson and Taylor (2008) employ both panel data and instruments constructed from the spatial distribution of dirty industries across US states. Using this industry-level data they find $10 \%$ of the change in US trade flows to Canada and Mexico, can be attributed to changing regulatory costs. More recent work has exploited firm-level data and geography more fully. Cherniwchan and Najjar (2020) use firm-level data and exploit variation in regulatory stringency across time, region and industry in the implementation of more stringent Canadian air quality standards during the period 2004-2010. They found that the new standards reduced export revenues from the average continuing exporter by about 20\%. Several studies have found little or no evidence that the European Emission Trading System had large effects on the net exports of affected firms (Joltreau and Sommerfeld 2019; Verde 2020). However most of the data comes from a period when emission permit prices were low.

There is some evidence that environmental policy affects foreign direct investment, however effects vary across industry and country. Keller and Levinson (2002) use panel data and variation across U.S. states in abatement costs and find a small negative effect of the stringency of environmental regulation on incoming FDI. Hanna (2010) uses a panel of firmlevel data and found that the U.S. Clean Air act caused US multinationals to shift some production out of the U.S. ${ }^{12}$

Overall, the recent evidence is supportive of a pollution haven effect, but its strength

\footnotetext{
${ }^{10}$ Pollution abatement cost data is also subject to reporting and interpretation problems. For example, when the emission intensity is associated with the design of a plant, how much of the fixed and operating cost should be allocated to "abatement"?

${ }^{11}$ See for example Brunnermeier and Levinson (2004), Copeland and Taylor (2004), Dechezlepetre and Sato (2017) and Cole et al. (2017).

${ }^{12}$ See Cole et al. (2017) for a review of the interaction between environmental policy and foreign direct investment.
} 
and existence varies with circumstance. Some studies, such as Levinson and Taylor (2008), Broner et al. (2012) and Cherniwchan and Najjar (2020) have found quite large effects of environmental policy on trade flows. However, there is little or no evidence as of yet that the European Emission Trading System has affected trade flows. Most studies have found the effects of environmental policy on FDI to be small, and they vary across industries and source countries.

The existence of a pollution haven effect only tells us that environmental policy is one of many factors that affect trade and investment flows. The stronger pollution haven hypothesis is that freer trade will cause polluting industry to concentrate in countries with weak environmental regulation. This requires either that environmental policy is a key determinant of comparative advantage, or that weak environmental policy is correlated with other factors that are attractive for producers of pollution intensive goods. There is however little evidence to support this.

One place to look for evidence of the pollution haven hypothesis is to assess the role of composition effects in explaining changes in environmental quality or pollution emissions over time and / or as a result of trade. Composition effects driven by comparative advantage play a key role in the pollution haven hypothesis. If correct, we would expect to see trade cause the composition of production to shift towards dirty production in low regulation countries and towards clean production in high income countries. To isolate this potential shift in the demand for pollution in the data, researchers must somehow account for other shifts in demand (scale effects), and any policy induced shift in MD (technique effects).

To this end, Antweiler et al. (2001) estimated the scale, technique and composition effects created by openness to trade on sulfur dioxide concentrations in broad international sample of cities. Their data was an updated version of the GEMS panel exploited by Grossman and Krueger (1993). Scale effects were positive as expected and raised pollution; as well, income-induced technique effects lowered pollution. Technique effects were however, surprisingly strong suggesting a $1 \%$ increase in income per capita lowered concentrations by $1.5 \%$. Consistent with comparative advantage playing a role, they found that composition effects were heterogeneous across countries but small; moreover, they tended to raise pollution in rich countries and reduce pollution in low income countries contrary to the PHH. This evidence is consistent with Grossman and Krueger (1993) who conclude that other forces (factor endowments, technology, etc.) are more important than environmental policy in affecting trade flows. It is also consistent with stylized fact 9: composition effects are small, technique effects are large. Follow-on work such as Cole and Elliott (2003); Frankel and Rose (2005); Managi et al. (2009) also find small composition effects.

The finding of small composition effects is puzzling as it suggests that comparative ad- 
vantage may not be playing much of a role in influencing the distribution of productiongenerated pollution across countries. This somewhat surprising given that stylized fact 8 shows positive net exports of embodied emissions from low-income / low regulation countries to high-income countries. One possibility is that developing country production is relatively emission intensive across all industries, but their comparative advantage is not tightly tied to dirty industries. In this case, a trade liberalization would create small or even negative composition effects but the factor content of their exports would still be relatively dirty.

One way to investigate further is to focus on measurement, by using decomposition methods. Levinson (2009) applies the decomposition methods that we outlined in Section 3 to study the large decrease in emissions from U.S. manufacturing during the period 1987 2001. U.S. manufacturing grew by $24 \%$ during this time, but air pollution emissions fell by about $25 \%$ on average. Given that scale increased by $24 \%$, this means that composition and technique effects have to account for a 49 percentage point drop in emissions. He finds that U.S. production shifted towards cleaner industries during this period, but the composition effect is small and accounts for only 13 percentage points of this drop. Levinson then calculates the changes in emissions embodied in U.S. imports and concludes that imports can only account for about a third of the composition effect (about 4 percentage points of the overall drop in emissions). In short, he again finds that composition effects are small, and most of the fall in emissions is attributed to technique effects. ${ }^{13}$

Shapiro and Walker (2018) use more finely disaggregated US product data for the period 1990-2015 and also find small composition effects and large technique effects. Similar results have been found for Canada (Najjar and Cherniwchan 2021), Europe (Brunel 2017) and for sulphur dioxide emissions generated by 62 countries from 1990-2000 (Grether et al. 2009). Auffhammer et al. (2016) do a decomposition analysis of the changes in industrial carbon dioxide emissions in 287 Chinese cities over the period 1998 - 2009. They also find small composition effects in aggregate, but there is some heterogeneity across cities, with negative composition effects for larger cities and positive composition effects for smaller cities.

Figure 6 in Section 3 shows decompositions for $\mathrm{CO}_{2}$ and $\mathrm{NO}_{x}$ for 43 countries. Our industry data is more aggregated than that used in most of the studies noted above, but for most countries in our sample, technique effects are large. Figure 6 also reveals some heterogeneity across countries, with composition effects playing an important role in changes in emissions in some countries. For example, composition effects for $\mathrm{CO}_{2}$ are quite large for

\footnotetext{
${ }^{13}$ A potential weakness of this exercise is that the "technique" effect is calculated as a residual. Levinson (2015) addresses this issue using data from the U.S. Environmental Protection Agency's National Emissions Inventory from 1900 to 2008 . His results are broadly consistent with the earlier results.
} 
India, a result consistent with Barrows and Ollivier (2018).

Overall, the evidence that composition effects are relatively small suggests that trade driven by comparative advantage has not been responsible for systematically shifting pollution intensive production out of higher income countries. Ederington et al. (2004) probe this further by estimating the emissions that would have been generated if U.S. imports from lower income countries had been produced in the U.S. and compare this with U.S. exports to these countries for the period 1972-94. ${ }^{14}$ They found that the pollution content of U.S. imports (using U.S. emission intensities) fell relative to the pollution content of U.S. exports during this time. Levinson (2010) takes into account pollution generated during the production of intermediate goods and finds that the pollution content of U.S. imports grew much more slowly than the overall growth in imports. He refers to this as a "green shift" in the pattern of U.S. imports. Accounting for pollution generated during the production of intermediates dampens this "green shift" by only a relatively small amount.

Weber and Matthews (2007) find what appear to be contradictory results. Using data from the seven largest trading partners of the U.S. (Canada, China, Mexico, Japan, Germany, the U.K. and Korea) for the period 1997-2004, they find that there is a large net increase in U.S. net imports of embodied emissions for $\mathrm{CO}_{2}, \mathrm{SO}_{2}$, and $\mathrm{NO}_{x}$. As with Levinson (2010), they take account of emissions from intermediate goods, but differing from Levinson, they use emission intensities from the country when the goods were produced (Levinson calculates the emissions that would have been generated if a unit of imported steel from China was instead produced in the U.S.; Weber et al. estimate the emissions that were generated by Chinese production of the steel). Levinson (2010) accounts for the differences in their results as being driven by higher emission intensities relative to the U.S. in some of the exporting countries. The growth in net imports of embodied emissions into high income countries has been found in numerous studies of $\mathrm{CO}_{2}$ emissions (see for example Peters et al. (2011) and is also consistent with our stylized facts $\# 8$, where we show a large increase of net imports of embodied air pollutants into high income countries from the late 1990's to 2008.

Weber and Matthews (2007) do a decomposition into a scale effect (more trade), changes in the mix of commodities traded and changes in trading partners. Consistent with the other work discussed here, they find very small changes in the mix of imported commodities - and their evidence is that this composition effect actually contributed to a small decreased in embodied imports of emissions. However, the change in pattern of trading partners (including a large increase in trade with China) had a large positive effect on embodied imports of emissions.

Much of the work using decompositions and calculating emissions embodied in trade

\footnotetext{
${ }^{14}$ They also do this for all of U.S. trade and find similar results.
} 
has been confined to measurement. There has been relatively little work that attempts to identify the causal effect of increased trade due to comparative advantage in affecting environmental outcomes. A recent paper that does this is Bombardini and Li (2020). They study the effect of increased exports on regional pollution and infant mortality in China using an approach similar to that used by Autor et al. (2013) to identify the effects of increased imports from China on regional unemployment in the U.S. Bombardini and Lee construct two variables. ExShock measures the extent to which each prefecture in China initially specialized in industries that experienced an export shock (increased demand for exports driven by changes in trade policy in the rest of the world). PollExShock measures the interaction between the export shock and the pollution intensity of the industries in which the prefecture specializes. They find that an export shock alone tended to reduce infant mortality and improve local air quality, although the effects were small and not statistically significant. However, an export shock in a region with a specialization in pollution intensive production resulted in a significant deterioration in air quality and an increase in infant mortality (relative to trends in other prefectures). To the extent that patterns of production across prefectures reflected comparative advantage prior to the trade shock, these results are consistent with regional comparative advantage playing a role in affecting the regional effects of increased trade on the environment, although other explanations, such as agglomeration effects may also have played a role.

Most of the evidence from recent empirical work is consistent with view that relatively more stringent pollution policy tends to contribute to a comparative disadvantage in pollution-intensive production. That is, there is evidence for a pollution haven effect. However there is little evidence in support of the stronger pollution haven hypothesis. Sectoral composition effects are small for most countries - the fall in emissions in high income countries cannot be attributed to a shift towards cleaner industries. As we discuss below, this does not, however rule out the possibility that firms offshoring pollution-intensive parts of their production could be a channel via which trade is affecting domestic sectoral emission intensities.

\subsubsection{The pollution reduction by rationalization hypothesis}

Trade liberalization will cause a reallocation of production among firms. If production shifts to more productive firms, and if more productive firms are cleaner, then for any given level of production within a sector, the D curve will shift inward, as on average production within that sector becomes cleaner.

A surprising result from much of the work discussed above is that for most countries technique effects are large and sectoral composition effects are small. This was highlighted 
as our Stylized Fact \#9. Levinson (2009) hypothesizes that large technique effects and small composition effects imply that the fall in emissions in U.S. manufacturing was due to regulation and technology and that trade has played a very small role. A key question for researchers is whether this is in fact the case. In particular we need to dig more deeply into what lies behind the large measured technique effects, and look for evidence as to what has driven the changes.

The technique effect is calculated as a change in sectoral emission intensity, but it could be due to many things - changes in technology, outsourcing, changes in the mix of inputs, and changes in shares of production accounted for by different firms with different emission intensities within a sector. Standard decomposition methods following Levinson (2009) use industry data. In some cases, such as Shapiro and Walker (2018), industries are very finely disaggregated, but nevertheless the data aggregates firm responses within a sector. With the increased availability of firm-level data, it is possible to do decompositions that shed light on how firm-level adjustments affect sector emission intensities. The pollution reduction by rationalization hypothesis is that part of the reduction in sectoral emission intensities is driven by the effect of trade in shifting output shares to cleaner, more productive firms. To investigate this, we begin with a firm level decomposition of emission intensities, then consider theoretical models that introduce pollution emissions into models with heterogeneous firm, and finally review the evidence.

\section{Heterogenous firms: Theory}

A useful way to explore what lies behind changes in sectoral emission intensities is to use a firm-level decomposition. ${ }^{15}$ We follow the approach of Cherniwchan et al. (2017). Each industry $\mathrm{i}$ has a continuum of firms on the interval $\left[0, n_{i}\right]$. Emissions of firm $\mathrm{n}$ are denoted $z_{i}(n)$ and total industry emissions are

$$
Z_{i}=\int_{0}^{n_{i}} z_{i}(n) d n
$$

Emission intensity in industry i is

$$
E_{i}=\frac{Z_{i}}{S_{i}}=\int_{0}^{n_{i}} e_{i}(n) \varphi_{i}(n) d n
$$

where $S_{i}$ is the scale of output in industry $i$, which is the sum of value added $v_{i}(n)$ across firms

\footnotetext{
${ }^{15}$ See Martin (2011); Cherniwchan et al. (2017); and Barrows and Ollivier (2018). Firm level decompositions have been used extensively in the productivity literature for example Foster et al. (2008).
} 
in the industry; $e_{i}(n) \equiv z_{i}(n) / v_{i}(n)$ is the emission intensity of firm $n$; and $\varphi_{i}(n) \equiv v_{i}(n) / S_{i}$ is firm $n$ 's share of value added in industry $i$.

Changes in the emission intensity can then be decomposed by differentiating (4):

$$
\hat{E}_{i}=\int_{0}^{n_{i}} \hat{e}_{i}(n) \theta_{i}(n) d n+\int_{0}^{n_{i}} \hat{\varphi}_{i}(n) \theta_{i}(n) d n+n_{i}\left[\theta_{i}\left(n_{i}\right)-\varphi_{i}\left(n_{i}\right)\right] \hat{n}_{i}
$$

where $\theta_{i}(n) \equiv z_{i}(n) / Z_{i}$ is firm n's share of emissions in industry $i$.

$\hat{E}_{i}$ is the technique effect for industry $i$ that is obtained in standard decompositions. Equation (5) shows this industry technique effect is in turn determined by three withinindustry changes. First, there is a true technique effect - the first term on the right hand side of (5) is a weighted average of firm level changes in emission intensities. Second are reallocation effects within an industry. The second term in (5) is an industry composition effect - industry emission intensities fall if the share of value-added from relatively clean firms rises. And finally, there is a selection effect driven by entry and exit, captured by the final term in (5). Emissions rise if the emission intensity of an entering firm is higher than the average emission intensity of the industry. In principle, even if trade had zero industrylevel composition effects, it could have large effects on pollution by affecting each of these firm-level effects. ${ }^{16}$

Recent work has begun to explore these issues using models with heterogeneous firms based on Melitz (2003). ${ }^{17}$ For example, Kreickemeier and Richter (2014) consider unilateral trade liberalization in a one sector version of the Melitz model. ${ }^{18}$ Production generates emissions, and they assume that emission intensity is a decreasing function of productivity - more productive firms are cleaner. As is standard in the Melitz model, less productive domestic firms are squeezed out by import competition and the productivity cut-off for exporting falls. Trade therefore reallocates production to more productive firms. They show that this increases the scale of output, which would tend to increase pollution. However, referring to our decomposition (5), there are both reallocation and selection effects (there is no technique effect because emission intensities are assumed to be exogenous). The reallocation of output to more productive firms tends to reduce pollution, and the exit of the least productive firms

\footnotetext{
${ }^{16}$ The unit of measurement in this decomposition could be individual plants rather than firms. Barrows and Ollivier (2018) go one step further and account for changes in the product mix of firms. Cherniwchan et al. (2017) also consider within-firm changes and decompose the change in firm-level emission intensities into changes in the emission intensities of various tasks performed by a firm, changes in the importance of various tasks in the firm, and changes due to domestic outsourcing and offshoring particular tasks.

${ }^{17}$ See Cherniwchan et al. (2017) for a review.

${ }^{18}$ See also an unpublished paper by Bajona et al. (2012) for an early application of the Melitz model to polluting firms. Similarly to Kreickemeier and Richter (2014), they show how trade will reduce sectoral emission intensity by reallocating production to more productive firms, which are cleaner.
} 
(the selection effect) reinforces this. Average emission intensity within the sector falls but there is no actual change in firm level emission intensities: this is a trade-induced effect driven a change in the composition of active firms.

Forslid et al. (2018) consider a two-sector model and focus on the role of trade-induced investments in abatement technology in affecting emission intensities. The numeraire sector produces a clean homogeneous good with constant returns to scale. The other sector has heterogeneous firms producing differentiated goods as in Melitz (2003). Pollution is proportional to output, but firms face an emission tax and have access to an abatement technology based on Copeland and Taylor (2003), augmented to include a fixed as well as variable abatement cost. More productive firms invest more in abatement and so are cleaner. And for given productivity, exporters invest more than non-exporters in abatement because they are larger. ${ }^{19}$ Trade liberalization causes exporters to reduce their emission intensity, but surviving non-exporting firms increase their emission intensity because they lose market share. The effect of trade on sectoral emission intensity is determined by the interaction between selection and reallocation effects, and the trade-induced changes in abatement. One implication of their model is that country size has implications for the global incidence of pollution due to trading costs in the heterogeneous firms sector. Using a numerical simulation, they show that if countries are identical except for size, firms producing the differentiated goods will tend to concentrate in the larger country due to the home market effect. Trade will increase pollution in the large country and reduce it in the small country.

Shapiro and Walker (2018) develop a multi-sector version of the Melitz model where firms pollute. Firms have an abatement technology similar to that in Copeland and Taylor (2003). In their model, more productive firms are cleaner because they abate more. Both emission taxes and trade liberalization lower sectoral pollution intensity. Pollution taxes cause firms to increase abatement, which lowers emission intensity. Trade liberalization lowers sectoral emission intensity through two channels. There are iceberg trade costs, which effectively means that trade costs generate pollution. Lowering these trade costs means that less pollution is generated when per value of final goods delivered. And there are selection and reallocation effects as in Kreickemeier and Richter (2014). Trade liberalization reallocates market share to more productive firms, which are cleaner. Because there are multiple sectors, the Shapiro / Walker model allows for an interaction between scale effects, sectoral composition effects, and firm-level selection and reallocation effects.

LaPlue (2019) uses the Bernard et al. (2007) generalization of Melitz (2003) to allow for

\footnotetext{
${ }^{19}$ Forslid et al. (2018) and several others in this literature are influenced by Bustos (2011) who studies technology upgrading in a Melitz model. If there are fixed costs of technology upgrading (which in the present discussion is investment in abatement), then the larger firm scale due to export opportunities can stimulate investment in more productive technology.
} 
heterogeneous firms and comparative advantage based on differences in relative factor abundance. Trade liberalization generates sectoral composition effects in addition to the selection and reallocation effects of Kreickemeier and Richter (2014). They use numerical simulations to consider how these effects interact. A key finding is that selection and reallocation effects can be large relative to sectoral composition effects. The selection and reallocation effects result in declines in emission intensity, and in standard decompositions these would be attributed to technique effects. However, in this case the change in emission intensity is due to trade liberalization, not to changes in regulation or technology.

\section{Heterogeneous firms: Evidence}

A key prediction of heterogeneous firm models is that selection and reallocation effects will reduce sectoral emission intensities if more productive firms are cleaner. As discussed around Stylized Fact 4, a small body of work studies the link between firm level productivity and emission intensity. Some papers lack data on productivity and have instead looked at the relation between exporting and emission intensity. Batrakova and Davies (2012), using data on Irish manufacturing firms, find that that for a pooled sample of firms there is no effect of exporting on energy intensity. However, in the subsample of energy-intensive firms, export status is associated with lower energy intensity. Holladay (2016) uses data on US manufacturing for the period 1990-2006 and finds some evidence that export status is associated with lower emission intensity. However the results do not hold for all sectors or pollutants.

A few papers have used firm-level data to carry out decompositions similar to (5). Martin (2011) uses firm-level data on fuel use in India to study changes in $\mathrm{CO}_{2}$ emissions. She finds that sectoral composition effects have been important in accounting for changes in emissions in India. Over the period 1985-2004, fuel use and $\mathrm{CO}_{2}$ emissions grew substantially (by over $250 \%$ ) but the sectoral composition effect played an important role in preventing emissions from rising even more - holding scale constant, the composition effect would have reduced emissions by over $35 \%$. To understand within-sector changes in emission intensity, she employs a firm-level decomposition and finds that within-sector reallocation was about $38 \%$ as important as reallocations across sectors.

Barrows and Ollivier (2018) also use Indian firm-level level data on $\mathrm{CO}_{2}$ emissions and carry out a decomposition similar to (5). ${ }^{20}$ For the period 1991-2010, they find a fall in average industry level emission intensity. However, the firm-level emission intensities on

\footnotetext{
${ }^{20}$ Because they use a discrete time decomposition, they account separately for changes due to entering and exiting terms, and include an interaction effect of within and cross firm changes. Their approach is based on Foster et al. (2008).
} 
average actually increased. The fall in industry level emission intensities is entirely driven by reallocation and selection effects across firms. Barrows and Ollivier then go beyond (5) and consider selection and reallocation effects across products within firms. Here they find that average emissions intensities at the product level fall - the observed increase in firm-level average emission intensities is driven by a shift towards a mix of more emission intensive products over time. A key implication of the Barrows and Ollivier results is that selection and reallocation effects are quantitatively large and can be large and opposite in sign to actual changes in firm-or product-level level emission intensities. Changes in industry-level emission intensities are not simply driven by changes in technology.

Holladay and LaPlue III (2021) use U.S. firm level data from the Toxic Release Inventory (TRI). They focus on 4 types of air pollution and also look at water pollution. Consistent with other work, they find that total pollution emissions fell during the period 1990-2001. There was a positive scale effect, and sectoral composition effects are small. This means, consistent with Levinson (2009) and Shapiro and Walker (2018), that there is a large "technique" effect at the industry level - emissions have fallen due to a large decline in industry-level emission intensities. Using a decomposition method that follows Melitz and Polanec (2015), they break this down into plant-level declines in emission intensities and reallocation and selection effects. For particulate matter $\left(\mathrm{PM}_{10}\right)$, they find that most of the fall in emissions is due to reductions in plant-level emissions (a true technique effect). However for other air pollutants (volatile organic compounds, $\mathrm{SO}_{2}$ and an aggregate level of emissions of toxins weighted by hazard scores), they find that reallocations across plants and selection effects (entry and exit or plants) account for between $40 \%$ and $80 \%$ of the fall in emissions, with reallocation effects being much more important than selection. Reallocation and selection effects are also important drivers of the decline in on-site discharge of water pollutants.

Overall, the work to date on heterogeneity in emission intensity across firms and the decomposition studies suggest that within-sector reallocation and selection effects have the potential to explain some of the large measured technique effects. However, decompositions simply measure changes in emissions from different channels over time. They do not shed much light on what has driven these changes, and in particular on the role of trade and foreign direct investment. A few recent papers have attempted to use firm-level data to look for a causal effect of globalization on emissions.

Martin (2011) exploits India's trade liberalization and market reforms of 1991 to try to determine whether trade played a role in driving changes in emissions. She finds that reduction in tariffs on intermediate goods improved within-industry fuel intensity by about $23 \%$. Interestingly, the firm-level reallocation effect in this case dampened this increase as lower input prices allowed some high emission firms to survive and slightly increase their 
market share. Changes in industrial licensing policies reduced within industry fuel intensity by about $7 \%$, and this was entirely driven by within-sector firm re-allocation effects - more fuel-efficient firms increased their market share. Strictly speaking, the changes in industrial licensing are an internal reform and not a trade policy reform, but they were part of a broader package of reforms accompanying IMF-mandated changes.

Cherniwchan (2017) studies the effects of NAFTA on U.S. plant-level pollution in manufacturing. He uses data on air pollution from the TRI and links this to the National Establishment time series over the period 1991-1998. He uses a triple-difference strategy, exploiting variation in US and Mexican tariffs over time and across industry, and also variation in trade costs across firms in the US due to dispersion in their geographic location. He finds that plant level emissions fell due to increased access to the Mexican market and to lower US tariff on imports of intermediate goods from Mexico. The magnitude of the fall in emission intensity is significant - he estimates that trade-induced reductions in plant-level emission account for almost two-thirds of the reductions in particulate matter $\left(\mathrm{PM}_{10}\right)$ and $\mathrm{SO}_{2}$ over the period 1994-98. He finds that the emission reductions are mostly due to reductions in emission intensities by continuing firms; entry and exit of plant did not play much of a role. Regarding the channel via which trade reduced emission intensities, he finds evidence consistent with increased offshoring of dirtier production processes: part of the reduction in emission intensity can be accounted for by increased access to imports of intermediate goods that have a relatively pollution intensive production process.

Gutierrez and Teshima (2018) study the effects of tariff reductions on Mexican production facilities from 2000-2003. Using plant-level data, they find that increased import competition due to lower tariffs caused firms to increase their energy efficiency, but reduce their investments in abatement. The net effect on emissions is difficult to assess but they use measures of local air quality and find a small net improvement. This work suggests that the effects of firm-level responses to trade competition on the environment are complex. The fall in abatement expenditures is consistent with the Forslid et al. (2018) model which predicts that increased domestic competition could reduce the incentive to abate, but this appears to have been more than offset by the effect of trade on creating incentives for firms to increase their energy efficiency.

An alternative approach to assessing the importance of globalization relative to other factors in explaining the large fall in sector emission intensities is to use a quantitative model. Shapiro and Walker (2018) develop a quantitative implementation of their Melitz-based heterogeneous firms model. This approach has been used extensively in the international trade literature but has had limited application in the environmental literature. A key aspect of the application of this approach to the study of the interaction between globalization, 
environmental policy and emissions is the estimation of pollution elasticities, which measure the responsiveness of emission intensity to abatement activity. The structural model allows them to run counterfactuals (domestic and foreign market access changes, domestic demand shocks, and domestic pollution regulation changes). Their counterfactuals show that changes in the trade regime have had little impact on emissions, but that a doubling of the shadow price of emissions facing firms from 1990 to 2008 due to more stringent environmental policy can account for the fall in emissions in U.S. manufacturing during the period 1990-2008. Shapiro and Walker conclude that the large technique effect, first measured by Levinson (2009), can be explained in large part by a tightening up of U.S. environmental policy.

In our view, there is a role for both quasi-experimental evidence and quantitative modelling in helping us understand what has driven changes in emissions over time. There have been many environmental and trade policies implemented over the last 20-30 years, and reduced form identification approaches typically focus on isolating the effect of one particular policy. A quantitative modelling approach can remedy this weakness by taking a big picture approach and asking whether a package of trade and / or environmental policies can account for observed changes. However the conclusions of such a study can be buttressed by quasiexperimental work that identifies major policy changes that have (or have not) contributed to the changes in emissions.

The Shapiro / Walker finding that changes in environmental policy have been largely responsible for changes in air pollution from U.S. manufacturing raises the question of whether there is causal evidence of large declines in emissions due to policy. Several studies have found that U.S. air pollution regulation has been responsible for emission declines. Fowlie et al. (2012) found that the California $\mathrm{NO}_{x}$ emission allowance trading program accounted for a fall in $\mathrm{NO}_{x}$ emissions from regulated plant of between $10 \%$ and 30\%. Gibson (2019) found that the Clean Air Act reduced particulate matter emissions from affected plants by $38 \%$ from 1987 to 2014. Other work has identified some of the channels of adjustment. Becker and Henderson (2000) find that the Clean Air Act reduced new plant births in regulated counties. Greenstone (2002) identifies employment effects. Despite these findings, the very large technique effects found for China and other countries (for $\mathrm{CO}_{2}$ ) in Figure 6 should give us pause. It is very difficult to ascribe these extremely large technique effects to active policy interventions; and therefore, other - as of yet unidentified - forces must be driving emission intensities downward in these cases.

A recent study by Najjar and Cherniwchan (2021) is relevant for our purposes because it identifies the causal effect of environmental regulation on sectoral emission intensities, but also identifies the role of selection, reallocation, and abatement activities in achieving this outcome. They use Canadian data so their conclusions are not directly relevant to the work 
on U.S. emission intensities. However, they document a pattern in Canada that is similar to the U.S. There was a large fall in air pollution emissions from Canadian manufacturing during the period 1992-2015. Composition effects played only a very small role, and so the change was driven by a large fall in sectoral emission intensities - a large technique effect. To assess the role of policy in affecting the change in sectoral emission intensities, they consider a program - the Canada Wide Standards for Particulate Matter and Ozone (CWS) - that has some similarities to the U.S. Clean Air Act - regulation was targeted towards regions that violated air quality standards. Moreover, specific industries were targeted, which introduces an additional source of variation. They find that the CWS can account for $38 \%$ of the fall in manufacturing emission intensity during 2004-2010. They also find that firm selection and reallocation effects account for most of this. Plant exit accounted for 6.7 percentage points of this drop; reallocation effects across firms account for another 24 percentage points. Process effects (a reduction in plant-level emission intensity accounted for only 8 percentage points of the fall in emission intensity). ${ }^{21}$ This work therefore provides casual evidence that pollution policy had a major effect in reducing sectoral emissions intensities. However, the CWS accounted for only about $40 \%$ of the reduced emissions intensity, and so other factors still to be accounted for played a role - these could be other environment policies, technological change, or trade. The work is also useful in demonstrating how selection and reallocation effects play an important role in sectoral adjustment to environmental policy. Theory predicts that changes in market access due to globalization, and changes in environmental policy will both generate selection and reallocation effects. Empirical work is needed to disentangle the different drivers of observed changes. ${ }^{22}$

\subsubsection{The Pollution offshoring hypothesis}

Globalization encourages the fragmentation of production. If the dirtiest parts of production within firms are shifted from countries with stringent regulation to those with weaker regulation, then in Fig. 7, D shifts right for low regulation countries and left for high regulation countries. This would reduce the observed emission intensity of their domestic production, and be consistent with a large measured "technique" effect. While this is closely related to the pollution haven hypothesis, but the focus is on the interaction between globalization, environmental regulation, and the structure of value chains within firms.

Cole et al. (2014) model offshoring of polluting production as a firm-level choice between investing in abatement and investing in offshore sourcing. Cherniwchan et al. (2017) develop a simple model in which tasks vary in their pollution intensity. Openness to trade

\footnotetext{
${ }^{21}$ There is also a small negative interaction effect.

${ }^{22}$ On the effects of environmental policy with heterogeneous firms see for example, Anouliès (2017).
} 
creates incentives for a firm to outsource relatively dirty tasks to a country with relatively weak environmental policy. Schenker et al. (2018) develop a North-South trade model that generalizes Copeland and Taylor (1994) by allowing each good to have two stages of production. Both upstream and downstream goods generate pollution, and pollution regulation is more stringent in North than South. A movement from autarky to free trade generates both pollution haven and pollution offshoring effects: dirty final good producers relocate to the region (South) with weaker environmental policy, and some of the downstream firms that do not relocate, offshore the dirty upstream part of their production. ${ }^{23}$ Park et al. (2020) develop a model where firms have endogenous production networks. A reduction in trade costs allows larger firms with larger networks to keep their emission intensities low via both investments in abatement and offshoring parts of their production.

To date, there is relatively little empirical evidence on the importance of offshoring in affecting emission intensities. ${ }^{24}$ Using a decomposition approach with industry level data from Belgium during 1995-2007, Michel (2013) finds the fall in emission intensity for domestic intermediates can be partially accounted for by the substitution towards imported intermediates. As discussed above, Cherniwchan (2017) attributes part of the reduction in US manufacturing emission intensity to offshoring induced by NAFTA - there is evidence that firms increased their purchases of dirty intermediates. Li and Zhou (2017) find evidence that plant level emission in the US are lower when their parent company imports more intermediates from low wage countries, and that these intermediate imports tend to be relative pollution intensive. Cole et al. (2017) study firms that outsource production in Japan during 2009-2013. They find that carbon emission intensity falls for firms that outsource to foreign producers but not for those that outsource to domestic producers.

\subsection{Consumption-generated pollution}

Much of the economics literature on globalization and the environment has focused on production-generated pollution. There has been relatively little work on pollution generated during consumption.

The scale / composition / technique decomposition is a useful starting point. If trade increases real income, it will increase the scale of consumption, which will increase pollution. The composition of consumption will change both because of relative price changes and because of access to a different mix of products. The technique effect reflects changes in

\footnotetext{
${ }^{23}$ They also develop a computable general equilibrium model with a richer production structure and use it to show how firms would react to a more stringent carbon emissions policy in the EU in part by offshoring parts of their production.

${ }^{24}$ For a more detailed review of some of this and related work, see Cole et al. (2017).
} 
emission intensities, and here there are several different possible channels. The income effect of trade may result in tightened pollution regulation, which could affect policies that regulate emission intensities (regulation changes could affect emission intensities of automobiles for example). And depending on how a "product" is defined, the emission intensities of imported and domestic products may differ - an imported 10 year old subcompact car may have a different emission intensity that the average 10 year old domestic subcompact car. Strictly speaking we could think of this as a within-product-class composition effect, but depending on how data is reported, it may be measured as a technique effect. And much of the emissions from consumption come from energy use. Imported fossil fuels or "green energy" inputs, such as solar cells, will have a direct effect on the emission intensity of domestic energy consumption.

To highlight the role of trade in affecting consumption-generated pollution, Copeland and Taylor (1995a) develop a simple two-good North-South model where there is no productiongenerated pollution, but where consumption of one good pollutes. North is richer than South and its higher income generates high consumption and hence also higher pollution than South, even though pollution is taxed. ${ }^{25}$ The model is set up so that there is no comparative advantage on the supply side of the model, but because North has relatively high income, it will also have relatively stringent pollution regulation. This gives the North comparative advantage in the dirty good because its more stringent regulation drives down domestic producer prices. When trade opens up, North exports the polluting good to the South. Trade causes consumption of the relatively dirty good to increase in the South and to decrease in the North. Trade shifts pollution away from the North, a pollution-haven type result, but it is achieved by changes in the pattern of consumption rather than production. North's production of the dirty good increases because its relative price rises with the export opportunity.

In one of the few empirical studies of the effects of trade on consumption-generated pollution, Davis and Kahn (2010) study the effects of US-Mexico trade in used vehicles on air pollution in Mexico. ${ }^{26}$ NAFTA provided for a gradual opening of trade in used vehicles between the US and Mexico. Starting in August 2005, Mexico allowed used vehicles 10-15 years old to be imported from the U.S. These vehicles were more emission intensive than the stock of vehicles in the U.S., but less emission-intensive than the stock of vehicles in Mexico. They also show that the exported vehicles were more emission intensive, even when

\footnotetext{
${ }^{25}$ The result on pollution levels depends on regulator behavior and preferences; they assume perfect regulation and an income elasticity of demand for environmental quality that is equal to one.

${ }^{26} \mathrm{Hu}$ and McKitrick (2016) use a method similar to ? and, using data from OECD countries, find that increased openness to trade tends to increase carbon monoxide emissions (a pollutant that is associated with vehicle emissions).
} 
including a set of controls - such as vintage, model, and mileage. And for the same vintage / model, exported vehicles had higher mileage. Consequently, they conclude that U.S. exported relatively emission-intensive used vehicles to Mexico. They then estimate the effect of this trade on emissions in both countries. There is a slight fall in emission in the U.S. In Mexico, there are two effects - a scale effect of increased vehicle usage, which tends to raise emissions; and a composition effect due to the lower emission intensity of imported vehicles relative to the stock of vehicles in Mexico. They estimate that the scale effect dominates and that increased trade in used vehicles resulted in increased air pollution in Mexico. ${ }^{27}$

\subsection{Emissions in Transport}

Until quite recently the focus of the literature has been on emissions created in production, and how these were affected by international trading opportunities. Pollution generated by transport was virtually ignored. This focus is somewhat surprising given the charges by environmental groups that trade creates needless transport pollution. Fortunately, several recent papers have started to investigate transport emissions and assess their importance. At present we now understand quite a bit about transport emissions and their link to trade, but this is an area of research that will surely grow in the future.

The first substantial contributions were made by Cristea et al. (2013). This paper is noteworthy for two reasons: first, it developed a database of transport emissions the authors used to document a set of stylized facts on the emission intensity of trade across countries and sectors; and second, it provided an initial environmental evaluation of two counterfactual policy experiments taking into account transport emissions. The subsequent literature has built on this initial attempt in important ways. In conducting this research, researchers have focused on $\mathrm{CO}_{2}$ emissions arising from energy use in transport and production.

Transport emissions would of course not be important or interesting to study if emissions were very small, if the emission intensities of production and transport were very similar across industries, or if transport emissions varied little by trading partner. As it turns none of these is true.

One of the key findings of Cristea et al. (2013), is that although $\mathrm{CO}_{2}$ generated by transport is a small fraction of overall $\mathrm{CO}_{2}$ emissions (3-4\% in their data), transport generated emissions are fully one third of total emissions (production and transport) created by traded

\footnotetext{
${ }^{27}$ Chen et al. (2019) use a different method - they simulate counterfactuals based on regression equations - and they use more recent data after the regulations were relaxed to allow a wider range of used vehicles to be imported. They also refer to a "technique" effect which is really just the change in composition between imported used vehicles and other vehicles of the same age class. Their estimate of this "technique" effect is surprisingly large.
} 
goods. Therefore, while international transport emissions are in some sense small they loom large in terms of trade created emissions and should not be ignored.

A second key finding of Cristea et al. (2013) is that our classification of clean and dirty goods can look very different once transportation is taken into account. For example, natural resource commodity production tends to be very energy intensive and dirty but its transport mode is almost exclusively via maritime shipping in bulk carriers which are very fuel efficient. In contrast, machinery and electronic equipment are generally very clean in production, but very dirty in transport since they often rely on air transport. Therefore, taking into account the transport emissions from trade can lead to surprising conclusions.

Finally, there is also an interesting country pair data feature following from an interaction between geography and modal shares. Countries proximate to each other on a land mass tend to use rail and road services intensively. These modes of transport are relatively clean, and much cleaner than air transport.

To develop these findings, the authors pool data from several sources to generate transport and production emission intensities for 40 regions across 23 trade and 6 non-traded sectors. A key ingredient is the weight to value ratio for output and this is drawn from detailed product level data in US, EU and Latin American databases that contains information on modal share by product. Missing data is imputed, and they "test" their bottom up approach to calculating transport emissions by comparing their estimates to those of the International Transport Forum.

Having constructed the database, the authors present three policy experiments. In the first, they shut down trade entirely and force every country to produce its benchmark consumption in their base year 2004. This, very partial equilibrium, exercise finds that in over $25 \%$ of the re-allocations ( $31 \%$ by value), emissions fall. In these cases, trade is shifting production from a dirty production country to a clean production country, and these gains on the production side more than outweigh the transport emissions trade creates. This is a somewhat surprising and provocative result. Overall, however, trade raises $\mathrm{CO}_{2}$ emissions with the vast majority of the increase being tied to international transport. The overall response to trade is surprisingly small with emissions rising approximately $5 \%$.

In their second and third experiment, they adopt the GTAP modelling framework to consider the implications of trade liberalization and growth. Trade liberalization is modeled as a full liberalization with removal of all tariffs. As such, it eliminates the preferential access that proximate countries have to each others markets and moves trade to more distant sources of supply. This requires growth in air and maritime transport, and emissions rise more than do trade flows. A final experiment envisages a world where China and India remain growth leaders. This has the similar effect of redistributing trade to distant countries, and emissions 
again grow faster than trade.

While these results are interesting and provocative, there is still much we do not know about trade and transport emissions. For example, how would alternative assumptions for generating the bottom up estimates affect emission estimates across industries and country pairs? Is the provocative result that trade actually lowers emissions in $25 \%$ of all cases, robust to alternative methods? Even if subsequent researchers all agree on the methods for data collection and construction, what is the best method of using this information to conduct policy experiments. And if we use these methods what is the answer to one key question these authors fail to address - are the environmental costs of transport emissions large in relation to the gains from trade the transport of goods allow?

Subsequent research has addressed a subset of these questions. The most important of these contributions is Shapiro (2016) which develops a new and more detailed database to estimate transport emissions, and then employs this data to calibrate a structural gravity model of international trade. ${ }^{28}$ He uses the calibrated model to answer three key questions. The first is do carbon emissions rise or fall in the movement to trade? He finds the response is relatively small - it raises worldwide carbon emissions by about $5 \%$. The second is what are the overall welfare implications of trade, taking into account the added emissions. By employing an overall worldwide social marginal cost of carbon of $\$ 29 /$ ton he finds the gains from trade swamp the environmental costs by a factor of 161! The final exercise considers the unilateral imposition of a carbon tax on transport emissions. He constructs three different policy scenarios fitting this description, and imposes a carbon tax of $\$ 29 /$ ton on selected transport emissions. The results are similar. The imposition of carbon taxes on transport has large distributional consequences, with negative impacts falling primarily on relatively poor countries. Poor countries, in general, export commodities and agricultural products that have high weight to value ratios. As a result, the carbon tax falls more heavily on them. As well, poor countries are typically distant from their export markets and hence must transport their goods further. In total, these two attributes imply taxing transport makes them worse off despite lowering worldwide emissions. In contrast, the countries or regions which unilaterally impose these taxes (either the US or the EU) benefit from them by creating a terms of trade effect in their favor. Overall, global welfare rises, even from these partial and unilateral policies.

Together the contributions of Cristea et al. (2013) and Shapiro (2016) are complementary. Despite using very different methods of linking emissions to trade flows, both find the

\footnotetext{
${ }^{28}$ The calibration requires more than just the data constructed, it needs an estimated (bilateral) trade elasticity for each of the 13 sectors he examines. Shapiro estimates these elasticities using panel data on trade flows and transport costs from the US and Australia. The panel estimation of these elasticities is an independent contribution of the paper.
} 
movement from autarky to trade raises emissions only marginally. Shapiro goes further and compares the welfare cost of this change in emissions to the overall gains from trade to find these swamp the environmental costs. They differ in what follows. For example, Cristea et al. (2013) focus on the heterogeneity across industries in the split between production and transport emissions and by doing so make us rethink clean and dirty goods. They also present the provocative result that a large share of trade flows actually lower rather than raise emissions. In contrast, Shapiro's analysis highlights the heterogeneity across countries arising from geography and development levels. These differences across countries, lead to very unequal incidence of even global welfare improving carbon policies. The policy experiments of Cristea et al. (2013) vary trade policy and future patterns of growth; those of Shapiro (2016) vary environmental policy.

Despite the gains these authors have made there is clearly much more work to be done, however it will not be easy. One of the most difficult problems facing researchers in this area is establishing a credible empirical link between country pair trade flows and their attendant transport emissions. This requires researchers combine, only partial data on mode of transport shares by sector and country, with estimates of weight to value ratios for each sector's goods, and then multiply these flows by some measure of average distance between country pairs. The exercise is complicated by the need to apply a similar method to within country transport to international transport. This data exercise quickly becomes almost insurmountable. Once we allow for the possibility of emissions produced in transport, every good delivered to the factory gate - which we would typically associate with a given known and unique emission intensity of production - becomes a transport mode $\times$ trading partner pair many headed monster. With 5 transport modes (road, rail, air, river, and maritime) and 80 bilateral trading partners, every single good produced at the factory gate multiplies itself into 400 destination-mode specific goods. As a result, a host of assumption and decisions have to be made concerning data collection, aggregation, imputation and measurement. Even though these two contributions are very transparent about their procedures, they differ in the method for calculating distances over land and sea; they differ in their sources for modal share data; and they differ in their methods for imputing missing data. Reproducing and replicating these analyses is not easy, nor is it obvious how we should choose between the alternative methods employed. One goal of future research should be to evaluate these methods to establish best practices, and develop means for evaluating the host of decisions made in data construction.

On the theory front, researchers have been less active. This is unfortunate, because the channels through which trade can affect emissions is magnified greatly once we admit transport. Transport itself involves choices over modes; distances become relevant to modal 
choice; and therefore optimal transport methods are likely to be trade partner and volume specific. ${ }^{29}$ One recent applied theory paper investigating these issues is Forslid et al. (2011). Forslid presents an applied theory argument showing trade liberalization may lower emissions by shifting resources from dirtier to cleaner activities. In Forslid et al. (2011) however, the reallocation of economic activity that lowers emissions is not that envisaged by the estimates of Cristea et al. (2013) showing aggregate emissions fall in $25 \%$ of the sector/country pair cases studied. Instead, emissions fall because a trade liberalization lowering frictional trade costs makes foreign markets more attractive and this raises exports to them. This requires an increase in transportation services. If transportation services are cleaner than tradable goods production, this composition effect will lower emissions. While this is an interesting result it relies on transportation being relatively clean (or taxed more heavily), and conceptually is no different from any other composition effect created by a liberalization. Therefore, this within country composition effect is entirely different from the across country pair composition effect found in Cristea et al. (2013). ${ }^{30}$

\subsection{Renewable resources}

The literature linking globalization to the health of natural resource stocks has proceeded along similar lines to the trade and industrial pollution literature. The same issues arise: does a lack of regulation confer comparative advantage; what impact may a market expansion caused by liberalization cause; and does this liberalization unleash other forces which may mitigate or enlarge the partial impacts of trade? There are however several differences.

First, since natural resource stocks grow and yield harvests which are then turned into marketable goods, there is an important distinction to be made between short run and long run steady state impacts. Second, natural resource production is often tied to the initial endowments of countries. As a result, world production is typically concentrated in a small set of countries. Third, the costs of lax regulation and overuse typically comes in the form of reduced productivity of the natural asset, leading to interesting new possibilities. Finally, while at bottom all environmental problems stem from incomplete property rights assignment or enforcement, property rights issues loom very large in discussions over renewable resources.

\footnotetext{
${ }^{29}$ For example, the costs of air freight are very sensitive to distance travelled because take off and landings burn an incredible amount of fuel relative to flight at cruising altitude.

${ }^{30}$ It is perhaps important to clarify that models with iceberg trade costs have a built in transportation sector. With iceberg costs, producers need to produce $\delta>1$ units of any good to enable delivery of 1 unit. Therefore, the fraction $(\delta-1) / \delta$ of factors employed in this industry are effectively employed in international transport. Transport costs are denominated in the good itself, and if the good's production is polluting, then so too is its transport. The reason why Forslid et al. (2011) needs to introduce another transport sector to generate a composition effect, is not because iceberg transport does not pollute, but rather its emission intensity exactly matches that of goods production.
} 


\subsubsection{A Canonical Model}

To understand the literature and its limitations we employ the simple model of trade and renewable resources of Brander and Taylor (1997a). The Brander Taylor model is a marriage of the canonical two good Ricardian model with the renewable resource model of Gordon (1954) and Schaefer (1957), and allows for a simple, primarily graphical, analysis. ${ }^{31}$

The purpose is to use the model to illustrate three core hypotheses that drive much of the theoretical and empirical research. A sketch of the model suffices for our purposes. There are $L$ agents who can allocate their one unit of time to either manufacturing, $M$, or harvesting, $H$. If employed in manufacturing one unit of effort delivers one unit of $M$. If employed in harvesting, one unit of effort delivers $\alpha S$ units of the harvest good. $S$ measures the current health of the resource stock and can vary from zero to its natural carrying capacity of $K$. The evolution of the resource stock over time is determined by natural growth minus harvesting; that is: $d S / d t=r S(1-S / K)-H$ where $r>0$ is the intrinsic rate of resource growth.

We need a mechanism to determine harvesting decisions. One option is to let market forces dictate entry decisions, producing a situation of free and open access to the resource. This was the case originally studied by Gordon (1954) and later popularized by Hardin (1968). Let $p$ be the relative price $p=p_{H} / p_{M}$, then if production is diversified labor must earn the same return in each sector and $p \alpha S=1$. An efficient resource policy will restrict harvesting by limiting access to only a subset of agents. Such a policy limits entry, generates economy-wide rents, and requires monitoring and enforcement to be credible. For our purposes we adopt as an alternative the most conservative resource management policy possible. This policy would arise if agents were infinitely patient. In this case, the optimal solution is to maximize steady state rents from the resource.

\subsubsection{Does market integration lead to excessive exploitation?}

In an early and somewhat controversial paper, Chichilnisky set out an argument against free trade based on environmental concerns. The model features a developed North and underdeveloped South who differ only in the degree of property rights protection afforded their natural resource. ${ }^{32}$ In the South there was open access to the resource; while in the North, a social planner ensured harvesting was conducted optimally. The model was static. Apart from these differences the countries were identical. With free trade the South increased output and exported the resource product to the North. Importantly, this trade would not have occurred but for the lack of property rights in the South. In this sense, the North "over

\footnotetext{
${ }^{31}$ For an excellent treatment of renewable resource economics and the Schaefer model in particular see Clark (1990).

${ }^{32}$ See Chichilnisky (1994) or an earlier very similar version in Chichilnisky (1991).
} 
consumed" Southern resources, and the resulting trading equilibrium was Pareto inefficient.

The result that exogenous differences in regulation can generate trade and that such trade can exacerbate pre-existing distortions is reminiscent of simple pollution haven models (Pethig (1976) is perhaps the earliest demonstration). The channels through which trade can affect productivity and welfare via its effects on the stock of a renewable resource are however different. To understand these channels, and how gains and losses from trade occur, we need to incorporate a renewable resource model into the trade model. This is the approach taken by Brander and Taylor (1997a).

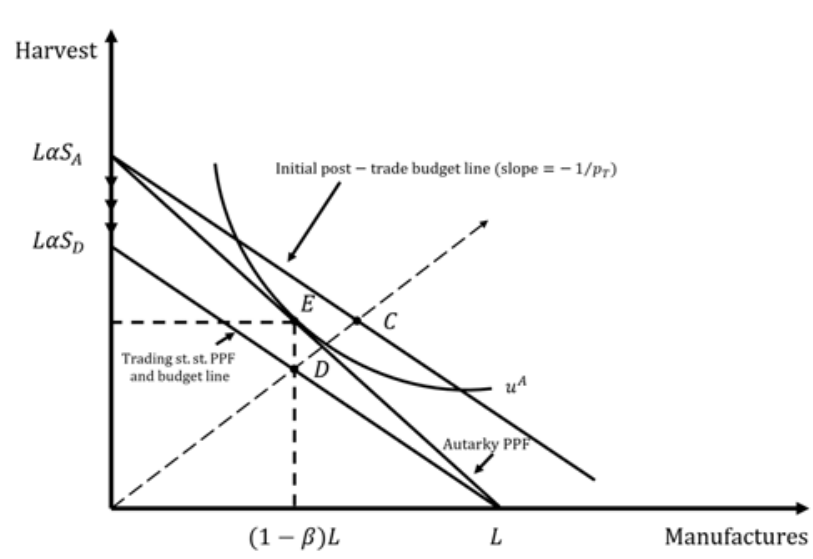

(a) Diversified-trading steady state

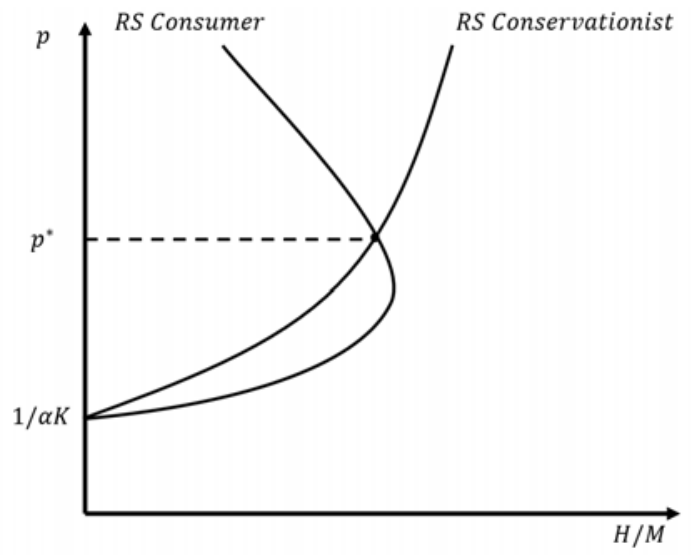

(b) Consumer and Conservationist supply

Figure 8

To understand how losses from trade could occur, consider the left panel of Figure 8. In it we depict the autarky and free trading steady state for a small open Southern economy with comparative advantage in the resource product. The autarky steady state occurs at point E. The relative prices in autarky are given by the PPF slope which itself is determined by the autarky steady state stock $S_{A} \cdot{ }^{33}$ If this economy opens up to the world economy at a relative price $p_{T}>p_{A}$, it immediately specializes in harvesting producing $H=L \alpha S_{A}$. Manufacturing shuts down, and consumption moves to point $C$ along the free trade budget line. There are short run welfare gains for the usual reasons. Complete specialization in harvesting is however not sustainable at the current stock, and the resource stock starts to fall driving productivity downwards. As productivity falls, and the PPF pivots inward following the arrows on the vertical axis. This has the effect of shifting in the free trade budget line lowering the initial gains from trade. When and where this process ends depends on parameters. If complete specialization in harvesting would drive the resource to extinction, then the diversified steady

\footnotetext{
${ }^{33}$ If agents spend $\beta<1$ of their income on the resource good, then $(1-\beta) L$ of the labor force is in manufacturing and $\beta$ in harvesting. The harvest in autarky is $H=\alpha \beta L S$ and combining this with the natural growth function solves for the autarky steady state $S_{A}=K[1-\alpha \beta L / r]$.
} 
state shown must result. Consumption falls from $C$ to $D$ in the process, and in the long run there are losses from trade. ${ }^{34}$

Two questions stand out. First, are losses from trade necessarily the result? No. If the economy could specialize in harvesting in steady state, then long run gains could arise. This requires some combination of a more resilient or faster growing resource, and a diminished ability of harvesters to take from it (lower $\alpha L$ ). As well, even in the diversified case we need to weigh short run gains against the long run losses. For high enough discount rates overall welfare would rise with trade.

Second, what is driving the losses? The key to the loss is the reduced productivity in the resource sector. As the stock falls, average productivity falls and this can imply lower national income as shown. The extent of these production losses is determined by the curvature of the PPF and the extent to which the resource sector could absorb further factors. In the model developed here, all harvesters are identical and the PPF is linear. If they differed in productivity, then the PPF would have some curvature, and there would be less entry to the resource sector and rents would not be completely dissipated. Gains from trade are then far more likely. Similarly, if damage to the resource was in some way bounded so that harvesting could not fall below some minimum level, then high enough world prices or elastic enough preferences, will ensure gains from trade. ${ }^{35}$

\subsubsection{Evidence}

There is a relatively small empirical literature looking directly at the connection between trading opportunities and resource use. ${ }^{36}$ Of these, the vast majority employ reduced form identification driven hopefully by exogenous world events. There is of course also a large closely related literature in development linking market access to resource use, but here market access is not necessarily access to world markets but rather access to national or regional markets that were previously not available.

Wildlife and in particular, charismatic mega-fauna, like elephants, rhinos and whales have drawn a huge amount of media attention to the role of global markets. Even the plight of the not so charismatic shark has drawn substantial interest. See Erhardt and Weder (2020), but again formal empirical work is scarce (McPherson and Nieswiadomy 2000a).

One study that makes some progress along these lines is Taylor (2011). Taylor (2011)

\footnotetext{
${ }^{34}$ This occurs when the labor force is large, technology very efficient, and resource is slow growing. In terms of parameters, diversification must result if $\alpha L>r$.

${ }^{35}$ See Brander and Taylor (1997a).

${ }^{36}$ The United Nations Environment Program funded a series of case studies of trade liberalization/reforms many of which involve natural resource industries. These are primarily sectoral based, very specific case studies (UNEP 2001).
} 
reconsiders the virtual extinction of the North American bison over the 1870-1883 period, and provides compelling evidence linking it to international trade in bison hides. Circa 1865, there were perhaps 15 million bison present on the Great Plains of the United States, but by the early 1880s the number of wild bison present numbered in the hundreds. Conventional historical accounts hold responsible some combination of deliberate US government policy, native over hunting, habitat destruction facilitated by railroad construction, and even to some extent, climate change. By compiling evidence from buffalo hunter diaries, newspaper accounts, auction notices in foreign ports, and advertisements in business directories Taylor weaves together an entirely different narrative. In his explanation, prior to 1870 bison was hunted primarily for its meat, but soon after 1870 a tanning innovation in England allowed the tanning of thicker bison hides into useful industrial leather. The innovation created a new international market for bison hides from North America, and since the tanning was only done in the UK (and later other countries in Europe), international trade in bison hides was necessary. Since there was no regulation of the bison kill, the destruction of the bison provides especially clean evidence that demand shocks from world markets can very rapidly destroy poorly protected resources. Taylor's estimates suggest the kill off for exports amounts to 10 million bison, making international trade in bison hides by far the most important determinant of their demise.

The problem with case studies like the Buffalo Hunt is determining whether they uncover general tendencies or peculiarities of history. However, a broadly similar result is contained in Eisenbarth (2018) who also exploits a demand shock to identify the impact of world markets on fishery resources. Eisenbarth's identification strategy is simple: a collapse of domestic fisheries in Japanese territorial waters, directed domestic demand elsewhere and created a Japanese demand shock on all other related fisheries. Using a rich panel of data, she exploits variation across 109 different fish species and 40 years of time to link an increase in exports to Japan to subsequent fishery collapses.

Eisenbarth links the probability of a fishery collapse of species $\mathrm{i}$, in country $\mathrm{k}$, at some time $t$ to a species specific fixed effect, country specific fixed effect, region by time dummy, and exports of species i in country $\mathrm{k}$ lagged one period. The basic idea is simple. If a country $\mathrm{x}$ species pair were to experience a demand shock in the recent past, harvesting would rise and may well lead to an unsustainable fall in the resource stock. If we assume there is a minimum viable population, this one time demand shock can create a future fishery collapse.

With this empirical strategy, she finds two key results. First, there is a strong relationship between fishery exports and subsequent fishery collapses. There are a variety of ways to measure this importance: one metric finds that two thirds of the increase in fishery collapses occurring over the last half of the sample period, 1991-2006, are due to previous Japanese 
collapses. Second, these collapses are concentrated in those fisheries that are poorly managed. Fisheries with existing catch regulations such as individual transferable quotas are unaffected by the collapses, while others are not. These results are in line with our expectation for how a demand shock should affect poorly managed and well managed resources.

While the analysis is well done there are a few nagging details. For example, the empirical work employs a measure of fishery exports rather than the theoretically correct production or catch data. However, as world prices rise from a Japanese collapse, both domestic production and domestic consumption should adjust. As a result, it is unclear which of these two adjustments is driving the observed variation in exports. If harvesting supply was inelastic, the catch would remain constant while exports rise, and the Japanese demand shock would then have a zero effect on subsequent fishery collapses contrary to the hypothesis.

\subsubsection{Does weak natural resource regulation provide a source of comparative advantage?}

A common assumption is that the lack of property rights enforcement, necessarily confers comparative advantage on the least regulated or open access country. All else equal, it is easy to see how a lack of regulation would imply lower costs which may generate comparative advantage. This is the same logic at work in simple pollution haven models, and we have already discussed how other determinants of comparative advantage could work against these motivations (i.e., if they were negatively correlated). A parallel result holds here, but with particular force. In many models of natural resource use, greater harvesting today implies lower resource stocks and lower productivity tomorrow (i.e., they are negatively correlated). Since weak regulation can lower future productivity and tight regulation raises future productivity, it is no longer clear whether a lack of regulation lowers or raises long run costs.

Since static models, such as Chichilnisky (1991), do not exhibit resource depletion there are no attendant long run costs from over harvesting. To understand how long run productivity effects work and what they can imply for comparative advantage, we return to our model. Brander and Taylor (1998) developed a two country version of their simple Ricardian resource model to highlight the role of regulation in determining comparative advantage. In the Conservationist country, the planner implements the very conservationist harvesting policy of maximizing steady state rents. ${ }^{37}$ In the Consumer country the planner has no ability to restrict harvesting, so open access results. The countries differ only in the degree to which

\footnotetext{
${ }^{37}$ Maximizing steady state rents leads to the same steady state solution for the optimal resource stock as occurs in a fully optimal dynamic planning framework when the discount rate approaches zero. This is a well known feature of many Gordon-Schaefer type models.
} 
they can enforce harvesting restrictions. The authors show these two different regulation assumptions produce vastly different supply curves as shown in panel b) of Figure 8. In the Conservationist country the relative supply is upward sloping throughout. Higher world prices induces the planner to harvest more and deplete the stock, but these productivity changes never lower the harvest obtained. In contrast, in the Consumer country the supply curve bends backwards as prices rise. The backward bending region comes about when agents drawn into the sector by high prices, severely overuse the resource. Since this overuse is not internalized, high prices eventually produce lower harvesting output and the supply curve bends backwards. ${ }^{38}$ Brander and Taylor (1997b) show the two supply curves intersect once as shown.

As a result of these differences, two different types of trade equilibria can arise. In the limited over use case, the productivity losses from over harvesting are not severe and the cost advantage of having no regulation outweighs the loss of productivity open access entails. Autarky equilibria for both countries would lie at the intersection of their common relative demand curve with their individual relative supplies at prices below the critical price $p *$. The Consumer country exports the resource product and suffers long run losses from trade in a manner similar to that shown in panel a). The Conservationist country gains from trade. This worst case scenario mimics what our simple pollution haven logic might suggest.

In the second case, which they refer to as the severe overuse case, the autarky equilibrium prices lie above $p *$. The consumer country severely overuses its resource even prior to trade. Severe over use arises if the population relying on the resource is large, the resource regenerates slowly, demand for the product is substantial, or the harvesting technology is very productive. In this severe overuse case, open access to the resource creates large productivity losses. As a result, the tightly regulated Conservationist country has lower comparative costs than does the zero regulation open access country. In the severe overuse case, the trade pattern is reversed. The perfectly regulated Conservationist country now supplies the Consumer country's demand for the harvest good. In the severe over use case, both countries gain from trade. ${ }^{39}$

\subsubsection{Evidence}

For many resources, it is obvious that abundance creates comparative advantage because the deposits of these resources is highly concentrated while demand is diffuse. Very little theory is required to understand why the Middle East exports oil, while Japan imports it. For other

\footnotetext{
${ }^{38}$ This is a general equilibrium version of a result originally due to Copes (1970).

${ }^{39}$ This result is possible because internalizing the production externality raises productivity more than enough to offset the direct costs of regulation. That is, it is one theory consistent way to rationalize the Porter Hypothesis in Porter and Van der Linde (1995).
} 
resources, particularly renewable resources that are more widely dispersed it is unclear to what extent abundance matters. One method is to treat the natural resource in question just like a conventional factor of production, and employ similar methods to investigate its importance. The novelty of such an approach is that, in some cases, these natural resources have not been thought of being important to comparative advantage. The downside is that by focusing on the similarities with conventional factor endowments, researchers may lose sight of the externality (and property rights) issues plaguing many resource industries.

One attempt along these lines is Debaere (2014). He investigates the role of water abundance on trade on a broad set of 96 industries comprising both manufactures and agriculture for a set of 68 developed and developing countries. The data is cross-sectional, and he links the across sector and country variation in exports to the intensities of factor use in a sector and the abundance of countries in those same resources. The specification is very similar to that employed by Nunn (2007) which is in turn an improvement on a very old Heckscher-Ohlin-Samuelson literature reinvented by Romalis (2004).

The paper's main finding is that water intensive industries have higher exports in countries that are water abundant. Therefore, despite the fact that water markets are incomplete, absent or highly imperfect, abundance seems to matter. To make allowance for very different pricing in water scarce and water abundant countries, Debaere creates an indicator variable dividing countries into those two categories. He then interacts the binary abundance classification with country specific continuous measures of abundance. One rationale is that in water abundant countries water's effective price may well be zero; therefore, any further abundance should be irrelevant to prices, costs, and trade flows. Although this method has some merit, the relation between water abundance and productivity is likely more complex. Consider our simple model when the resource is a free input to production. In this case with a zero price for the natural resource, abundance still matters greatly because the health of the resource is complementary to conventional factors of production (labor). ${ }^{40}$ Therefore, abundance should still matter even at zero prices. Perhaps not surprisingly, the empirical results show no clear pattern of difference between water scarce and abundant countries casting doubt on the exercise. Overall, while Debaere's work provides evidence that the abundance of water seems to matter for trade flows, there is potential for much more work that takes into account the ways in which water differs from conventional factors of production, and the complexity and heterogeneity of water regulation across sectors, regions and countries.

A more direct approach tailored to the specifics of resource industries was adopted by

\footnotetext{
${ }^{40}$ For example, if the water for irrigating your crops is free, would you prefer to have on your land a well that produces at 8000 liters/minute or one producing 8 liters per minute. A healthy aquifer (abundant resource) probably saves me time, collection and distribution costs (i.e. raises the productivity of complementary inputs).
} 
Ferreira (2004). Ferreira investigates how the cross country pattern of deforestation over the 1990-2000 period is linked to openness to trade. Using a panel of 89 developed and developing countries, she shows that changes in forest cover over this period are negatively correlated with development status. Developing countries exhibit forest loss (deforestation), while most developed countries exhibit forest growth (reforestation). Next she presents data on a set of five variables capturing institutional quality (risk of expropriation, rule of law, quality of bureaucracy, etc.) to show that the set of developed countries in the sample have average values for these institutional variables significantly higher than those for the developing countries. And finally, she examines whether the correlation between the strength of institutions and deforestation (shown by step one and two), is in fact driven by openness to international markets. Very simply, does an increase in openness raise deforestation most for those countries with the weakest of institutions. This is evaluated by regressing a set of country characteristics and an interaction of institutional quality and a measure for openness, on country level deforestation rates. The empirical results are mixed which is perhaps not surprising because there is no clear identification strategy. Only two of the institutional quality measures enter consistently and significantly in the many alternative specifications; and the signs of their coefficients are opposing which makes an interpretation difficult. Moreover, many of the explanatory variables are jointly determined with trade and openness. Nevertheless, the paper does set out some basic guideposts for others to follow: a recognition that institutional variables driving property rights enforcement should matter; and a recognition that openness will imply different adjustments for countries that differ in comparative advantage.

These same issues are addressed more successfully in Erhardt (2018). Erhardt addresses the dynamics of renewable resource growth by using a stock adjustment model; treats openness as a potentially endogenous regressor; and presents a clear empirical horse-race between competing theories. Using data on EEZ fisheries over the 1976-2009 period, he examines how the fraction of collapsed (or overused) stocks within countries EEZ are affected by openness to trade and the quality of their governance. ${ }^{41}$ Each country's EEZ contains numerous fisheries (always more than 20 in his sample), and for each EEZ he constructs the simple ratio of the number of collapsed (or overused) stocks to the total number of stocks. Collapsed stocks are those whose current harvest is below 10\% of historic norms; overused are those whose current harvest is below $50 \%$ of historic norms.

Erhardt's goal is to provide an empirical horse race between the severe and mild overuse cases of Brander and Taylor (1998) just discussed. He shows how the two hypotheses lead to very different conclusions on the impact of openness. For example, openness should lower the

\footnotetext{
${ }^{41}$ The data is drawn from the Sea Around Us panel data.
} 
ratio of collapsed stocks in poorly governed countries only if their severe overuse is reduced by trade. In this case, international trade relieves the pressure on domestic resources.

He develops a relatively simple stock adjustment estimating equation relating an EEZ's collapse share today to its lagged value, measures of country openness and governance, and a measure of their interaction. Openness is measured in two different ways, and the governance measure is an index number published by the Policy Risk service. To estimate the model he employs both a dynamic panel fixed effects estimator, and a system wide GMM estimator. The system wide GMM provides a better treatment of potential endogeneity, while the fixed effects has the benefit of being more transparent. The results across the two estimation methods are very similar. He finds consistent evidence that openness lowers the severe overuse of fisheries for countries with low level of governance; moreover, the impact of openness can be quite large. ${ }^{42}$ For countries with high levels of governance, openness appears to have little or no effect at all.

One interpretation of these findings is openness to trade is surprisingly good for resource stocks, despite other evidence to the contrary. A more nuanced view is that in this case, and industry, trade's impact was positive but perhaps for good reason. In an early and important paper investigating resource overuse and property rights, Bohn and Deacon (2000) find that the lack of secure property rights affects resource industries differently. In industries where physical capital needs are very large, such as oil drilling and exploration (and perhaps industrial fishing?), weak ownership rights deters investment, production and overuse. In contrast, in industries with smaller capital requirements, such as small scale forestry and slash and burn agriculture, weak ownership over land will instead encourage exploitation.

This suggests an examination of trade's effect on resource use needs to be finely tuned to country and industry details; and as we now show, this conclusion is only strengthened when we allow for the possibility that regulation itself can respond to trade.

\subsubsection{Can Market Integration Improve Resource Management?}

A long standing view in economics is that property rights are an institution created to facilitate trade; therefore the degree to which rights to an asset are delineated and enforced depends on market conditions. This basic idea - that property rights will evolve as the value of the resource changes - is often credited to Harold Demsetz (1967) and called the Demsetz hypothesis. While the Demsetz hypothesis would perhaps help explain how some countries conserve valuable resources, many in the resource and development community

\footnotetext{
${ }^{42}$ For example, on average in the sample, openness rose by about $5 \%$ points over each of the five-year increments in the sample, and a change of this average magnitude reduces the share of collapsed fish stocks by approximately $1 \%$ point in the short run but a much higher $4.5 \%$ points in the long run. Since the average ratio of collapsed stocks in the sample is only $20 \%$ this long run effect is quite large.
} 
point to changes in available technology brought about by globalization as a destabilizing force destroying existing property rights arrangements. ${ }^{43}$ At some level, the debate over whether more trade is good or bad for wildlife conservation hinges on these same forces.

To investigate the potential for world markets to improve property rights enforcement, Copeland and Taylor (2009) introduce a monitoring problem into a simple resource model much like the one presented before. They assume harvesters actions are only imperfectly observed by the regulator, who only detects cheating on harvesting restrictions with some probability. The regulator's most severe punishment is ostracism - a lifetime ban from operating in the resource sector. Higher world prices make the opportunity cost of cheating higher and this allows the regulator to restrict harvesting further.

Their theory contains two key results. The first is that rising world prices for resource products allows some, but not all, countries to enforce stricter regulations. For example in terms of panel a) of Figure 8, our open access economy may not move from C to D, but instead somewhere along the transition path regulation would tighten, stock adjustment would cease, and the economy would gain rather than lose from trade. Alternatively, some countries will be remain in open access generating the dismal outcome previously shown. Countries with no ability to regulate effectively have severe problems with overcapacity. Overcapacity arises with slow growing resources and efficient harvesting technologies. The second result is that all countries exhibit open access in their resource sector when world prices are sufficiently low. When resource prices are low, the planner must impose harsh restrictions to generate any rent, but these small rents are not an effective deterrent against cheating and all countries end up with open access.

Together these two results imply that observing a poorly regulated resource at one set of prices (perhaps autarky), tells us nothing about whether this economy could enforce stricter protection at higher world prices in trade. Therefore, it will be very difficult to determine which countries (or sectors) are good candidates for liberalization. This is especially true if liberalization brings access to new technologies that raise harvesting capacity and destabilize current enforcement efforts.

\subsubsection{Evidence}

There is substantial evidence that property rights, and their enforcement, are sensitive to market conditions. This evidence ranges from case study evidence drawn from economic history to more formal empirical work in developing country settings. ${ }^{44}$ More recent evidence is provided by Foster and Rosenzweig (2003) who study the evolution of protection for Indian

\footnotetext{
${ }^{43}$ See for example the excellent book length treatment of these issues by Baland and Platteau (1996).

${ }^{44}$ For the former see the original contribution Demsetz (1967); for the latter see Besley (1995).
} 
forests and link rising forest product prices (driven by economic growth) to successful management. Finally, directly on point is a series of resource specific studies linking access to new markets for fishery products to success or failures in management (Jones and Bixby 2003). At this point it is difficult to draw any broad conclusions from this literature. The case study evidence from fisheries finds, not surprisingly, that resource characteristics matter. Fishery resources that are found close to shore, and in remote settings are very difficult to monitor and manage. In those settings, a new market or higher prices has produced poor results. In contrast, in fisheries where substantial capital investment is required makes monitoring easier and market openings far more successful. ${ }^{45}$ The work of Foster and Rosenzweig (2003) finds some evidence that open developing economies have less success with implementing a management reform than do closed ones. The key difference being that rents distributed to harvesters is larger in the latter, and the distribution of the rents from resources is critical to the success of reforms. Sharing rents from world markets is the idea behind the movement towards community based natural resource management (CBNRM) which, as the name suggests, engages the local community in protecting and managing a potentially valuable resource. The fine and rent sharing structure built into Copeland and Taylor (2009) fits the characteristics of many such programs. These programs are in place and have been suggested for many of the world's most endangered species, and some evidence exists on their success. For example, McPherson and Nieswiadomy (2000b) examine the evolution of the African Elephant population and finds that countries with rent sharing programs such as CBNRM have succeeded in growing their elephant population. Despite their economic logic, programs allowing trophy hunting to fund conservation; or the commercial exploitation of previously protected species, remain controversial. ${ }^{46}$

\section{Globalization and the environment: Policy}

The literature on the interaction between globalization, trade policy, and environmental policy has focused on a variety of issues, but it is useful to divide it into two main branches. ${ }^{47}$

First is a large body of work that studies the role of trade policy in influencing envi-

\footnotetext{
${ }^{45}$ Similarly, McWhinnie (2009) finds fisheries shared by several countries are far more likely to be declining and overfished. And Erhardt and Weder (2020) link the decimation of certain shark species to the characteristics of their natural environment. Slow growing sharks populating shallow water are most at risk.

${ }^{46}$ There are a variety of good reasons why they remain controversial. For example, one purely economic argument against liberalizing trade in ivory (from countries who are managing their populations' well) is that this new legal trade will make it very easy to sell ivory illegally obtained from countries with poor records of conservation. An argument from the animal rights community is that any consumption of ivory furthers a world view that animal species are only valuable to the extent they serve human needs.

${ }^{47}$ For a more detailed expository review of the theoretical literature on the interaction between trade policy and environmental policy, see Copeland (2011).
} 
ronmental outcomes. One key question is whether environmental degradation has been an unintended side effect of successive rounds of trade policy reform. Other questions focus on the explicit use of trade policy to affect domestic environmental outcomes. For example in the WTO trade dispute over Chinese restrictions on exports of rare earths, China argued that trade restrictions were necessary to protect the environment (WTO 2015). There is a large and active literature on the use of trade policy to target foreign environmental outcomes, such as responding to carbon leakage or deforestation. We discuss that work later in the section on climate change.

The second branch of the policy literature studies the effects of openness to trade on environmental policy. Key issues are whether concerns about international competitiveness will increase pressures on governments to weaken (or not tighten up) environmental policy; and whether weak environmental policy could be used as a substitute for trade protection when trade agreements constrain the use of trade policies and subsidies.

The targeting principle (Bhagwati 1971; Dixit 1985) provides a useful benchmark for much of the literature on the interaction between trade and environmental policy. The idea is that an efficient outcome can be achieved by using environmental policy to deal with environmental problems and trade policy to deal with trade issues. This requires that that we have appropriate policy instruments to deal with all of the distortions and policy objectives. However, a full range of policy instruments is unlikely to be available in practice. Some instruments may not be feasible because of information constraints or other issues, while others are ruled out because of legislative constraints or international agreements. Moreover, the targeting principle presumes that efficiency is a policy objective, when in fact actual policy implementation is driven by politics.

Much of the work we discuss below is at root based on restrictions on either the range of available policy instruments or the potential to adjust these instruments. If lump sum transfers are not feasible and if there are political constraints on other redistributive instruments, then trade and environmental policy are used both to affect income distribution and to deal with trade and environmental objectives. And an explicit objective of international trade agreements has been to restrict the policy space available to governments, especially to place limits on the ability to manipulate trade restrictions and subsidies. Instruments unconstrained by trade agreements (such as environmental policy) are then candidates for alternatives to subsidies or trade restrictions. 


\subsection{Trade policy and environmental outcomes}

The existing pattern of trade protection (and trade promotion) and its evolution over time has been influenced by many factors - political influence, national power, past colonial ties, geography, and others. Until recently the environmental consequences of trade have not played a major role in the determination of trade policy. Nevertheless, it is useful to ask if the existing pattern of trade policy has either a positive or negative environmental bias, whether intentional or otherwise.

Shapiro (2021) analyzes the structure of trade protection and finds that tariff and nontariff barriers are lower in carbon-intensive industries than in clean industries. The pattern holds globally and within almost all countries. To arrive at this fact, he calculates the embodied carbon content of trade - this includes both direct emissions and emissions generated during the production of intermediate goods used to produce traded goods. To infer the environmental bias of trade policy, he estimates:

$$
t_{j s}=\alpha E_{j s}+\mu_{j}+\varepsilon_{j s}
$$

where $t_{j s}$ is the tariff (or tariff-equivalent of the non-tariff barrier) imposed by country $j$ on goods from industry $s . E_{j s}$ is the average embodied emissions for imports in industry $s$ (measured as tons of emissions per dollar of imports). The estimated parameter $\mu_{j}$ captures country $j$ 's average rate of trade protection, and $\alpha$ can be interpreted as the implicit carbon tariff; that is, it is the tax (per ton of $\mathrm{CO}_{2}$ ) on imports of embodied carbon. If $\alpha>0$, carbon intensive goods face higher tariffs on average. If $\alpha<0$, carbon intensive goods face lower than average tariffs. He finds that $\alpha$ is in the range of -85 to -120 . This is equivalent to a subsidy to trade in embodied carbon emissions of between $\$ 85$ and $\$ 120$ per ton.

This is a striking result in that it suggests not just that trade per se has contributed to increased carbon emissions, but that the entire structure of trade policy is biased towards promoting trade in carbon intensive goods. Why would this be? Shapiro considers several possible explanations, and the most compelling is that trade barriers tend to be lower on upstream goods (goods that are mainly used as inputs into production) than on downstream goods (goods closest to final consumption goods). This is consistent with a model where firms pressure governments for low tariffs on imported inputs and high tariffs to protect their production of final goods. And it turns out that upstream goods (which includes raw materials, steel, etc.) tend to be more carbon intensive than downstream goods. This is our Stylized Fact 3 and is illustrated in Figure 9 which uses a measure of the "upstreamness" of a good from Antràs et al. (2012): this measures the economic distance of an industry from final consumers. The downward sloping dashed line is a nonparametric regression of 
carbon intensity on upstreamness. More upstream industries are more carbon intensive. And the upward sloping solid line shows the relation between upstreamness and trade protection. More upstream industries face lower trade barriers. Putting these together yields the environmental bias of trade policy.

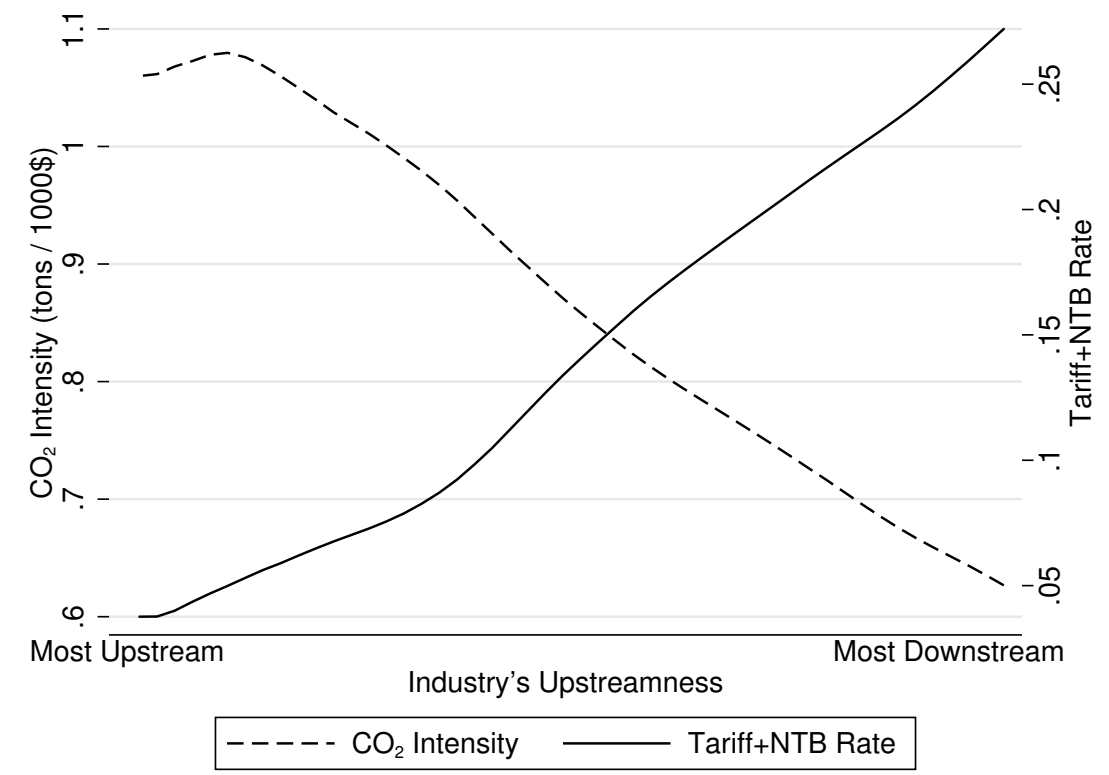

Figure 9: Pollution intensity, upstreamness, and protection.

Notes: For global trade, the tariff plus non-tariff rate is decreasing in the "upstreamness" of goods, and the carbon emission intensity is increasing in the "upstreamness". Source: Shapiro (2021)

\subsection{Trade policy reform}

The negative environmental bias of the structure of trade protection suggests that there is scope for a pro-environment reform of trade policy. A small literature, starting with Copeland (1994) has studied the interaction between trade policy reforms and environmental problems. ${ }^{48}$ Even if there is no pollution, it is well known that arbitrary tariff reductions need not improve welfare (see for example Hatta (1977) and Diewert et al. (1989)). In the presence of pollution, piecemeal trade liberalization is potentially even more problematic because it can exacerbate environmental distortions.

Copeland (1994) considered rules for piecemeal policy reform in this context. A key issue is whether on average trade policy reform increases or decreases output in sectors intensive in pollutants that are under-regulated. If trade policy reform increases output in such sectors, it will tend to increase environmental damage. But if it decreases output in such sectors

\footnotetext{
${ }^{48}$ See also Beghin et al. (1997) and Turunen-Red and Woodland (2004).
} 
(that is, if previously trade-protected sectors are highly polluting and under-regulated), then there will be a double dividend from trade policy reform - reduced trade distortions and less environmental damage. Proposals for liberalizing trade in environmental goods and services can also be seen as an example of a piecemeal trade policy reform aimed at targeting sectors than can contribute to reduced environmental degradation (Cosbey et al. 2010).

Shapiro (2021) develops a quantitative model of the global economy to assess a trade policy reform under which each country implements a single tariff per trading partner equal to mean baseline bilateral tariff (with a similar procedure similarly for NTBs). Given his evidence that the existing structure of trade protection involves an implicit trade subsidy for carbon intensive industries, this reform would tend to raise trade barriers in carbon intensive sectors and lower trade barriers in cleaner sectors. And given that carbon emissions tend not to be efficiently regulated in most countries, this is broadly consistent with a reform that in the context of Copeland (1994) would reduce relative global output in pollution damage intensive sectors. Shapiro finds that such a reform would yield a modest $(0.65 \%)$ increase in global real income, but would reduce global carbon emissions by $3.6 \%$. This is a striking result as it provides an example of how a trade policy reform can generate a substantial reduction in carbon emissions without any long run aggregate global cost. ${ }^{49}$

\subsection{Use of trade policy to achieve domestic environmental objec- tives}

In principle, trade policy can be used as a second best environmental policy. Import restrictions are sometimes used to restrict products that cause environmental damage or to limit the spread of invasive species. ${ }^{50}$ In a number of cases, export restrictions have been justified on environmental grounds for renewable and nonrenewable resources (Czaga 2004). One recent well-known example of the use of an environmental rationale for trade restrictions is the Chinese restriction on exports of rare earths (WTO 2015). Canada has previously used a conservation rationale to justify export restrictions for unprocessed herring and pink and sockeye salmon (WTO 1988). ${ }^{51}$

An export tax is equivalent to an output tax and a consumption subsidy. This helps clarify both the potential merits of using an export restriction as a substitute for an environmental policy, and also why it can be problematic. The output tax component of an

\footnotetext{
${ }^{49}$ There would however be distributional effects within and across countries as the pattern of global production adjusts to the new regime. Notably, there would be a large increase in carbon-intensive production in Europe.

${ }^{50}$ See for example McAusland and Costello (2004).

${ }^{51}$ In both of these cases, the U.S. launched a complaint that the policies violated GATT or WTO commitments, and in both cases the dispute panels found in favor of the U.S.
} 
export restriction will reduce pollution by reducing output. But if there is market power at the national level, there are international spillover effects: a country could claim that it is using the tax for environmental reasons when in fact it is more interested in the terms of trade benefits (which harm foreign importers). The terms of trade effects are to some extent unavoidable because any policy targeting emissions is likely to reduce output and push up the price. But there are less trade-distorting instruments available, such as emission or output restrictions. Moreover, the consumption subsidy component of an export tax is another key feature that makes it attractive for the home government but problematic for trading partners: it shields home's consumers from the price increase, because an export tax tends to push down the domestic price. If the exported good is a raw material used as an input in other sectors, then an export restriction shifts supplies of the raw material to local producers and helps to promote their output. This in turn will adversely affect foreign producers in competing sectors.

In 2010, China substantially increased its export restrictions (both quotas and export taxes) on rare earth elements, which are used in electronics. China had over a $90 \%$ market share for these materials and so this resulted in substantial price increases in foreign markets. In 2012, the U.S. launched a complaint through the WTO on a number of grounds, one of which was that it violated the terms of the accession agreement under which China came into the WTO. This agreement limited China's flexibility to use export restrictions. Canada, the European Union and Japan joined in the complaint. China argued that the export restrictions were necessary to reduce pollution from mining and to conserve resources. The WTO dispute panel ruled against China, finding that export restrictions were not necessary to reduce or control pollution (other instruments were available) and that the export quotas were "designed to achieve industrial policy goals rather than conservation" (WTO 2015).

Eisenbarth (2018) studies two Chinese policies that discourage exports - export taxes and a system under which exporters get only partial value-added tax rebates. These policies apply to a wide range of exports, not just rare earth elements, and are justified in part as a response to environmental concerns (Wang et al. 2010). Eisenbarth finds some evidence that the VAT rebate system discourages exports of pollution intensive products. However, she finds little evidence that export taxes are influenced by the pollution intensity of production.

\subsection{Effects of openness to trade on environmental policy}

We now turn to the question of whether openness to trade has an important qualitative effect on the setting of environmental policy. We focus on two key channels: the direct impact of openness on political pressure; and the interaction between trade agreements and 
environmental policy.

Oates and Portney (2003) provide a review of the political economy of environmental policy. Aidt (1998) and Schleich (1999) show how environmental policy will deviate from full internalization of externalities in a Grossman and Helpman (1994) lobbying model when not all sectors of the economy have organized lobbies. In the Grossman-Helpman framework there is an incentive to support lobbies in a way that minimizes harm to the rest of the economy. This least cost way, however, typically involves manipulating both output and input prices. This implies both trade and environmental policy will deviate from the social optimum.

The large literature on the effects of environmental policy on competitiveness in an open economy reviewed earlier in this chapter provides one channel through which trade will affect the pressures facing governments when setting environmental policy. In a closed economy, environmental regulation targeting polluting producers will raise their costs, and some of these costs will be passed on to consumers via increased prices. However, in a competitive industry in an open economy, prices will be less sensitive to local cost changes, and so the incidence of cost-increasing environmental regulation falls mostly on local producers. This implies that local producers will be more resistant to tighter environmental regulation in an open economy than in a closed economy.

McAusland (2008) however notes that lobbying incentives are very different for consumptiongenerated pollution. When pollution is generated during consumption (such as driving automobiles), then environmental regulations such as product standards will raise costs. In a closed economy, these costs will be shared between producers and consumers. In contrast, in a small open economy, producers can pass the full costs of complying with product standards onto consumers, possibly without losing market share. This is because the regulations can be applied to all such products used in the country, regardless of whether they are locally produced or imported. This suggests that in an open economy, domestic producers have less incentive to lobby against tighter environmental standards than in a closed economy.

A weakness of most applications of political economy models in explaining how trade affects environmental policy is that the policy space is typically restricted - governments have only a very small set of available policy instruments, one of which is environmental policy. With a wider range of instruments available that can achieve the objectives of a lobby group at less cost to the rest of the economy, then it is not obvious why environmental policy would be manipulated. ${ }^{52}$ Informational asymmetries provide one explanation. Coate and Morris (1995) show that if governments prefer that the electorate is not fully aware

\footnotetext{
${ }^{52}$ Both Schleich (1999) and Aidt (1998) discuss the targeting principle in the context of a Grossman Helpman lobbying framework.
} 
of the extent to which they are helping out interest groups, then inefficient policies may be used if they are more opaque than efficient policies. Given the complexity of the links between pollution emissions and either health or ecological outcomes, voters find it difficult to judge whether environmental policy is too weak. If so, it can be attractive to both lobbyists and the government to manipulate environmental policy to support the interests of an organized group (Sturm 2006; Kawahara 2011). Drazen and Limão (2008) suggest an alternative explanation. If governments can credibly commit to restrictions on the use of efficient policies to support special interest groups, they can improve their bargaining power in subsequent lobbying games which are restricted to the use of relatively inefficient policies.

Trade agreements explicitly put constraints on the use of various instruments, such as tariffs, quotas, and some subsidies to favor local producers over foreign producers in tradeexposed sectors of the economy. This provides another channel via which trade liberalization can affect the implementation and enforcement of environmental policy. Trade agreements do not eliminate the incentives that governments face to influence the terms of trade or to protect and support local producers. This means that trade agreements can lead to policy substitution. That is, governments and lobbyists have incentives to look for alternatives to trade policy instruments to implement their objectives. ${ }^{53}$ If an industry was previously protected with an import tariff, then a domestic subsidy could shield the industry from the effects of increased foreign competition once the tariff is removed. Weak environmental policy is an alternative way to provide a subsidy to producers.

Policy substitution need not lead to weaker environmental policy. When pollution is generated during consumption, product standards and other environmental regulation can be applied to both imports and domestically produced products. If an import tariff is eliminated by a trade agreement, its effects can be replicated by imposing more stringent product standards on imported goods (Copeland 2011; Staiger and Sykes 2011). Trade agreements have responded to this incentive with the National Treatment rule, which allows governments to regulate or tax emissions of products, provided that domestic and foreign products are subject to the same rules.

The National Treatment rule however does not eliminate the incentive to use emissions policy to influence the terms of trade. Recall that an import tariff is equivalent to a production subsidy and a consumption tax. With a tariff ruled out, an emission tax (or stringent product standard) can be used to substitute for the consumption tax component of a tariff. The stringent environmental regulation lowers domestic import demand, which pushes down the import price and improves Home's terms of trade.

\footnotetext{
${ }^{53}$ For the theory behind policy substitution, see Copeland (1990), Ederington (2001), and Bagwell and Staiger (2001). Ederington and Ruta (2017) provide an excellent review.
} 
Even if terms of trade effects are not relevant for policy, product standards consistent with the National Treatment Rule can be used to favor local producers. ${ }^{54}$ Consider Figure 10 which illustrates the domestic market for some good $X$. The world price is $p_{0}$ and prior to environmental regulation, domestic output is $x_{0}$, consumption is $d_{0}$, and imports are $M_{0}$. Suppose an emission standard is imposed on all products sold in the domestic market, and that it raises costs by $c$ for both domestic and foreign producers. The domestic supply curve shifts up from $S_{0}$ to $S_{1}$, but the import price rises from $p_{0}$ to $p_{0}+c$. Consumption falls, but domestic output is unaffected. If instead the marginal compliance is higher for foreign firms than for domestic firms, then a tighter standard will raise domestic output (the import price shifts up more than the domestic supply curve). ${ }^{55}$ This suggests that domestic producers can have incentives to lobby for tighter product standards, and if there are options in how to design the standards, domestic lobbying will focus on promoting polices that are cheaper for domestic firms to comply with than foreign firms, even though both domestic and foreign producers face the same standard.

Figure 10: The effect of a product standard on domestic output

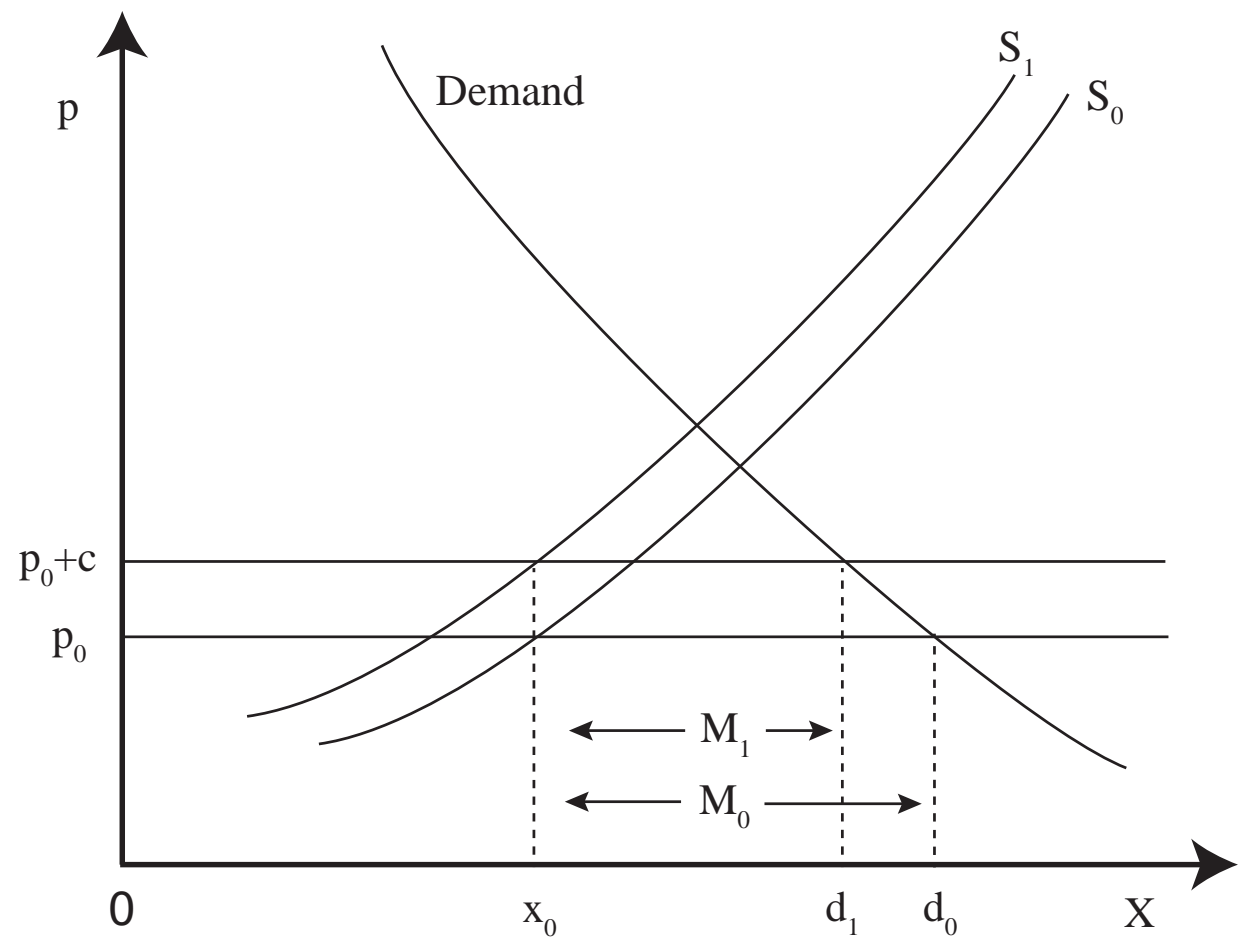

\footnotetext{
${ }^{54}$ See Gulati and Roy (2008), Copeland (2011) and Staiger and Sykes (2011).

${ }^{55}$ See Salop and Scheffman (1983) on "Raising rivals' costs."
} 


\subsection{Evidence}

While theory suggests that trade liberalization has the potential to affect the design and stringency of environmental policy, the empirical evidence is limited. A large literature, discussed earlier in the paper, has found evidence that more stringent environmental policy targeting producers tends to reduce net exports and other indicators of international competitiveness. However there is little direct evidence on whether this has systematically affected environmental policy. Several papers have investigated the "race to the bottom" hypothesis, under which the pressures of freer trade would induce governments to weaken environmental policy to attract new production facilities or to increase the competitiveness of existing firms. In a recent review of the literature, Carruthers and Lamoreaux (2016) conclude that "there is little systematic evidence for regulatory races-to-the bottom in the case of environmental regulations, either at the global level or that of US states."

The empirical evidence on policy substitution mostly comes from studies using an index of nontariff barriers as an alternative to trade barriers. Several papers have found that reductions in tariffs tend to increase the use of non-tariff barriers. Limão and Tovar (2011) find this result for Turkey, and Gawande (1999) for the U.S. Kee et al. (2009) and Niu et al. (2020) use large samples of countries and products and find that non-tariff barriers are substitutes for tariffs. Some work has found that tariffs and non-tariff barriers can be complements (Goldberg and Pavcnik 2005; Lee and Swagel 1997), but they did not study the effects of changes in tariffs on non-tariff protection.

Two recent papers use data on Specific Trade Concerns (SPCs) raised by exporting countries in response to policies in an importing country. Beverelli et al. (2019) focus on product standards as technical barriers to trade and find evidence of policy substitution for developed but not developing countries - they argue that their evidence is consistent with developed countries imposing stringent product standards in response to tariff or quota reductions because it is easier for their domestic firms to comply with the standards than for firms in developing countries. Orefice (2017) study sanitary and phytosanitary (SPS) measures which potentially play a dual role in protecting consumers and in restricting trade. They find evidence that these policies are a substitute for tariffs: tariff cuts increase the probability that a Specific Trade Concern action will be initiated.

Overall, while there is evidence that governments engage in policy substitution, most existing studies have not focused on the effects of tariff reductions on specific domestic policies, such as environmental regulation. The closest are the papers by Beverelli et al. (2019) and Orefice (2017) which are consistent with predictions from the product standards literature that governments face pressure to impose product standards that favor domestic firms at the expense of foreign firms. 


\subsection{Implications for the design of trade agreements}

Trade agreements can respond to policy substitution in a variety of ways. If domestic policy instruments are expected to be used to replace trade policies then the scope of trade agreements can be extended to cover instruments that are prime candidates as instruments to substitute for trade barriers or export subsidies. This leads to the notion of deep integration (Lawrence 1996). Countries can potentially harmonize or coordinate domestic policy regulations, including environmental policy.

However there is a trade-off between allowing governments the flexibility to respond to internal policy concerns, and constraining their ability to use domestic policy instruments to achieve trade objectives. And it is costly to design such agreements. Horn et al. (2010) study the role of contracting in influencing the design of trade agreements to deal with policy substitution. There is no obvious focal point for environmental policy in many situations optimal policies depend on preferences, incomes, and local climate and ecological conditions. As a result, designing an agreement to coordinate policy would be difficult. When contracting costs are high, it may not be worth including environmental policies in a trade agreement. When trade flows between countries are high, or where there are strong similarities between countries in their approach to environmental policy, then the potential for deeper integration increases.

As a result, as Horn et al. (2010) put it, trade agreements will be "endogenously incomplete contracts." Previous work has studied trade agreements with exogenous limitations on their scope. Copeland (1990) considered a model with two instruments - tariffs and domestic policy. The implicit assumption was that contracting costs for tariffs are zero and for domestic policy are infinite. Countries negotiate a deal on tariffs anticipating that there will be a non-cooperative game in domestic policy in the future. As long as trade and domestic policy instruments are imperfect substitutes, there are gains to negotiating a trade agreement, although zero tariffs may not be an outcome. Bagwell and Staiger (2001) also assume that contracting costs for negotiating policy are prohibitively high, but they argue that a first best outcome can be achieved by negotiating a market access agreement. Countries agree to provide their trading partner a certain level of market access and then they are free to choose domestic policy subject to that constraint. This eliminates the international spillover effect of changes in domestic policy, and it creates incentives for countries to minimize the cost of achieving internal objectives subject to the constraint of not reducing foreign market access. However enforcement would be difficult, especially since the agreement would in principle

need to be state contingent - efficient levels of bilateral market access would evolve over time due to changes in technology, tastes, and other factors. 


\section{Trade and climate change}

While this chapter discusses a range of environmental and natural resource goods, climate change is particularly important overall and also has especially direct potential links to international trade, investment, and policy issues. Given these concerns, we now turn to discuss issues relating globalization and climate change in detail. This section discusses two questions. How does globalization affect global pollutants? And, how does globalization affect climate change policy?

\subsection{How does globalization affect global pollutants?}

Global pollutants are the most extreme examples of transboundary pollution, i.e., pollutants that cross political borders. Greenhouse gas emissions are the leading example, though substances that deplete the tropospheric ozone layer are another.

Almost every pollutant crosses city, county, state, or international borders to some extent. The management of pollutants that cross intra-national borders like counties, states or provinces can be centralized to the national level, which often helps resolve some challenges of managing transboundary pollutants. The literature on fiscal federalism (Oates 1999) emphasizes that local management of regional pollutants is inefficient, since one local community may ignore the externality imposed on other local communities. Indeed, empirical research has found important cases where allowing sub-national governments to manage air or water pollution leads them to essentially export the pollution to downstream or downwind local communities (Sigman 2002, 2005; Lipscomb and Mobarak 2016; Wang and Wang 2020).

Global pollutants represent the more complex case where higher levels of government cannot solve the externality problem. Instead, independent countries choose policy and seek to use treaties or other means to coordinate these policies. Much research on globalization and the environment dealing with global pollutants seeks to understand or interpret these environmental relationships between countries.

Our Stylized fact 7 indicates that the embodied carbon content of trade is large (about $29 \%$ of global emissions) and has increased considerably since 1995 . Stylized fact 8 indicates that high income countries are net importers of embodied carbon emissions, and these net imports have also increased over time. This raises the question of to what extent international trade is responsible for a net increase in carbon emissions.

Trade liberalization affects emissions of global pollutants through similar channels as for local pollutants. Trade-induced changes in the scale and composition of production and consumption, and reallocations of production across firms will all affect emissions. Indeed, some of the evidence we discussed in Section 4 on reallocation effects used data on carbon 
emissions. Emission intensities can change via trade in technology and intermediate inputs or via endogenous policy changes. Trade also affects emissions from international transport. The quantitative models of Cristea et al. (2013) and Shapiro (2016) discussed in section 4.3 found that a movement from autarky to free trade increased carbon emissions by a modest amount (about 5\%). However these studies did not take into account the effects of trade on carbon emissions policy.

A key difference between the effects of trade on global and local pollution is the incidence of pollution and the ensuing welfare effects. If pollution haven effects are operative, tighter pollution policy in one country shifts polluting activity to other countries. A country may therefore bear the cost of more stringent pollution policy, but not realize the full benefits because shifting the location of production has no effect on the location of the damage caused by emissions of a global pollutant. This has implications both for the welfare effects of freer trade and the incentives to tighten up environmental policy.

This is illustrated in the simple pollution haven models of Copeland and Taylor (1995b) and Hemous (2016). In Copeland and Taylor (1995b) there is a continuum of goods that vary in emission intensity; and two regions, North and South, with North being richer than South. Differences in the stringency of (endogenous) regulation is the only motive for trade, pollution is global, and countries choose pollution policy non-cooperatively. Surprisingly, in this setting North loses from trade, mostly because of the effect of trade on the non-cooperative game in emissions. A movement to free trade shifts pollution-intensive production to South, where policy is weaker. As a result, the free trade regime puts North at a strategic disadvantage in the global game in emissions policy. This is because the South's lower income gives it a credible commitment to pollute more in free trade. ${ }^{56}$ In Hemous (2016), the pollution haven effect is reinforced by directed technical change. ${ }^{57}$ There are dirty and clean inputs, and the allocation of innovative activity is divided between the two types of inputs based in part on market size effects. Suppose that innovations do not spill over borders, and that only North has a carbon tax. In free trade, pollution-intensive production shifts to the South and North's carbon tax redirects its innovation towards cleaner technology. But the opposite happens in the South because of its trade-induced increase in dirty input production. This increased innovative activity in dirty good inputs reinforces South's comparative advantage in dirty production and magnifies the pollution haven effect. In the absence of an effective global climate agreement, restrictions on trade are needed to shift the world to a cleaner growth path. The interaction between trade, directed technical change, and climate policy

\footnotetext{
${ }^{56}$ See Copeland (2000) for a more detailed discussion of the implications for global climate negotiations.

${ }^{57}$ For earlier work on the interaction between directed technical change, trade, and carbon emissions, see Di Maria and Smulders (2005), Di Maria and Van der Werf (2008) and Acemoglu et al. (2014).
} 
is a fruitful area for future research, in part because of the importance of innovations in abatement technology and green energy for reducing emissions and for achieving political support for lower emission targets.

\subsection{Trade policy and climate change}

Climate change is a global problem, and first best solutions require international negotiations. To date, negotiated agreements have been not been successful and effective. Much of the trade policy literature on climate change has been driven by the challenges of reducing global carbon emissions in the absence of global agreements and the presence of heterogeneity in the stringency of policy across countries.

It is useful to distinguish between three different motivations for using trade policy to respond to global environmental problems. In one set of cases, Home attempts to reduce environmental damage due to foreign activity that is more or less independent of Home's domestic environmental policy. Examples include deforestation, conservation of fragile ecosystems, and the preservation of biodiversity. Second, a large literature addresses issues that fall under the general category of "leakage". In this case, emission increases in foreign countries are caused by more stringent environmental policy at Home that cause a reallocation of polluting production to other countries. ${ }^{58}$ And third is a literature on "linkage." The issue is whether trade policy can be a tool to help enforce and sustain global climate agreements.

Markusen (1975) is the starting point for much of the work on targeting pollution in foreign countries. Markusen shows that in the absence of a deal to implement foreign pollution policies, Home's optimal policy is to use environmental policy to target its domestic emissions and an import tariff to target foreign emissions. The optimal tariff formula has two components - one is the standard optimal tariff (the inverse of the foreign export supply elasticity) used to exploit domestic monopsony power to push down the import price; and the other is intended to push down the foreign price even more to reduce pollution emissions. There have been several extensions to Markusen's analysis. Hoel (1996) considered multiple polluting goods and Copeland (1996) showed that a pollution content tariff (a tariff that depends on embodied imported emissions) can be superior to simple tariff on goods. Other related work focuses on issues related to leakage, such as subsidies for trade-exposed domestic polluters via output-based allocation of emission permits (see for example Fischer and Fox (2012)). We will discuss this later in our section on leakage.

\footnotetext{
${ }^{58}$ Leakage in the context of deforestation is sometimes referred to as forest displacement. Recent empirical work examining how unilateral forest conservation practices have spilt over borders is contained in Meyfroidt and Lambin (2008) and Meyfroidt and Lambin (2009). For theoretical work demonstrating how leakage works in a renewable resource context see Brander and Taylor (1998).
} 
Markusen's work highlights two of the major concerns about using trade policy to influence foreign pollution. First, the policy is only effective if Home is able to influence foreign production. If the export supply curve facing Home is very elastic, then Home's optimal tariff is low because it creates distortions at Home but does not have much of an effect on foreign pollution. Even if foreign pollution is responsive to the world price, Home may have very little way of influencing the price if it is only one of Foreign's many trading partners. And second, because the tariff leads to a Foreign terms of trade deterioration, it redistributes income from Foreign to Home. Quantitative studies have shown that the use of such tariffs to deal with carbon leakage would tend to shift income from low to high income countries because the terms of trade of countries that are net importers of embodied carbon would improve. ${ }^{59}$

\section{Targeting foreign conservation}

There are numerous examples of cases where countries have used trade policy to target environmental damage in other countries. Examples include bans on trade in ivory, restrictions on imports of tropical timber, the US restrictions on imports of tuna harvested using methods that kill porpoises, and US restrictions on imports of shrimp from countries where endangered sea turtles were harmed during harvesting. Some of these policies have generated a large literature on their consistency (or not) with WTO rules; that is beyond our scope here. For our purposes, a key issue is the efficacy of such policy and potential unanticipated side effects.

Hsiao (2020) estimates a quantitative model to study the effectiveness of using trade policy to target carbon emissions generated by the palm oil industry in Indonesia and Malaysia. The industry has been a large contributor to carbon emissions due to the conversion of tropical forests to plantations (accounting for nearly 5\% of global emissions from 1986 to 2016). In principle, trade restrictions could be highly effective because most of the output is exported, and indeed Hsiao finds that carbon emissions due to palm oil production would be reduced by around half if all importing countries coordinated the use of trade restrictions. Trade taxes do almost as well as a Pigouvian tax - they fall short of the full optimum because they cannot target domestic consumption in Malaysia and Indonesia.

The model is also useful in highlighting the pitfalls of using trade policy. International coordination is the key to an effective policy. Even relatively large countries (or groups of countries) can achieve little on their own. For example, if only the European Union used an import restriction, the EU's optimal tariff would reduce carbon emissions very little. This reflects the point discussed above - when there are multiple trading partners, a small coalition

\footnotetext{
${ }^{59}$ See for example Mattoo et al. (2009); Böhringer et al. (2018).
} 
of countries faces a relatively elastic export supply curve. This both reduces the optimal tariff and weakens its effectiveness. Moreover, the paper shows why it can be difficult to maintain a coalition. Countries that do not participate in a coalition to restrict trade gain both by free riding (global carbon emissions fall due to the coalition's trade policy), and because the fall in global demand for palm oil reduces its price, which benefits non-coalition importing countries.

There are other potential weaknesses of trade policies aimed at promoting conservation. A long term commitment to maintain trade restrictions in place is required (Hsiao 2020). Once a forest is cut down, the benefits of maintaining trade restrictions are substantially reduced. If those developing plantations anticipate this, then trade restrictions may have little deterrent value. And alternative land uses need to be considered. Trade policy to promote conservation of land-based resources can encourage a shift in land use. For example, restrictions on imports of tropical timber can reduce the incentives to invest in forest management and preservation, and encourage conversion of the land to other uses (Barbier and Schulz 1997).

In recognition of the limitations of using trade policy to target foreign conservation, a large literature considers other options, such as contracting for conservation and payments for ecosystem services (Harstad 2016; Jayachandran et al. 2017), or certification strategies such as green fair trade (Dragusanu et al. 2014).

\section{Leakage}

The literature on leakage is concerned with changes in pollution emissions in non-coalition countries that occurs as a result of emission reductions by a coalition of one or more countries. Most of the literature deals with carbon leakage, and that will also be our focus.

There are three main channels for carbon leakage. ${ }^{60}$ The first is driven by the same channels we discussed in the literature on the competitiveness effects of environmental policy. Introducing carbon pricing or other policies to induce polluting industries to reduce carbon emissions will raise costs, and in trade-exposed industries this can cause production to relocate to other countries either by shifting trade patterns or by offshoring and / or foreign direct investment. The evidence we reviewed earlier has found that trade and foreign direct investment flows are affected by environmental policies, although the magnitude of the effect is still subject to debate. This suggests that concerns about leakage via the competitiveness

\footnotetext{
${ }^{60}$ More generally, Copeland and Taylor (2005) show that a unilateral cutback in emissions by a large bloc of countries will create a free rider effect plus income and substitution effects (one of which is conventional carbon leakage) arising from world price changes. In some cases, emissions in other countries can fall rather than rise. Similarly, Baylis et al. (2014) identify a different channel via which leakage could in theory be negative due to general equilibrium effects.
} 
channel are real.

The second channel is via the effects of carbon policy on the price of fossil fuels. Policies aimed at reducing carbon emissions - either by raising costs for users of fossil fuels, or by subsidizing the development or use of alternatives to fossil fuels - will reduce the demand for fossil fuels. This will reduce their price and potentially increase the use of fossil fuels in countries that do not restrict their use. ${ }^{61}$

The third channel is also driven by the fossil fuel market. Rather than (or in addition to) focusing on policies that restrict the demand for fossil fuels, a fossil fuel-producing country could restrict supply. Although the intention of the policy would be to reduce emissions, the reduction in fossil fuel supply could push up the price, and encourage producers in other countries to increase their extraction.

Leakage is a concern for a global pollutant both because it reduces the efficacy of domestic environmental policy - emission decreases at home can be offset by increases in foreign emissions - and because it undermines domestic political support for climate policies.

There is relatively little econometric evidence of the magnitude of carbon leakage. Aichele and Felbermayr (2012) use a gravity model and estimate that embodied imports of carbon emissions into countries that ratified the Kyoto Protocol (which they use as a proxy for the intensity of climate regulation) from non-ratifying countries rose by about $8 \%$. However, as Branger and Quirion (2014) note, much of the increase in embodied carbon imports is due to a large increase in trade with China, which was driven by other factors (such as rapid economic growth and membership in the WTO). Aldy and Pizer (2015) estimate the effects of changes in US fuel prices on net imports from fuel- intensive industries. They then use these estimates in a simulation to infer the potential effects of a $\$ 15$ per ton US carbon tax, and find that leakage would be relatively small. As discussed in Section 4, there is to date little or no evidence that the European Emission Trading System had significant effects on the net exports of affected firms (Joltreau and Sommerfeld 2019; Verde 2020).

Most of the empirical work on leakage uses quantitative models. Dozens of papers use computable general equilibrium models to estimate leakage under various scenarios. ${ }^{62}$ These studies have a wide range of estimates, though most papers find leakage rates of less than a third. In other words, if a given set of countries decreases greenhouse gas emissions by some amount, these numerical papers typically find that the rest of the world increases its

\footnotetext{
${ }^{61}$ There is also the possibility of intertemporal leakage. Expectations of future policies to phase out the use of fossil fuels can shift production to the present. This is the "green paradox" (Sinn 2008). We do not focus on this channel here because it is not primarily an international trade issue - but see Eichner and Pethig (2011).

${ }^{62}$ For example, Babiker (2005); Zhang (2012); Branger and Quirion (2014); Carbone and Rivers (2017); Droge et al. (2021).
} 
greenhouse gas emissions by less than a third of that amount. There are also papers that use partial equilibrium quantitative models and find potential leakage ranging from 20 to 73 per cent in specific industries such as cement, aluminum, and steel (Demailly and Quirion 2006; Ponssard and Walker 2008; Fowlie et al. 2018).

A large literature studies policies to mitigate leakage. Most of the work focuses on three types of policies: trade policies or "border carbon adjustments" (BCAs); domestic policies that shelter trade-exposed sectors, such as output subsidies or output-based allocation of emission rights; and supply side policies - these are mostly policies aimed at reducing the supply of fossil fuels.

Markusen (1975) is the basis of much of the theory of BCAs - trade policy is used to influence foreign emissions. If emissions are directly proportional to output, a trade policy attempting to influence foreign emissions is equivalent to a policy targeting foreign output levels. If emission intensities are endogenous, then policies can target the embodied carbon content of trade. ${ }^{63}$ Although much of the literature is motivated by the optimal unilateral policy for a coalition that introduces more stringent carbon regulation than the rest of the world, Keen and Kotsogiannis (2014) show that a global planner would use border carbon adjustments when implementing an optimal carbon policy in a world where some countries do not have the capacity to implement effective domestic carbon policy. That is, the use of a border carbon adjustment can be constrained Pareto efficient. However they also note that the efficient border carbon adjustment does not in general simply offset the difference in the shadow price of emissions across countries; it also depends on export supply elasticities.

If trade instruments are not available, domestic policies that subsidize trade exposed firms - such as output-based allocation of emission permits are an option that have been widely discussed. Because a tariff is equivalent to an output subsidy combined with a consumption tax, an output subsidy is a second best instrument to target foreign emissions. Bohringer et al. (2017) explicitly exploit the equivalence between a tariff and a production subsidy combined with a consumption tax. They point out that output-based rebating will be more efficient if combined with a consumption tax; and that even if trade policy is ruled out, the optimal tariff can be perfectly replicated with these two domestic policies.

The empirical evidence on the effectiveness of policies to mitigate leakage comes from quantitative models. Using a CGE model, Böhringer et al. (2012) find that border adjustments accompanying carbon taxes imposed by OECD countries reduce leakage by about a third. Larch and Wanner (2017) use a structural gravity model and find that leakage would be reduced from $13.4 \%$ to $4.1 \%$ with border adjustments. CGE models also indicate that BCAs would tend to shift some of the cost of reducing carbon emission from OECD countries

\footnotetext{
${ }^{63}$ See for example Copeland (1996) and Kortum and Weisbach (2020).
} 
to developing countries via terms of trade effects (Mattoo et al. 2009; Böhringer et al. 2018).

Some industrial organization papers provide partial equilibrium models that can provide additional insight into specific challenges that are difficult for global economy-wide models to accommodate. Fowlie et al. (2016) study carbon pricing in the U.S. cement industry. This is a highly concentrated industry with substantial markups, more than many other industries (Ganapati et al. 2020). Because market power already pushes output below the socially optimal level, Pigouvian taxes can exacerbate this distortion by further discouraging output (Buchanan 1969). Scholars have debated, however, how the market power distortions compare in magnitude to the environmental externality (Oates and Strassmann 1984). Fowlie et al. (2016) develop a plant-level dynamic model which accounts for entry, exit, investment, and disinvestment. They find large environmental benefits from domestic carbon prices, but also substantial costs due to exacerbating market power and leakage. A border tax adjustment creates substantial domestic benefits, both due to preventing leakage and improving the domestic terms of trade. Their model highlights the challenges of using output subsidies to combat leakage. In their simulations, output-based emission allocations reduce leakage and mitigate the social costs due to the exercise of market power, but they also reduce the effectiveness of a carbon tax in reducing emissions (the output subsidy undoes much of the effect of a carbon tax if options for abatement are limited).

Electricity is perhaps the industry that most contributes to climate change. While it is mostly not traded internationally, electricity does contribute substantially to production of most internationally traded goods, and much electricity crosses borders across states or provinces within a country. Intra-national trade in electricity is important because many existing climate change policies cover only parts of a country. Fowlie (2010) develops an analytical model of an electricity market, then calibrates it using data from California and neighboring states. She finds that electricity market leakage is fairly important. Ignoring out-of-state emissions undermines a third of intra-state decreases in greenhouse gas emissions and doubles the per-ton cost of emissions reductions.

As noted above, two key channels for leakage are driven by the effects of domestic carbon policies on the global fossil fuel market. It is therefore useful to consider models that specifically include fossil fuels as a traded input. This has led to a literature on "supply-side policies" that target fossil fuel production. ${ }^{64}$ Should countries restrict production of fossil fuels to influence foreign emissions? That is, should countries rely exclusively on policies (such as carbon taxes) to reduce demand for emissions, or should they also target domestic production of fossil fuel?

\footnotetext{
${ }^{64}$ See for example Golombek et al. (1995); Harstad (2012); Fæhn et al. (2017); Kortum and Weisbach (2020).
} 
The simplest way to see that there is a potential role for supply-side policies is to consider an extreme case where all pollution is generated by the use of fossil fuels and where Home has a global monopoly on fossil fuel supply. Then home can completely control global pollution by controlling the supply of fossil fuels with an output tax. However, this supply side policy can be replicated with a combination of a domestic emissions tax (a demand-based policy) and an export tax on fossil fuels (a trade policy). In this case, the output tax (the supplyside policy) is not needed. The export tax is equivalent to a production tax combined with a consumption subsidy, but the consumption subsidy is more than offset with the domestic emission tax. The key point here is that trade policies are a combination of demand and supply side policies. Whether to use trade policies or purely domestic demand and supply side policies depends on administrative complexity, domestic politics, and trade agreements.

Kortum and Weisbach (2020) consider the optimal unilateral carbon policy in a model where all pollution comes from fossil fuels, and where both fossil fuels and goods produced using fossil fuels are traded. Their model combines the many-good Ricardian model of Dornbusch et al. (1977) and the solution strategy of Costinot et al. (2015). Equivalence relations imply that a variety of policies will implement Home's optimal policy, but they focus on a policy that taxes domestic extraction of fossil fuels. This is supplemented with border adjustments on import or export of energy, and on the fossil fuel content of imports. The tax rate for the border adjustment may differ from and typically be below the tax rate for extraction. Because foreign countries can adjust the energy intensity of their exported goods, an import tax on the fossil fuel content of goods reduces foreign emission intensities. In addition, because Home cannot control the emission intensity of goods produced by foreign for foreign consumption, Home has an incentive to subsidize exports of a range of emission intensive goods. Their preliminary quantification suggests that the border adjustment generates only modest gains when compared against the production tax, and the quantification does not account for the nontrivial administrative costs of a border adjustment.

While border adjustments can mitigate some leakage, Harstad (2012) points out that use of domestic emissions policies in combination with either trade policies or policies targeting domestic supply of fossil fuels cannot eliminate all leakage when fossil fuels are produced both inside and outside coalition countries. He therefore proposes targeting the foreign supply of fossil fuels directly - that is, he shows how buying foreign fossil fuel deposits and shutting down production can eliminate leakage and be welfare-improving for a coalition. The key idea is to use this strategy to make the foreign supply of fossil fuels inelastic in the relevant region - so that changes in the price of fossil fuels induced by Home's internal carbon policies do not result in any change in foreign usage of fossil fuels. Moreover, this eliminates the need for trade-distorting policies targeting embodied carbon imports. While 
this strategy would face implementation challenges due to the threat of nationalization and the unwillingness of some governments to allow such contracts, the work highlights the advantages of climate negotiation strategies that focus on fossil fuel supply issues, rather than simply on commitments to reduce emission demand.

\section{Linkage}

Trade policy could also be used to enforce climate agreements. ${ }^{65}$ Limao (2005), building on Spagnolo (1999), shows that there can be efficiency gains from linking trade and climate agreements because of the wider range of incentives and punishments available. There are, however, tradeoffs as linkage may result in less enforcement for the trade component of an agreement. That is, although global efficiency is increased because of greater enforcement power for a climate agreement, trade may be less free than if would have been without linkage to a climate agreement. Several papers have also considered the use of trade sanctions, or

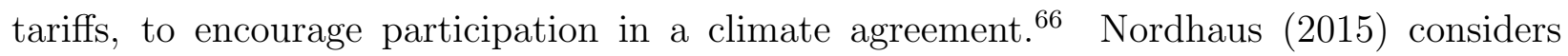
a "Climate Club" in which participants agree to a price on carbon and non-participants are penalized with a uniform tariff. Using a numerical simulation model, he finds that no countries would join a climate agreement in the absence of penalties. However a tariff of $5 \%$ on non-participants can encourage enough participation to achieve $90 \%$ efficiency if the social cost of carbon is $\$ 50$ per ton. As the cost of carbon increases, however, the enforcement mechanism is less effective as more large countries find that the costs of cooperation (high abatement costs) exceed the benefits.

\subsection{Trade and adaptation to climate change}

Although trade creates challenges in responding to climate change via the potential for carbon leakage, it can potentially play a useful role in helping countries adapt both to the effects of climate change on productivity, and to the effects of policy interventions.

Climate change is projected to have substantial effects on productivity both through the effects of temperature and extreme weather events on workers, and via its effects on natural capital - agricultural productivity in particular will be affected. Moreover, these effects will be heterogeneous both within and cross countries, with some regions expected to see significant decreases in agricultural productivity while others will become more productive. Climate change is therefore projected to cause changes in comparative advantage, and so trade can potentially help in mitigating the costs of reallocating production and consumption.

\footnotetext{
${ }^{65}$ See Maggi (2016) for an excellent exploration of issue linkage in international agreements.

${ }^{66}$ See for example, Barrett (1997).
} 
The extent to which international trade can help is an ongoing subject for research.

Costinot et al. (2016) use a quantitative model with detailed data on land heterogeneity to study the global adaptation of agriculture to climate change. Their simulations indicate that reallocations of agricultural production within countries can play an important role in responding to the effects of climate change, and that while international trade can help, its effects are quantitatively less important than increased within-country trade. ${ }^{67}$ Gouel and Laborde (2021) find that adjustments in agricultural trade can play a more important role, particularly through changes in bilateral import shares - countries gain by switching to alternative sources of supply. Nath (2020) considers the effects of temperature change on productivity in both manufacturing and agriculture. In countries that already have a hot climate, climate change shifts comparative advantage away from food production towards manufacturing. Endogenous changes in trade patterns could potentially help such countries adapt to climate change, but because of high trade costs and subsistence food requirements, climate-induced reductions in agricultural productivity can end up pulling workers out of manufacturing into agriculture in such countries.

More broadly, an emerging body of research is using quantitative gravity and spatial models to explore the role of trade in climate change adaptation. For example, Conte et al. (2020) develop a quantitative dynamic spatial model to study how the interaction between trade and human migration influences the costs of adapting to climate change in different parts of the world. This work highlights the unequal incidence of the costs of climate change across the world (some regions gain while others lose), as well as the critical role of both trade and migration frictions in affecting these costs. ${ }^{68}$ There is much potential for future work using such models. Recent work such as Barrot and Sauvagnat (2016), Boehm et al. (2019) and Carvalho et al. (2021) shows how the effects of natural disasters are transmitted across countries via international supply chains, suggesting that the costs of climate change will be transmitted across countries via trade, but also that climate change will lead to changes in the structure of supply chains. And the inequality in the incidence of climate change and the potential pressures due to the incentives for human migration highlighted by these models will play a role in the affecting the evolution of international agreements on climate change and potential linkages to trade policy.

Trade can also help with the adjustment to climate policy. For example if countries adopt arbitrary carbon emission targets, the shadow price of emissions will differ across countries. Copeland and Taylor (2005) show how trade in goods can substitute for trade

\footnotetext{
${ }^{67}$ See also Burgess and Donaldson (2010) who show how adaptation by farmers within India reduced the impact of weather shocks.

${ }^{68}$ See also Dingel et al. (2019) and Cruz Alvarez and Rossi-Hansberg (2021).
} 
in emission permits and reduce effective national-level marginal abatement costs. Acemoglu et al. (2012) study the role of directed technical change in responding to climate policy. Export opportunities allow for larger markets and increase the incentives for innovation. ${ }^{69}$

\section{Conclusion}

This chapter distills evidence, theory, and recent research on links between globalization and the environment. While it highlights a burgeoning literature, it also clarifies important areas not yet a focus of research. We describe a few topics where, in our subjective view, the current level of research activity is below the socially optimal level given either the possible research insights or given relevance to important policy and global environmental and economic concerns.

Several developments in the global economy have potentially important but under-explored implications for the environment. What do the expansion of global value chains, offshoring, and fragmentation mean for the environment and environmental policy? Over recent decades, the share of intermediate goods in production has gradually increased, and the number of stages of producing goods and offshoring individual stages of production have expanded. Lengthening global value chains may increase the role of emissions from transportation and expand the scope of potential pollution haven effects. Additionally, the growth of India, China, and other Asian and middle-income countries and associated environmental impacts, led by exports and foreign investment, has considerable importance that has not been a major focus of research on globalization and the environment. China and India's domestic environmental policies differ in many respects from those of industrialized countries, their political economy considerations are quite different than those of the US and EU, and much projected growth in the coming decades in greenhouse gas emissions and natural resource extraction will occur in Asia.

Recent innovations in international economic policy are also potentially important for the environment, and would benefit from more research. Since at least NAFTA, most multilateral trade agreements have included environmental side agreements. While a rich theoretical literature discussed in this chapter provides some guidance on such agreements, the relationship between concerns driving actual policy and this literature is comparatively underdeveloped. In addition, many countries are discussing or have implemented international policies which target "green goods" that provide inputs to environmental quality. What principles

\footnotetext{
${ }^{69}$ See also Lovely and Popp (2011) who provide evidence that the availability of clean technology via imports increased the likelihood that governments adopt more stringent emission regulations because of reduced compliance costs.
} 
should guide such policies? Unfortunately, some of these policies discourage trade in these goods, such as the tariffs of up to 30 percent that the US imposed on solar cells and inverters from China in 2018, while the EU has discussed preferential trade policies for green goods. Another policy development which has been a focus of research, but we believe is critically important for the global environment, is the potential role of international economic policies to support global climate change agreements. Because the climate is a global public good subject to a severe free rider problem, mechanisms to support cooperation may be able to increase the level of cooperation and stringency of climate policy. International economic policy provides one such potential mechanism. While this is an active area of research, we believe that advances in this area have enormous potential environmental and social benefits.

Many recent advances in international and spatial economics research have environmental implications with limited associated research. Recent research has begun developing rich models of intra-national trade between cities and regions within a country to provide insight on transportation infrastructure, commuting, amenities, and other core economic ideas, and uses detailed data to link these models with data and estimate counterfactual policies. Research on intra-national trade and the environment is limited (e.g., Balboni 2019) but has important potential insights. A related innovation is the role of individual firms, neighborhoods, and more broadly finite outcomes in aggregate economic patterns (Eaton et al. 2013; Gaubert and Itskhoki 2018; Dingel and Tintelnot 2021). Individual firms have dramatically different environmental impacts (Lyubich et al. 2018), and individual locations within a country or state have different environmental policies and preferences. Most theoretical and empirical research on globalization and the environment uses substantial aggregation, which may obscure important roles of individual agents.

Finally, several advances in environmental research are potentially important to but not widely linked to international issues. Market power is widespread in energy-intensive industries. Market power implies that production is already below the socially optimal level, and thus environmental policies create an additional distortion by penalizing consumers. In part for tractability, much research on international environmental issues assumes all goods have a market structure of perfect competition, or less often monopoly, or a market structure like monopolistic competition where markups are fixed and all firms in an industry have the same markup. Yet actual market power varies widely between firms and in response to policy; better understanding how market power interacts with traditional concerns in international environmental issues may produce important insights. One especially recent and promising development is the widespread availability of data products using remote sensing (satellite) images from outer space, combined with enormous advances in the accuracy of artificial intelligence algorithms between 2010 and 2020. Remote sensing data have enabled measurement 
of environmental quality, agricultural production, economic activity, and other important outcomes at fine spatial scales of 30 meters or less. These measurements are particularly important in developing countries where in situ measurement of environmental quality has prohibitive cost or faces other obstacles that impede measurement (e.g., civil conflict). Much as the availability of Northern European population registers has supported an explosion of research in labor and public economics, becoming able to observe a wide range of environmental goods at fine spatial scale across the globe is allowing a range of new approaches to the study of globalization and the environment. 


\section{References}

Acemoglu, D., P. Aghion, L. Bursztyn, and D. Hemous (2012). The environment and directed technical change. American Economic Review 102(1), 131-066.

Acemoglu, D., P. Aghion, and D. Hemous (2014). The environment and directed technical change in a North-South model. Oxford Review of Economic Policy 30(3), 513-530.

Aichele, R. and G. Felbermayr (2012). Kyoto and the carbon footprint of nations. Journal of Environmental Economics and Management 63(3), 336-354.

Aidt, T. S. (1998). Political internalization of economic externalities and environmental policy. Journal of Public Economics 69, 1-16.

Aldy, J. E. and W. A. Pizer (2015). The competitiveness impacts of climate change mitigation policies. Journal of the Association of Environmental and Resource Economists 2(4), 565595.

Ambec, S., M. A. Cohen, S. Elgie, and P. Lanoie (2013). The Porter hypothesis at 20: can environmental regulation enhance innovation and competitiveness? Review of Environmental Economics and Policy 7(1), 2-22.

Anouliès, L. (2017). Heterogeneous firms and the environment: a cap-and-trade program. Journal of Environmental Economics and Management 84, 84-101.

Antràs, P., D. Chor, T. Fally, and R. Hillberry (2012). Measuring the upstreamness of production and trade flows. American Economic Review Papers and Proceedings 102(3), $412-416$.

Antweiler, W., B. R. Copeland, and M. S. Taylor (2001). Is free trade good for the environment? American Economic Review 91(4), 877-908.

Arto, I., J. M. Rueda-Cantuche, and G. P. Peters (2014). Comparing the gtap-mrio and wiod databases for carbon footprint analysis. Economic Systems Research 26(3), 327-353.

Auffhammer, M., W. Sun, J. Wu, and S. Zheng (2016). The decomposition and dynamics of industrial carbon dioxide emissions for 287 Chinese cities in 1998-2009. Journal of Economic Surveys 30(3), 460-481.

Autor, D. H., D. Dorn, and G. H. Hanson (2013). The china syndrome: Local labor market effects of import competition in the united states. American Economic Review 103(6), 2121-68. 
Babiker, M. H. (2005). Climate change policy, market structure, and carbon leakage. Journal of International Economics 65(2), 421-445.

Bagwell, K. and R. W. Staiger (2001). Domestic policies, national sovereignty, and international economic institutions. The Quarterly Journal of Economics 116(2), 519-562.

Bajona, C., P. Missios, and A. Pierce (2012). Trade and the environment with heterogeneous firms. Working Paper, Ryerson University.

Baland, J.-M. and J.-P. Platteau (1996). Halting Degradation of Natural Resources: Is There a Role for Rural Communities? Oxford: Oxford University Press.

Balboni, C. (2019). In Harm's Way? Infrastructure Investments and the Persistence of Coastal Cities. Working paper.

Barbier, E. B. and C.-E. Schulz (1997). Wildlife, biodiversity and trade. Environment and development economics $2(2), 145-172$.

Barrett, S. (1997). The strategy of trade sanctions in international environmental agreements. Resource and Energy Economics 19(4), 345-361.

Barrot, J. N. and J. Sauvagnat (2016). Input specificity and the propagation of idiosyncratic shocks in production networks. Quarterly Journal of Economics 131(3), 1543-1592.

Barrows, G. and H. Ollivier (2018). Cleaner firms or cleaner products? how product mix shapes emission intensity from manufacturing. Journal of Environmental Economics and Management 88, 134-158.

Batrakova, S. and R. B. Davies (2012). Is there an environmental benefit to being an exporter? Evidence from firm-level data. Review of World Economics 148(3), 449-474.

Baumol, W. (1971). Environmental Protection, International Spillovers, and Trade. Stockholm: Almkvist \& Wicksell.

Baylis, K., D. Fullerton, and D. H. Karney (2014). Negative leakage. Journal of the Association of Environmental and Resource Economists 1(1/2), 51-73.

Becker, R. and V. Henderson (2000). Effects of air quality regulations on polluting industries. Journal of Political Economy 108(2), 379-421.

Beghin, J., D. Roland-Holst, and D. Van der Mensbrugghe (1997). Trade and pollution linkages: piecemeal reform and optimal intervention. Canadian Journal of Economics 30(2), $442-455$. 
Bernard, A. B., S. J. Redding, and P. K. Schott (2007). Comparative advantage and heterogeneous firms. Review of Economic Studies 74(1), 31-66.

Besley, T. (1995). Property Rights and Investment Incentives: Theory and Evidence from Ghana. Journal of Political Economy 103(5), 903-937.

Beverelli, C., M. Boffa, and A. Keck (2019). Trade policy substitution: theory and evidence. Review of World Economics 155(4), 755-783.

Bhagwati, J. (1971). The generalized theory of distortions and welfare. In J. Bhagwati, R. Jones, R. Mundell, and J. Vanek (Eds.), Trade, balance of payments and growth: Essays in honor of Charles Kindleberger, pp. 69-90. Amsterdam: North-Holland.

Bloom, N., C. Genakos, R. Martin, and R. Sadun (2010). Modern accounting: Good for the environment or just hot air? Economic Journal 120, 551-572.

Boehm, C. E., A. Flaaen, and N. Pandalai-Nayar (2019). Input linkages and the transmission of shocks: Firm-level evidence from the 2011 Tohoku earthquake. Review of Economics and Statistics 101(1), 60-75.

Bohn, H. and R. T. Deacon (2000). Ownership Risk, Investment, and the Use of Natural Resources. American Economic Review 90(3), 526-349.

Bohringer, C., K. E. Rosendahl, and H. B. Storrøsten (2017). Robust policies to mitigate carbon leakage. Journal of Public Economics 149, 35-46.

Boitier, B. (2012). Co2 emissions production-based accounting vs consumption: Insights from the wiod databases.

Bombardini, M. and B. Li (2020). Trade, pollution and mortality in china. Journal of International Economics 125(103321).

Brander, J. A. and M. S. Taylor (1997a). International Trade and Open Access Renewable Resources: The Small Open Economy Case. The Canadian Journal of Economics 30(3), $526-552$.

Brander, J. A. and M. S. Taylor (1997b). International trade between consumer and conservationist countries. Resource and Energy Economics 19, 267-297.

Brander, J. A. and M. S. Taylor (1998). Open access renewable resources: Trade and trade policy in a two-country model. Journal of International Economics 44(2), 181-210. 
Branger, F. and P. Quirion (2014). Climate policy and the 'carbon haven effect. Wiley Interdisciplinary Reviews: Climate Change 5(1), 53-71.

Brock, W. A. and M. S. Taylor (2005). Economic growth and the environment: A review of theory and empirics. In P. Aghion and S. N. Durlauf (Eds.), Handbook of Economic Growth, Volume 1B, Chapter 28, pp. 1749-1821. Elsevier.

Broner, F., P. Bustos, and V. M. Carvalho (2012). Sources of comparative advantage in polluting industries. NBER Working Paper 18337.

Brunel, C. (2016). Pollution offshoring and emission reductions in eu and us manufacturing. Environmental and Resource Economics.

Brunel, C. (2017). Pollution offshoring and emission reductions in EU and US manufacturing. Environmental and resource economics 68(3), 621-641.

Brunnermeier, S. B. and A. Levinson (2004). Examining the evidence on environmental regulations and industry location. The Journal of Environment \& Development 13(1), $6-41$.

Buchanan, J. M. (1969). External economies, corrective taxes, and market structure. American Economic Review 59(1), 174-177.

Burgess, R. and D. Donaldson (2010). Can openness mitigate the effects of weather shocks? Evidence from India's famine era. American Economic Review 100(2), 449-53.

Bustos, P. (2011). Trade liberalization, exports and technology upgrading: Evidence on the impact of mercosur on argentinian firms. American Economic Review 101(1), 304-340.

Böhringer, C., J. C. Carbone, and T. F. Rutherford (2012). Unilateral Climate Policy Design: Efficiency and Equity Implications of Alternative Instruments to Reduce Carbon Leakage. Energy Economics 34(Supplement 2), S208-S217.

Böhringer, C., J. C. Carbone, and T. F. Rutherford (2018). Embodied carbon tariffs. The Scandinavian Journal of Economics 120(1), 183-210.

Carbone, J. C. and N. Rivers (2017). The impacts of unilateral climate policy on competitiveness: evidence from computable general equilibrium models. Review of Environmental Economics and Policy 11(1), 24-42.

Carruthers, B. G. and N. R. Lamoreaux (2016). Regulatory races: The effects of jurisdictional competition on regulatory standards. Journal of Economic Literature 54(1), 52-97. 
Carvalho, V. M., M. Nirei, Y. U. Saito, and A. Tahbaz-Salehi (2021). Supply chain disruptions: Evidence from the great East Japan earthquake. Quarterly Journal of Economics $136(2), 1255-1321$.

Chen, L., B. C. Garcia-Medina, and R. Wan (2019). Trade liberalization, consumption shifting and pollution: Evidence from Mexico's used vehicle imports. Review of International Economics 27(5), 1591-1608.

Cherniwchan, J. (2017). Trade liberalization and the environment: Evidence from nafta and u.s. manufacturing. Journal of International Economics 105, 130-149.

Cherniwchan, J., B. Copeland, and M. S. Taylor (2017). Trade and the environment: New methods, measurement, and results. Annual Reviews of Economics 9.

Cherniwchan, J. and N. Najjar (2020). Do Environmental Regulations Affect the Decision to Export? Working paper.

Chichilnisky, G. (1991). Global environment and North-South trade. Asian Journal of Economics Social Studies 10, 185-201.

Chichilnisky, G. (1994). North-South Trade and the Global Environment. American Economic Review 84(4), 851-874.

Clark, C. W. (1990). Mathematical Bioeconomics: The Optimal Management of Renewable Resources, 2nd ed (2 ed.). New York: Wiley.

Coate, S. and S. Morris (1995). On the form of transfers to special interests. Journal of political Economy 103(6), 1210-1235.

Cole, M. A., R. J. Elliott, and O. Toshihiro (2014). International environmental outsourcing. Review of World Economics 150(4), 639-664.

Cole, M. A., R. J. Elliott, and L. Zhang (2017). Foreign direct investment and the environment. Annual Review of Environment and Resources 42, 465-487.

Cole, M. A. and R. J. R. Elliott (2003). Determining the trade-environment composition effect: the role of capital, labor and environmental regulations. Journal of Environmental Economics and Management 46(3), 363-383.

Cole, M. A., R. R. Elliott, O. Toshihiro, and L. Zhang (2017). The pollution outsourcing hypothesis: an empirical test for Japan. Discussion paper no. 17096, Research Institute of Economy, Trade and Industry (RIETI). 
Conte, B., K. Desmet, D. K. Nagy, and E. Rossi-Hansberg (2020). Local sectoral specialization in a warming world. NBER Working Paper 28163.

Copeland, B. R. (1990). Strategic interaction among nations: negotiable and non-negotiable trade barriers. Canadian Journal of Economics 23(1), 84-108.

Copeland, B. R. (1994). International trade and the environment: Policy reform in a polluted small open economy. Journal of Environmental Econoimcs and Management 26, 44-65.

Copeland, B. R. (1996). Pollution content tariffs, environmental rent shifting, and the control of cross-border pollution. Journal of International Economics 40, 459-476.

Copeland, B. R. (2000). Trade and environment: policy linkages. Environment and Development Economics 5, 405-432.

Copeland, B. R. (2011). Trade and the environment. In D. Bernhofen, R. Falvey, D. Greenaway, and U. Kreickemeier (Eds.), Palgrave Handbook of International Trade, pp. 423--96. Basingstoke, UK: Palgrave Macmillan.

Copeland, B. R. and M. S. Taylor (1994). North-south trade and the environment. Quarterly Journal of Economics 109(3), 755-787.

Copeland, B. R. and M. S. Taylor (1995a). Trade and the environment: a partial synthesis. American Journal of Agricultural Economics 77(3), 765-771.

Copeland, B. R. and M. S. Taylor (1995b). Trade and transboundary pollution. American Economic Review 85(4), 716-737.

Copeland, B. R. and M. S. Taylor (2003). Trade and the Environment: Theory and Evidence. Princeton University Press.

Copeland, B. R. and M. S. Taylor (2004). Trade, growth, and the environment. Journal of Economic Literature 42(1), 7-71.

Copeland, B. R. and M. S. Taylor (2005). Free trade and global warming: a trade theory view of the Kyoto protocol. Journal of Environmental Economics and Management $49(2)$, $205-234$.

Copeland, B. R. and M. S. Taylor (2009). Trade, Tragedy and the Commons. American Economic Review 99(3), 725-749.

Copes, P. (1970). The backward bending supply curve of the fishing industry. Scottish Journal of Political Economy 17, 69-77. 
Cosbey, A., S. Aguilar, M. Ashton, and S. Ponte (2010). Environmental goods and services negotiations at the WTO: Lessons from multilateral environmental agreements and ecolabels for breaking the impasse. Available at ssrn 1730402.

Costinot, A., D. Donaldson, and C. Smith (2016). Evolving comparative advantage and the impact of climate change in agricultural markets: Evidence from 1.7 million fields around the world. Journal of Political Economy 124(1), 205-248.

Costinot, A., D. Donaldson, J. Vogel, and I. Werning (2015). Comparative advantage and optimal trade policy. Quarterly Journal of Economics 130(2), 659-702.

Crippa, M., G. Janssens-Maenhout, F. Dentener, D. Guizzardi, K. Sindelarova, M. Muntean, R. V. Dingenen, and C. Granier (2016). Forty years of improvements in european air quality: regional policy-industry interactions with global impacts. Atmospheric Chemistry and Physics 16, 3825-3841.

Cristea, A. D., D. Hummels, L. Puzzello, and M. G. Avetisyan (2013). Trade and the greenhouse gas emissions from international freight transport. Journal of Environmental Economics and Management 65(1), 153-173.

Cruz Alvarez, J. L. and E. Rossi-Hansberg (2021). The economic geography of global warming. NBER Working Paper 28466.

Czaga, P. (2004). Analysis of Non-Tariff Measures: The Case of Prohibitions and Quotas. Oecd trade policy papers 6, OECD Publishing, Paris.

Davis, L. W. and M. E. Kahn (2010). International trade in used vehicles: The environmental consequences of NAFTA. American Economic Journal: Economic Policy 2(4), 58-82.

Davis, S. J. and K. Caldeira (2010). Consumption-based accounting of co2 emissions. Proceedings of the National Academy of Sciences 207(12), 5687-5692.

Debaere, P. (2014). The Global Economics of Water: Is Water a Source of Comparative Advantage? American Economic: Applied Economics 6(2), 32-48.

Dechezlepetre, A. and M. Sato (2017). The Impacts of Environmental Regulations on Competitiveness. Review of Environmental Economics and Policy 11(2), 183-206.

Demailly, D. and P. Quirion (2006). Co2 abatement, competitiveness and leakage in the European cement industry under the EU ETS: Grandfathering versus output-based allocation. Climate Policy 6(1), 93-113. 
Demsetz, H. (1967). Towards a Theory of Property Rights. American Economic Review 57(2), 347-359.

Deschenes, O., M. Greenstone, and J. S. Shapiro (2017). Defensive investments and the demand for air quality: Evidence from the nox budget program. American Economic Review 107(10), 2958-89.

Di Maria, C. and S. A. Smulders (2005). Trade pessimists vs technology optimists: induced technical change and pollution havens. Advances in Economic Analysis Policy 4(2).

Di Maria, C. and E. Van der Werf (2008). Carbon leakage revisited: unilateral climate policy with directed technical change. Environmental and Resource Economics 39(2), 55-74.

Diewert, W. E., A. H. Turunen-Red, and A. D. Woodland (1989). Productivity-and Paretoimproving changes in taxes and tariffs. The Review of Economic Studies 56(2), 199-215.

Dingel, J. and F. Tintelnot (2021). Spatial Economics for Granular Settings. Working paper.

Dingel, J. I., K. C. Meng, and S. M. Hsiang (2019). Spatial correlation, trade, and inequality: Evidence from the global climate. NBER Working Paper No. 25447.

Dixit, A. K. (1985). Tax Policy in Open Economies. In A. J. Auerbach and M. Feldstein (Eds.), Handbook of Public Economics, Volume 1, Chapter 6, pp. 313-374. Elsevier.

Dornbusch, R., S. Fischer, and P. Samuelson (1977). Comparative advantage, trade, and payments in a ricardian model with a continuum of goods. American Economic Review 67(5), 823-839.

Dragusanu, R., D. Giovannucci, and N. Nunn (2014). The economics of fair trade. Journal of Economic Perspectives 28(3), 217-236.

Drazen, A. and N. Limão (2008). A bargaining theory of inefficient redistribution policies. International Economic Review 49, 621-657.

Droge, S., H. van Asselt, T. Brewser, M. Grubb, and R. Ismer (2021). Talking leakage in a world of unequal carbon prices. Technical report, Climate Strategies.

Eaton, J., S. Kortum, B. Neiman, and J. Romalis (2016). Trade and the global recession. American Economic Review 106(11), 3401-38.

Eaton, J., S. Kortum, and S. Sotelo (2013). Advances in Economics and Econometrics, Tenth World Congress, Volume II: Applied Economics, Chapter International Trade - Linking Micro and Macro, pp. 329-370. Cambridge University Press. 
Ederington, J. (2001). International coordination of trade and domestic policies. American Economic Review 91(5), 1580-1593.

Ederington, J., A. Levinson, and J. Minier (2004). Trade Liberalization and Pollution Havens. The BE Journal of Economic Analysis 85 Policy 3(2), 1-24.

Ederington, J. and J. Minier (2003). Is environmental policy a secondary trade barrier? An empirical analysis. Canadian Journal of Economics/Revue canadienne d'économique 36(1), 137-154.

Ederington, J. and M. Ruta (2017). Non-Tariff Measures and the World Trading System. In K. Bagwell and R. W. Staiger (Eds.), Handbook of Commercial Policy, Volume 1B, Chapter 5, pp. 211-277. Elsevier/North Holland.

Eichner, T. and R. Pethig (2011). Carbon leakage, the green paradox, and perfect future markets. International Economic Review 52(3), 767-805.

Eisenbarth, S. (2018). Do Exports of Renewable Resources Lead to Resource Depletion? Evidence from Fisheries. Mimeo.

Erhardt, T. (2018). Does International Trade Cause Overfishing? Journal of the Association of Environmental and Resource Economists 5(4), 695-711.

Erhardt, T. and R. Weder (2020). Shark hunting: On the vulnerability of resources with heterogeneous species. Resource and Energy Economics 61(4), 101181.

Ferreira, S. (2004). Deforestation, property rights, and international trade. Land Economics $80(2), 174-193$.

Fischer, C. and A. K. Fox (2012). Comparing policies to combat emissions leakage: Border carbon adjustments versus rebates. Journal of Environmental Economics and Management $64(2), 199-216$.

Forslid, R., T. Okubo, and K.-H. Ultveit-Moe (2011). International trade, co2 emissions and heterogeneous firms. CEPR Discussion Paper No. 8583.

Forslid, R., O. Toshihiro, and K. H. Ulltveit-Moe (2018). Why are firms that export cleaner? International trade, abatement and environmental emissions. Journal of Environmental Economics and Management 91, 166-183.

Foster, A. D. and M. R. Rosenzweig (2003). Economic Growth and the Rise of the Forests. Quarterly Journal of Economics 118(2), 601-637. 
Foster, L., J. Haltiwanger, and C. Syverson (2008). Reallocation, firm turnover, and efficiency: Selection on productivity or profitability? American Economic Review 98(1), 394-425.

Fowlie, M. (2010). Emissions trading, electricity industry restructuring, and investment in pollution control. American Economic Review 100(3).

Fowlie, M., M. Greenstone, and C. Wolfram (2018). Do energy efficiency investments deliver? evidence from the weatherization assistance program. Quarterly Journal of Economics 133(3), 1597-1644.

Fowlie, M., S. Holland, and E. Mansur (2012). What do emissions markets deliver and to whom? evidence from southern california's nox trading program. American Economic Review 102(2), 965-993.

Fowlie, M., M. Reguant, and S. P. Ryan (2016). Market-based emissions regulation and industry dynamics. Journal of Political Economy 124(1), 249-302.

Frankel, J. A. and A. K. Rose (2005). Is trade good or bad for the environment? sorting out the causality. Review of Economics and Statistics 87(1), 85-91.

Fæhn, T., C. Hagem, L. Lindholt, S. Mæland, and K. E. Rosendahl (2017). Climate policies in a fossil fuel producing country-demand versus supply side policies. The Energy Journal 38(1).

Ganapati, S., J. S. Shapiro, and R. Walker (2020). Energy cost pass-through in u.s. manufacturing: Estimates and implications for carbon taxes. American Economic Journal: Applied Economics 12(2), 303-42.

Gaubert, C. and O. Itskhoki (2018). Granular comparative advantage. NBER Working paper No. 24807.

Gawande, K. (1999). Trade barriers as outcomes from two-stage games: evidence. Canadian Journal of Economics 32(4), 1028-1056.

Genty, A., I. Arto, and F. Neuwahl (2012). Final database of environmental satellite accounts: Technical report on their compilation. Technical report, IPTS.

Gibson, M. (2019). Regulation-Induced Pollution Substitution. Review of Economics and Statistics 101(5,), 827--840. 
Goldberg, P. K. and N. Pavcnik (2005). Trade, wages, and the political economy of trade protection: evidence from the Colombian trade reforms. Journal of International Economics 66(1), 75-105.

Golombek, R., C. Hagem, and M. Hoel (1995). Efficient incomplete international climate agreements. Resource and Energy Economics 17(1), 25-46.

Gordon, H. S. (1954). The economic theory of a common-property resource: The fishery. Journal of Political Economy 62(2), 124-42.

Gouel, C. and D. Laborde (2021). The crucial role of domestic and international marketmediated adaptation to climate change. Journal of Environmental Economics and Management.

Greenstone, M. (2002). The impacts of environmental regulations on industrial activity: Evidence from the 1970 and 1977 clean air act amendments and the census of manufactures. Journal of Political Economy 110(6), 1175-1219.

Grether, J.-M., N. A. Mathys, and J. de Melo (2009). Scale, technique and composition effects in manufacturing so2 emissions. Environmental $\& 3$ Resource Economics 43(2), 257274 .

Grossman, G. M. and E. Helpman (1994). Protection for sale. American Economic Review $84(4), 833-850$.

Grossman, G. M. and A. B. Krueger (1993). The Mexico-U.S. Free Trade Agreement, Chapter Environmental Impacts of a North American Free Trade Agreement. M.I.T. Press.

Grossman, G. M. and A. B. Krueger (1995). Economic growth and the environment. Quarterly Journal of Economics 110(2), 353-377.

Gulati, S. and D. Roy (2008). National treatment and the optimal regulation of environmental externalities. Canadian Journal of Economics/Revue canadienne d'économique 41(4), $1445-1471$.

Gutierrez, E. and K. Teshima (2018). Abatement expenditures, technology choice, and environmental performance: Evidence from firm responses to import competition in mexico:. Journal of Development Economics 133, 264-274.

Hanna, R. (2010). Us environmental regulation and fdi: Evidence from a panel of us-based multinational firms. American Economic Journal: Applied Economics 2(3), 158-189. 
Hardin, G. (1968). The Tragedy of the Commons. Science 162(3859), 1243-1248.

Harstad, B. (2012). Buy coal! a case for supply-side environmental policy. Journal of Political Economy 120(1), 77-115.

Harstad, B. (2016). The Market for Conservation and Other Hostages. Journal of Economic Theory 166 (November), 124-151.

Hatta, T. (1977). A theory of piecemeal policy recommendations. The Review of Economic Studies 44(1), 1-21.

Hemous, D. (2016). The dynamic impact of unilateral environmental policies. Journal of International Economics 103, 80-95.

Hertwich, E. G. and G. P. Peters (2009). Carbon footprint of nations: A global, trade-linked analysis. Environmental Science \& Technology 43(16), 6414-6420.

Hoel, M. (1996). Should a carbon tax be differentiated across sectors? Journal of Public Economics 59, 17-32.

Holladay, J. S. (2016). Exporters and the Environment. Canadian Journal of Economics $49(1), 147-172$.

Holladay, J. S. and L. D. LaPlue III (2021). Decomposing Changes in Establishment Level Emissions with Entry and Exit. Canadian Journal of Economics forthcoming.

Horn, H., G. Maggi, and R. W. Staiger (2010). Trade agreements as endogenously incomplete contracts. American Economic Review 100(1), 394-419.

Hsiao, A. (2020). Coordination and commitment in international climate action: Evidence from palm oil. Mimeograph, MIT.

Hsieh, C.-T. and P. J. Klenow (2009). Misallocation and manufacturing tfp in china and india. Quarterly Journal of Economics 124(4), 1403-1448.

$\mathrm{Hu}$, B. and R. McKitrick (2016). Decomposing the environmental effects of trade liberalization: The case of consumption-generated pollution. Environmental and Resource Economics 64(2), 205-223.

Jaffe, A. B., S. R. Peterson, P. R. Portney, and R. N. Stavins (1995). Environmental regulation and the competitiveness of US manufacturing: what does the evidence tell us? Journal of Economic literature 33(1), 132-163. 
Janssens-Maenhout, G., M. Crippa, D. Guizzardi, F. Dentener, M. Muntean, G. Pouliot, T. Keating, Q. Zhang, J. Kurokawa, R. Wankmüller, H. D. van der Gon, J. J. P. Kuenen, Z. Klimont, G. Frost, S. Darras, B. Koffi1, and M. Li (2015). Htap v2.2: a mosaic of regional and global emission grid maps for 2008 and 2010 to study hemispheric transport of air pollution. 15, 11411-11432.

Jayachandran, S., J. de Laat, E. Lambin, C. Stanton, R. Audy, and N. Thomas (2017). Cash for Carbon: A Randomized Trial of Payments for Ecosystem Services to Reduce Deforestation. Science 357(6348), 267-273.

Joltreau, E. and K. Sommerfeld (2019). Why does emissions trading under the EU Emissions Trading System (ETS) not affect firms' competitiveness? Empirical findings from the literature. Climate policy 19(4), 453-471.

Jones, L. and M. Bixby (2003). Managing Fish: Ten Case Studies from Canada's Pacific Coast. Vancouver: The Fraser Institute.

Karp, L. (2011). The environment and trade. Annual Review of Resource Economics 3(1), $397-417$.

Kawahara, S. (2011). Electoral competition with environmental policy as a second best transfer. Resource and energy economics 33(3), 477-495.

Kee, H. L., A. Nicita, and M. Olarreaga (2009). Estimating trade restrictiveness indices. The Economic Journal 119(534), 172-19.

Keen, M. and C. Kotsogiannis (2014). Coordinating climate and trade policies: Pareto efficiency and the role of border tax adjustments. Journal of International Economics 94(1), $119-128$.

Keller, W. and A. Levinson (2002). Pollution abatement costs and foreign direct investment inflows to u.s. states. Review of Economics and Statistics 84(4), 691-703.

Kortum, S. and D. A. Weisbach (2020). Optimal unilateral carbon policy.

Kreickemeier, U. and P. M. Richter (2014). Trade and the environment: The role of firm heterogeneity. Review of International 22(2), 209-225.

LaPlue, L. D. (2019). The environmental effects of trade within and across sectors. Journal of Environmental Economics and Management 94, 118-139. 
Larch, M. and J. Wanner (2017). Carbon tariffs: An analysis of the trade, welfare, and emission effects. Journal of International Economics 109, 195-213.

Lawrence, R. Z. (1996). Regionalism, multilateralism, and deeper integration. Washington, DC: Brookings Institution Press.

Lee, J.-W. and P. Swagel (1997). Trade barriers and trade flows across countries and industries. Review of economics and statistics 79(3), 372-382.

Levinson, A. (2009). Technology, international trade, and pollution from us manufacturing. American Economic Review 99(5), 2177-2192.

Levinson, A. (2010). Offshoring Pollution: Is the US Increasingly Importing Polluting Goods? Review of Environmental Economics and Policy 4(1), 63--83.

Levinson, A. (2015). A direct estimate of the technique effect. Journal of the Association of Environmental and Resource Economics 2(1), 43-56.

Levinson, A. and M. S. Taylor (2008). Unmasking the pollution haven effect. International Economic Review 49(1), 223-254.

Li, X. and Y. M. Zhou (2017). Offshoring pollution while offshoring production? Strategic Management Journal 38(11), 2310-2329.

Limao, N. (2005). Trade policy, cross-border externalities and lobbies: do linked agreements enforce more cooperative outcomes? Journal of International Economics 67, 175-199.

Limão, N. and P. Tovar (2011). Policy choice: Theory and evidence from commitment via international trade agreements. Journal of international Economics 85(2), 186-205.

Lipscomb, M. and A. M. Mobarak (2016). Decentralization and pollution spillovers: Evidence from the re-drawing of country borders in brazil. Review of Economic Studies 84 (1), 464502.

Lovely, M. and D. Popp (2011). Trade, technology, and the environment: Does access to technology promote environmental regulation? Journal of Environmental Economics and Management 61(1), 16-35.

Lyubich, E., J. S. Shapiro, and R. Walker (2018). Regulating mismeasured pollution: Implications of firm heterogeneity for environmental policy. AEA Papers and Proceedings 108.

Maggi, G. (2016). Issue linkage. In K. Bagwell and R. W. Staiger (Eds.), Handbook of Commercial Policy, Volume 1B, Chapter 9, pp. 513-564. Elsevier/North Holland. 
Managi, S., A. Hibiki, and T. Tsurumi (2009). Does trade openness improve environmental quality? Journal of Environmental Economics and Management 58(3), 346-363.

Markusen, J. R. (1975). International externalities and optimal tax structure. Journal of International Economics 5, 15-29.

Martin, L. A. (2011). Energy efficiency gains from trade: greenhouse gas emissions and india's manufacturing sector. Mimeograph, UC Berkeley.

Martin, R., M. Muuls, L. B. de Preux, and U. J. Wagner (2014, August). Industry compensation under relocation risk: A firm-level analysis of the eu emissions trading scheme. American Economic Review 104(8), 2482-2508.

Mattoo, A., A. Subramanian, D. Van Der Mensbrugghe, and J. He (2009). Reconciling climate change and trade policy. World bank policy research working paper no. 5123, The World Bank.

McAusland, C. (2008). Trade, politics, and the environment: Tailpipe vs. smokestack. Journal of Environmental Economics and Management 55(1), 52-71.

McAusland, C. and C. Costello (2004). Avoiding invasives: trade-related policies for controlling unintentional exotic species introductions. Journal of Environmental Economics and Management 48(2), 954-977.

McGuire, M. C. (1982). Regulation, factor rewards, and international trade. Journal of public economics $17(3), 335-354$.

McPherson, M. A. and M. L. Nieswiadomy (2000a). African elephants: the effect of property rights and political stability. Contemporary Economic Policy 18(1), 14-26.

McPherson, M. A. and M. L. Nieswiadomy (2000b). African elephants: The effects of property rights and political stability. Contemporary Economic Policy 18(1), 14-26.

McWhinnie, S. F. (2009). The tragedy of the commons in international fisheries: An empirical examination. Journal of Environmental Economics and Management 57(3), 321-333.

Melitz, M. J. (2003). The impact of trade on intra-industry reallocations and aggregate industry productivity. Econometrica 71 (6), 1695-1725.

Melitz, M. J. and S. Polanec (2015). Dynamic Olley-Pakes productivity decomposition with entry and exit. The Rand journal of economics 46(2), 362-375. 
Meyfroidt, P. and E. F. Lambin (2008). The causes of reforestation in Vietnam. Land Use Policies 25(2), 182-197.

Meyfroidt, P. and E. F. Lambin (2009). Forest transition in Vietnam and displacement of deforestation abroad. Proceedings of the National Academy of Sciences 106(38), 1613916144.

Michel, B. (2013). Does offshoring contribute to reducing domestic air emissions? Evidence from Belgian manufacturing. Ecological economics 95, 73-82.

Miller, R. E. and U. Temurshoev (2015). Output upstreamness and input downstreamness of industries/countries in world production. International Regional Science Review 40(5), $443-475$.

Najjar, N. and J. Cherniwchan (2021). Environmental Regulations and the Clean-Up of Manufacturing: Plant-Level Evidence. Review of Economics and Statistics (j.a.), 1-45.

Nath, I. B. (2020). The Food Problem and the Aggregate Productivity Consequences of Climate Change. NBER Working Paper 27297.

Niu, Z., C. Milner, S. Gunessee, and C. Liu (2020). Are nontariff measures and tariffs substitutes? Some panel data evidence. Review of International Economics 28(2), 408428.

Nordhaus, W. (2015). Climate clubs: Overcoming free-riding in international climate policy. American Economic Review 105(4), 1339-70.

Nunn, N. (2007). Relationship-specificity, incomplete contracts, and the pattern of trade. Quarterly Journal of Economics 122(2), 569-600.

Oates, W. E. (1999). An essay on fiscal federalism. Journal of Economic Literature 37, $1120-1149$.

Oates, W. E. and P. R. Portney (2003). Handbook of Environmental Economics, Volume 1, Chapter The Political Economy of Environmental Policy, pp. 325-354. Elsevier.

Oates, W. E. and D. L. Strassmann (1984). Effluent fees and market structure. Journal of Public Economics 24, 29-46.

Orefice, G. (2017). Non-tariff measures, specific trade concerns and tariff reduction. The World Economy 40(9), 1807-1835. 
Park, D., J. Howard, and W. Ridley (2020). Regional Environmental Quality and International Trade: The Role of Production Networks. mimeo, University of Illinois.

Pasurka, C. (2008). Perspectives on pollution abatement and competitiveness: Theory, data, and analyses. Review of Environmental Economics and Policy 2(2), 194-218.

Peters, G. P. and E. G. Hertwich (2008). $\mathrm{Co}_{2}$ embodied in international trade with implications for global climate policy. Environmental Science \& Technology 42(5), 1401-1407.

Peters, G. P., J. C. Minx, C. L. Weber, and O. Edenhofer (2011). Growth in emission transfers via international trade from 1990 to 2008. Proceedings of the National Academy of Sciences 108(21), 8903-8908.

Pethig, R. (1976). Pollution, welfare, and environmental policy in the theory of comparative advantage. Journal of environmental economics and management 2(3), 160-169.

Ponssard, J.-P. and N. Walker (2008). Eu emissions trading and the cement sector: a spatial competition analysis. Climate Policy 8(5), 467-493.

Porter, M. E. and C. Van der Linde (1995). Toward a new conception of the environmentcompetitiveness relationship. Journal of economic perspectives 9(4), 97-118.

Qi, J., X. Tang, and X. Xi (2021). The size distribution of firms and industrial water pollution: A quantitative analysis of china. American Economic Journal: Macroeconomics 13(1), 151-83.

Romalis, J. (2004). Factor Proportions and the Structure of Commodity Trade. American Economic Review 94(1), 67-97.

Salop, S. C. and D. T. Scheffman (1983). Raising rivals' costs. The American Economic Review 73(2), 267-271.

Schaefer, M. B. (1957). Some Considerations of Population Dynamics and Economics in Relation to the Management of Marine Fisheries. Journal of Fisheries Research Board of Canada 14(5), 669-681.

Schenker, O., S. Koesler, and A. Löschel (2018). On the effects of unilateral environmental policy on offshoring in multi-stage production processes. Canadian Journal of Economics/Revue canadienne d'économique 51(4), 1221-1256.

Schleich, J. (1999). Environmental quality with endogenous domestic and trade policies. European Journal of Political Economy 15, 53-71. 
Shapiro, J. S. (2016). Trade costs, $\mathrm{co}_{2}$, and the environment. American Economic Journal: Economic Policy 8(4), 220-54.

Shapiro, J. S. (2021). The environmental bias of trade policy. Quarterly Journal of Economics 136(2), 831-886.

Shapiro, J. S. and R. Walker (2018). Why is pollution from u.s. manufacturing declining? the roles of environmental regulation, productivity, and trade. American Economic Review 108(12), 3814-54.

Sigman, H. (2002). International spillovers and water quality in rivers: Do countries free ride? American Economic Review 92(4), 1152-1159.

Sigman, H. (2005). Transboundary spillovers and decentralization of environmental policies. Journal of Environmental Economics and Management 50, 82-101.

Sinn, H.-W. (2008). Public policies against global warming: a supply side approach. International Tax and Public Finance 15(4), 360-394.

Spagnolo, G. (1999). On Interdependent Supergames: Multimarket Contact, Concavity, and Collusion. Journal of Economic Theory 89(1), 127-139.

Staiger, R. W. and A. O. Sykes (2011). International trade, national treatment, and domestic regulation. The Journal of Legal Studies 40(1), 149-203.

Stern, D. I. (2017). The environmental Kuznets curve after 25 years. Journal of Bioeconomics 19(1), 7-28.

Sturm, D. M. (2006). Product standards, trade disputes, and protectionism. Canadian Journal of Economics 39(2), 564-581.

Taylor, M. S. (2011). Buffalo Hunt: International Trade and the Virtual Extinction of the North American Bison. American Economic Review 101(7), 3162-3195.

Turunen-Red, A. H. and A. D. Woodland (2004). Multilateral reforms of trade and environmental policy. Review of International Economics 12(3), 321-336.

UNEP (2001). Economic Reforms, Trade Liberalization and the Environment: A Synthesis of UNEP Country Projects. A synthesis report on 5 november 2001, United Nations Environment Programme.

Verde, S. F. (2020). The impact of the EU emissions trading system on competitiveness and carbon leakage: the econometric evidence. Journal of Economic Surveys 34(2), 320-343. 
Walter, I. (1973). The Pollution Content of American Trade. Western Economic Journal 11, 61-70.

Wang, S. and Z. Wang (2020). The environmental and economic consequences of internalizing border spillovers. Technical report, U Chicago.

Wang, X., J. Li, and Y. Zhang (Dec. 2010). Can Export Tax be Genuine Climate Policy? An Analysis on China's Export Tax and Export VAT Refund Rebate Policies. Technical report, IDDRI, SciencesPo.

Weber, C. L. and H. S. Matthews (2007). Embodied environmental emissions in us international trade, 1997-2004. Environ. Sci. Technol. 41(14), 4875-4881.

WTO (1988). Canada - Measures Affecting Exports of Unprocessed Herring and Salmon. Report of the panel adopted on 22 march 1988, WTO.

WTO (Dec. 2015). China - Measures Related to the Exportation of Rare Earths, Tungsten and Molybdenum. Ds431, WTO.

Xepapadeas, A. (2005). Economic growth and the environment. In K.-G. Mäler and J. R. Vincent (Eds.), Handbook of Economic Growth, Volume 3, Chapter 23, pp. 1219-1271. Elsevier.

Zeng, D.-Z. and L. Zhao (2009). Pollution havens and industrial agglomeration. Journal of Environmental Economics and Management 58(2), 141-153.

Zhang, Z. (2012). Competitiveness and leakage concerns and border carbon adjustments. Technical report, Fondazione Eni Enrico Mattei. 